\title{
Design, sythesis and evaluation of a series of 3- or 4-alkoxy substituted phenoxy derivatives as PPARs agonists
}

\author{
Jun Zhang ${ }^{1}$, Xue-Jiao Wang ${ }^{1}$, Xin Liu ${ }^{1}$, Yi Huan ${ }^{2}$, Miao-Miao Yang ${ }^{2}$, Zhu-Fang Shen ${ }^{2}$, \\ Wen-Qing Jia ${ }^{1}$, Zhi Jing ${ }^{1}$, Shu-Qing Wang ${ }^{1}$, Wei-Ren $X u^{3}$, Xian-Chao Cheng ${ }^{1}$, Run- \\ Ling Wang ${ }^{1}$ \\ ${ }^{1}$ Tianjin Key Laboratory on Technologies Enabling Development of Clinical Therapeutics and Diagnostics (Theranostics), \\ School of Pharmacy, Tianjin Medical University, Tianjin 300070, China \\ ${ }^{2}$ Institute of Materia Medica, Chinese Academy of Medical Sciences and Peking Union Medical College, Beijing 100050, China \\ ${ }^{3}$ Tianjin Key Laboratory of Molecular Design and Drug Discovery, Tianjin Institute of Pharmaceutical Research, Tianjin \\ 300193, China
}

Correspondence to: Xian-Chao Cheng, email: chengxianchao@aliyun.com Run-Ling Wang, email: wangrunling@tmu.edu.cn

Keywords: PPARs, Type 2 diabetes mellitus, bioisosterism, docking analysis, molecular dynamic simulations

Received: December 28, 2016

Accepted: January 25, 2017

Published: February 08, 2017

\section{ABSTRACT}

Peroxisome proliferators-activated receptors (PPARa, y and $\delta$ ) are potentially effective targets for Type 2 diabetes mellitus therapy. The severe effects of known glitazones and the successfully approved agents (saroglitazar and lobeglitazone) motivated us to study novelly potent PPARs drugs with improved safety profile. In this work, we received 15 carboxylic acids based on the combination principle to integrate the polar head of bezafibrate with the hydrophobic tail of pioglitazone. Another 12 tetrazoles based on the bioisosterism principle were obtained accordingly. Furthermore, in vitro PPARs transactivation assays on these 3- or 4-alkoxy substituted phenoxy derivatives afforded six compounds. Interactions and binding stability from the docking analysis and $\mathbf{2 0}$ ns molecular dynamic simulations confirmed the representative compounds to be suitable and plausible for PPARs pockets. The abovementioned results demonstrated that the compounds may be used as reference for further optimization for enhanced PPARs activities and wide safety range.

\section{INTRODUCTION}

Peroxisome proliferators-activated receptors (PPAR $\alpha, \gamma$ and $\delta$ ) are classified as ligand-inducible nuclear receptors $[1,2]$. They were attractive targets for diabetes, dyslipidemia, obesity, inflammation and atherosclerosis [3]. These identified subtypes displayed high similarity in sequence and significant specificity in physiological functions and tissue distribution. PPAR $\alpha$ is highly expressed in liver, kidney, heart, skeletal muscle and adipose tissue [4]. When activated by ligands, fatty acid oxidation and lipoprotein metabolism would be improved. Drugs targeting PPAR $\alpha$ in market are fibrates such as fenofibrate and bezafibrate (Figure 1), which are mainly served as hypolipidemic drugs to treat hypertriglyceridemia [5]. PPAR $\gamma$ which highly ameliorates insulin sensitivity is widely expressed in adipose tissues [6-8]. Moreover, the fatty acid precipitation and decomposition would be accelerated through PPAR $\gamma$ activation. PPAR $\gamma$ ligands glitazones (rosiglitazone and pioglitazone, Figure 1) are deemed as insulin sensitizer to improve the symptoms of patients with Type 2 diabetes mellitus (T2DM) [9]. PPAR $\delta$, however, is expressed in ubiquity in almost all tissues to fasten the metabolism of lipids and sugars $[10,11]$. Nevertheless, there are no marketed drugs targeting PPAR $\delta$ available. GW501516 which exhibited potent and selective PPAR $\delta$ agonism has previously entered clinical trials [12].

However, despite of the potent activity, glitazones were discontinued in clinic due to the serious side effects such as weight gain, edema, hepatotoxicity and cardiovascular toxicity $[9,13,14]$. The primary reason may attribute to the single full or partial PPARs activation. Evidences from previous studies indicated that the roles of multi-targets would be beneficial to the pharmacological activities. Saroglitazar [15] and lobeglitazone [16] (Figure 1) with dual PPAR $\alpha / \gamma$ agonism have been approved by Drug Controller General of India and Korean 
Food and Drug Administration, respectively. Both agents exhibited excellent profile in glucose and lipids level and wide safety range in the treatment of T2DM.

Motivated by the hot concept of multi-targets, we aimed to design novel PPARs agents based on the structures of reported PPARs drugs. In this study, we utilized the combination principle to integrate the polar head of bezafibrate with the hydrophobic tail of pioglitazone (Figure 2). Various alkoxy groups were substituted in the meta- or para-position to afford 15 carboxylic acids initially. Another 12 compounds replaced with a tetrazole ring were produced according to the bioisosterism principle [17-19]. Therefore, 27 combinatorial molecules with the main structural skeleton of 3- or 4-alkoxy substituted phenoxyl were available as potential PPARs agents. The design process was listed as Figure 2. In further bioactivity evaluation on PPARs activation, six compounds were originally found with PPARs activation.

Herein, we carried out our work with 27 compounds for design, synthesis and biological evaluation details. Recent docking analysis and molecular dynamics (MD) simulations of 20 ns validated the binding modes and dynamics stability of best docked complexes with PPARs.

\section{RESULTS AND DISCUSSION}

\section{Synthesis}

The general synthetic routes of carboxylic acids and tetrazole compounds were depicted in Schemes 1 and 2, respectively.

With hydroquinone and resorcinol (1) respectively as raw materials, one important monosubstituted intermediate 3 was obtained through the nucleophilic substitution reaction with ethyl 2-bromo-2-methylpropanoate (Scheme 1), while the other unwanted disubstituted by-product was removed by flash column chromatography method. The esters 5 were synthesized via Williamson ether synthesis reaction with various halogenated organic compounds 4 . Under basic conditions, the final products of para- and meta-series (6) were received via the hydrolysis reaction to 5 [20]. Equally as shown in Scheme 2, intermediates 8 and 9 were successfully synthesized via the nucleophilic substitution reaction. Using toluene as the solvent, compounds 9 were<smiles>CC(C)OC(=O)C(C)(C)Oc1ccc(C(=O)c2ccc(Cl)cc2)cc1</smiles>

Fenofibrate PPAR a agonist<smiles>CN(CCOc1ccc(CC2SC(=O)NC2=O)cc1)c1ccccn1</smiles>

Rosiglitazone PPAR Y agonist

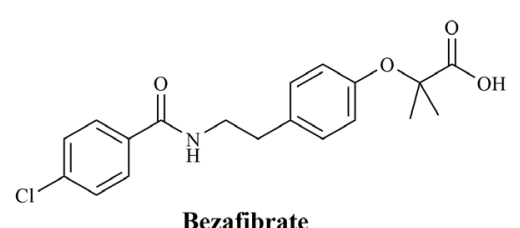

Bezafibrate PPAR a agonist

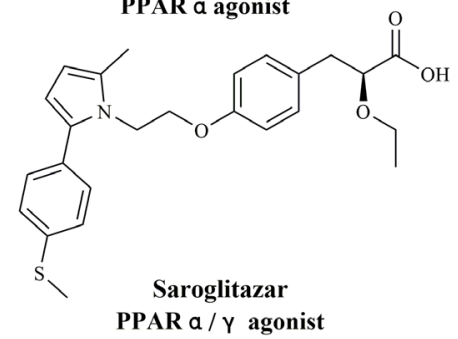

PPAR a / Y agonist<smiles>CCc1ccc(CCOc2ccc(CC3SC(=O)NC3=O)cc2)nc1</smiles>

Pioglitazone PPAR Y agonist

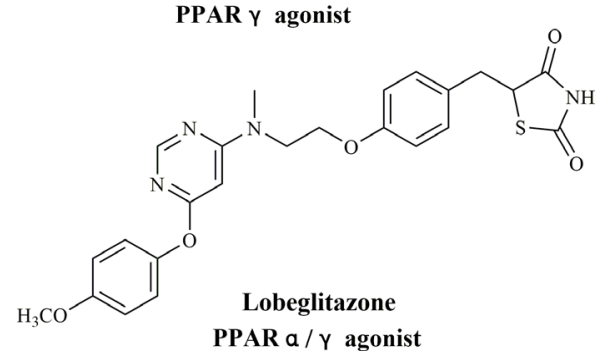

Figure 1: Structures of PPARs ligands.

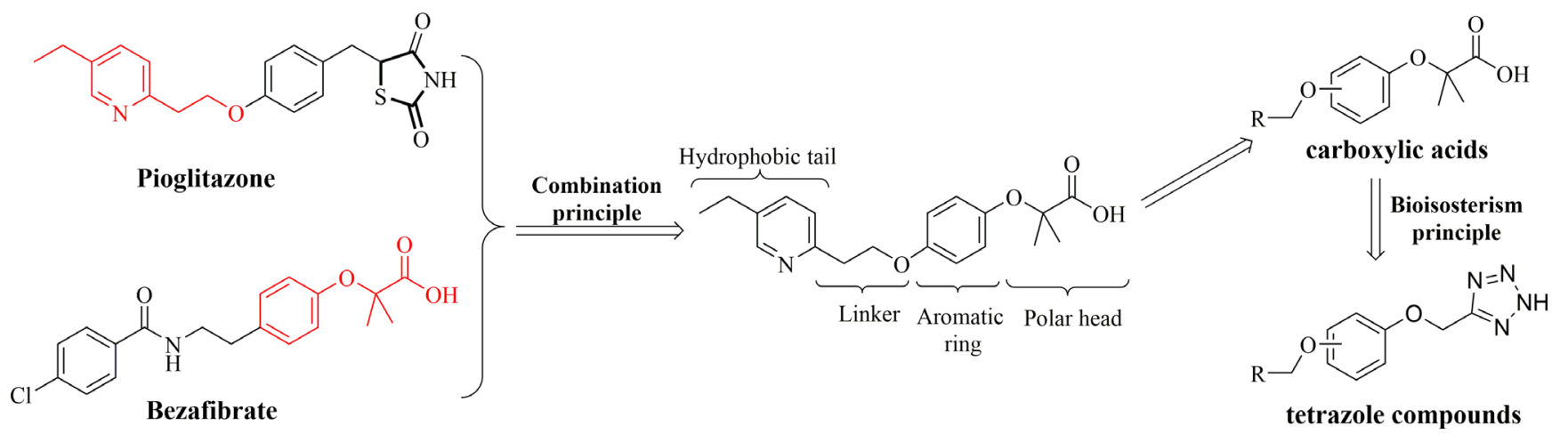

Figure 2: The design process of 3- or 4-alkoxy substituted phenoxy derivatives. 
reacted with triethylamine hydrochloride and sodium azide. Through dipolar cycloaddition, we afforded target tetrazoles of para- and meta-series (10) [21]. Additionally, the tautomerism occurred to the tetrazole molecules as indicated in Scheme 2.

\section{In vitro $\mathrm{PPAR} \alpha / \gamma / \delta$ transactivation assays}

As indicated in introduction section, we successfully synthesized 27 combinatorial molecules with the main structural skeleton of 3- or 4-alkoxy substituted phenoxyl. Three different PPARs ( $\alpha, \gamma$ and $\delta$ ) in vitro transaction assays were introduced to these molecules under the constant concentration $\left(10^{-5} \mathrm{M}\right)$. The relative activities were respectively compared to the positive controls. Supplementary Table 1 listed the structures and in vitro preliminary evaluation results of 3- or 4-alkoxy substituted phenoxy derivatives towards PPARs activation. After preliminary biological evaluation to these 27 compounds, six were examined and screened with potential PPARs agonistic activities (Table 1). Molecule 6h exhibited weaker PPAR $\alpha$ activation (48.5\%) compared to the positive control, $6 \mathrm{~g}$ and $10 \mathrm{~h}$ weakly activated PPAR $\gamma$ by $24.4 \%$ and $35.8 \%$, respectively while compounds 6e $(63.8 \%), 61(58.6 \%)$ and $101(89.7 \%)$ demonstrated medium intensity or high potency in PPAR $\delta$ activation. In further evaluation under various concentrations, these six molecules with potential PPARs affinities were investigated through median effective concentration $\left(\mathrm{EC}_{50}\right)$ and concentration at maximum efficiency percentage $\left(\mathrm{C}_{\max }\right)$. GW7647, rosiglitazone and GW501516 were selected as positive controls.

According to the relative activities of six screened compounds under various concentrations, $\mathrm{EC}_{50} \mathrm{~S}$ and $\mathrm{C}_{\max } \mathrm{S}$ values of molecules in activating PPARs were deduced in the concentration-relative activity curves (Figure 3). Clearly in Table 1, compound 6h activated PPAR $\alpha$ with an $\mathrm{EC}_{50}$ value of $5.30 \times 10^{-6} \mathrm{M}$ and attained the maximum efficiency percentage at the concentration of $1 \times 10^{-5} \mathrm{M}$. When compared to GW7647, the effect-acting concentration of $6 \mathrm{~h}$ was relatively higher and a significant discrepancy in efficiency existed in both compounds. Identically in activating PPAR $\gamma$, target compounds $6 \mathrm{~g}$ and $10 \mathrm{~h}$ took the $\mathrm{EC}_{50} \mathrm{~s}$ of $1.18 \times 10^{-5} \mathrm{M}$ and $6.97 \times 10^{-6} \mathrm{M}$,

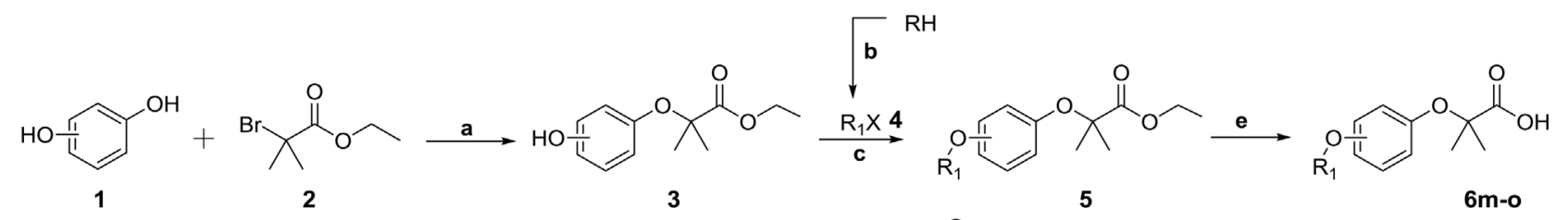

6a: para-, $\mathrm{R}_{1}=2-(1-$ indolyl) ethyl 6b: para-, $R_{1}=2$ - (1-carbazole) ethyl 6c: para-, $R_{1}=3-(1-$ indolyl) propyl 6d: para-, $R_{1}=3$ - (1-carbazole) propyl 6e: para-, $R_{1}=3-\left(1\right.$ - benzimidazole) propyl 6j: meta-, $R_{1}=3$ - (1- benzimidazole) propyl 6k:meta-, $R_{1}{ }^{\prime}=(3-$ phenyl) propyl 6l: meta-, $R_{1}=1$ - (3- pyridine) methyl

6f: meta-, $R_{1}=(2-o x o-2-b e n z y l)$ ethyl 6g:meta-, $R_{1}=2-(1$-carbazole) ethyl $R_{1}=3-(1-$ indolyl) propyl 6h:meta- $\mathrm{R}_{1}=3-(1$ - indolyl) propyl

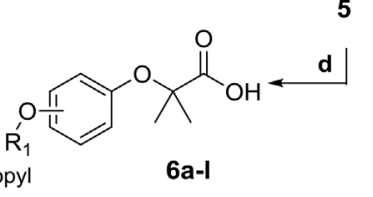

6a-I 6m:para-, $R_{1}=$ (3-phenyl) propyl 6n: para-, $R_{1}=(2-$ oxo-2-benzyl) ethy 6o: meta-, $\mathrm{R}_{1}=2-(1-$ indolyl) ethyll

Scheme 1: Reagents and conditions. (A) acetone, $\mathrm{K}_{2} \mathrm{CO}_{3}, \mathrm{NaI}$, at $65^{\circ} \mathrm{C}$; (B) $\mathrm{KOH}, \mathrm{K}_{2} \mathrm{CO}_{3}, \mathrm{TBAB}, 1$, 2-dihalogen ethane or 1, 3-dihalogen propane, water, at $45^{\circ} \mathrm{C}$; (C) acetone, $\mathrm{K}_{2} \mathrm{CO}_{3}$, NaI, at $65^{\circ} \mathrm{C}$; (D) THF- $\mathrm{CH}_{3} \mathrm{OH}$-water $(3: 1: 1)$, LiOH, hydrochloric acid; (E) $\mathrm{CH}_{3} \mathrm{OH}, \mathrm{NaOH}$, at $50^{\circ} \mathrm{C}$, hydrochloric acid.

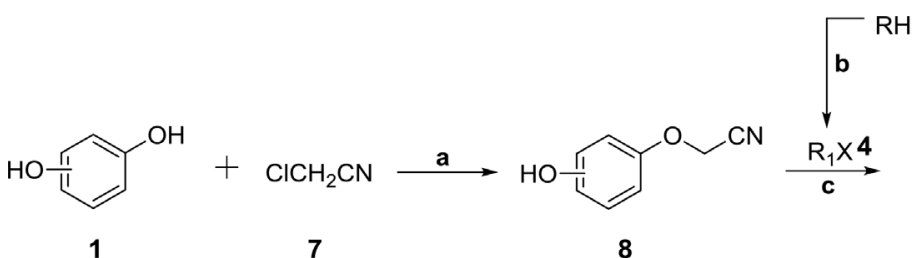

1

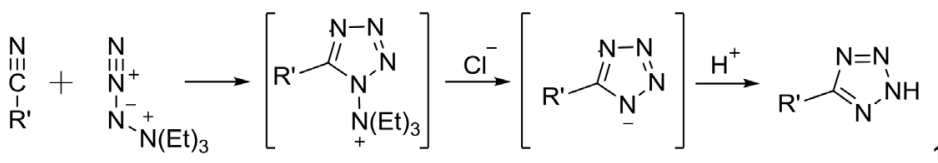

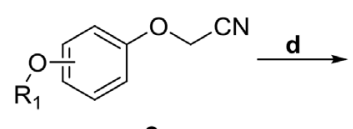

9

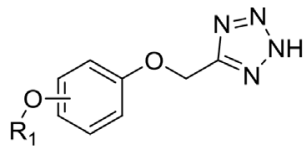

10

$$
\begin{aligned}
& \stackrel{\text { isomerisation 1 }}{\rightleftharpoons} \\
& \text { 10a: para-, } R_{1}=2 \text { - (1- indolyl) ethyl } 10 \mathrm{~g} \text { : meta-, } R_{1}=2 \text { - (1- indolyl) ethyl } \\
& \text { 10b: para-, } R_{1}=2 \text { - (1-carbazole) ethyl } 10 \mathrm{~h} \text { : meta-, } R_{1}=2 \text { - (1-carbazole) ethyl } \\
& \text { 10c: para-, } R_{1}=3-\left(1 \text {-indolyl) propyl 10i: meta-, } R_{1}=3-(1 \text { - indolyl) propyl }\right. \\
& \text { 10d: para-, } R_{1}=3 \text { - (1-carbazole) propyl 10j: meta-, } R_{1}=3 \text { - (1-carbazole) propy } \\
& \text { 10e: para-, } R_{1}=\text { (3-phenyl) propyl 10k: meta-, } R_{1}=\text { (3-phenyl) propyl } \\
& \text { 10f: para-, } R_{1}=1 \text { - (3- pyridine) methyl 10I: meta-, } R_{1}=1 \text { - (3- pyridine) methyl }
\end{aligned}
$$

Scheme 2: Reagents and conditions. (A) acetone, $\mathrm{K}_{2} \mathrm{CO}_{3}$, NaI, at $65^{\circ} \mathrm{C}$; (B) $\mathrm{KOH}, \mathrm{K}_{2} \mathrm{CO}_{3}$, TBAB, 1,2-dihalogen ethane or 1,3-dihalogen propane, water, at $45^{\circ} \mathrm{C} ;(\mathbf{C})$ acetone, $\mathrm{K}_{2} \mathrm{CO}_{3}, \mathrm{NaI}$, at $65^{\circ} \mathrm{C} ;(\mathbf{D})$ toluene, $(\mathrm{Et}){ }_{3} \mathrm{~N} \cdot \mathrm{HCl}, \mathrm{NaN}_{3}$, at $120^{\circ} \mathrm{C}$, hydrochloric acid. 
Table 1: The PPARs activation values of compounds from preliminary screening

\begin{tabular}{|c|c|c|c|c|c|c|c|c|c|}
\hline & \multicolumn{2}{|c|}{ PPAR $\alpha$} & \multicolumn{3}{|c|}{ PPAR $\gamma$} & \multicolumn{4}{|c|}{ PPAR } \\
\hline & $6 h$ & GW7647 & $6 g$ & $10 \mathrm{~h}$ & rosiglitazone & $6 e$ & 61 & $10 I$ & GW501516 \\
\hline $\mathrm{EC}_{50}{ }^{\mathrm{a}}$ & $5.30 \times 10^{-6}$ & $9.44 \times 10^{-9}$ & $1.18 \times 10^{-5}$ & $6.97 \times 10^{-6}$ & $3.954 \times 10^{-6}$ & $1.11 \times 10^{-8}$ & $1.90 \times 10^{-9}$ & $2.73 \times 10^{-8}$ & $4.293 \times 10^{-9}$ \\
\hline $\mathrm{C}_{\max }{ }^{\mathrm{b}}$ & $1 \times 10^{-5}$ & $1 \times 10^{-7}$ & $5 \times 10^{-5}$ & $3 \times 10^{-5}$ & $1 \times 10^{-4}$ & $1 \times 10^{-7}$ & $1 \times 10^{-7}$ & $1 \times 10^{-7}$ & $1 \times 10^{-5}$ \\
\hline
\end{tabular}

a: $\mathrm{EC}_{50}(\mathrm{M})$, median (50\%) effective concentration; b: $\mathrm{C}_{\max }(\mathrm{M})$, concentration at maximum efficiency percentage (Max $\left.\%\right)$.

respectively. However, their concentrations for maximum efficiency percentage $\left(5 \times 10^{-5} \mathrm{M}\right.$ and $3 \times 10^{-5} \mathrm{M}$, respectively) were some lower than rosiglitazone. As for PPAR $\delta$ activation, compounds $6 \mathrm{e}, 61$ and 101 exhibited lower $\mathrm{C}_{\max }$ values and agonistic activities with an extent close to the control, illustrating their moderate or strong agonism towards $\operatorname{PPAR} \delta$.

\section{Molecular docking}

To confirm the PPARs activities of known $6 \mathrm{~h}, 6 \mathrm{~g}$, $10 \mathrm{~h}, 6 \mathrm{e}, 61$ and 10l, we conducted the docking analysis to investigate the interactions with the corresponding receptor. The interaction behaviors between the reference drugs and PPARs active sites were shown in Supplementary Figures 1 and 2. Hydrogen bonds and hydrophobic contacts were essential to the docking stability and binding affinity in protein-ligand complexes. As indicated in Figure 4, compounds 6h (PPAR $\alpha), 6 \mathrm{~g}$ and 10h (PPAR $\gamma$ ), 6e, 61 and 101 (PPAR $\delta$ ) fitted well into PPARs active cavities where the original ligands bound, demonstrating their potentially strong binding affinity. Additionally, these compounds aligned very compactly and properly with the correspondingly original ligands, especially in polar head and hydrophobic regions. The binding modes were represented to be plausible and similar to those of co-crystal ligands.
The polar heads (carboxylic acid and tetrazole ring) of synthetic molecules were oriented towards AF-2 domain in $\mathrm{H} 12$ and interacted with key amino acids through the H-bonds networks as AZ242 in PPAR $\alpha$ $\mathrm{LBD}$, rosiglitazone in PPAR $\gamma$-LBD and D32 in PPAR $\delta$ LBD. The hydrophobic groups of $6 \mathrm{~h}, 6 \mathrm{~g}, 10 \mathrm{~h}, 6 \mathrm{e}, 6 \mathrm{l}$ and 101 were similarly located in the hydrophobic area of PPARs-LBD. According to the aforementioned results, the excellent interaction modes may exactly interpret the results from in vitro PPARs avtivities.

\section{Molecular dynamics simulation}

20 ns simulaions performed with Desmond v4.3 (D.E. Shaw Research, New York, NY, 2015) program were utilized to evaluate the binding stability in dynamics state. The RMSD trajectories of PPAR $\alpha-6 \mathrm{~h}, \operatorname{PPAR} \gamma-10 \mathrm{~h}$ and PPAR $\delta$ 6e complexes throughout 20 ns simulations (Figure 5) illustrated the conformations to be excellent. Relatively, the complexes tended to be in equilibrium, indicating stable binding conformations in dynamics environment. The ligand itself $(6 \mathrm{~h}, 10 \mathrm{~h}$ and $6 \mathrm{e})$ retained roughly unchanged over the entire simulations time. Additionally in Figure 6 , the interactions of molecules with PPARs pocket listed detailed fractions of residues. Obviously, the binding stability was available through the H-bonds, hydrophobic, ionic contacts and water bridges between molecules and

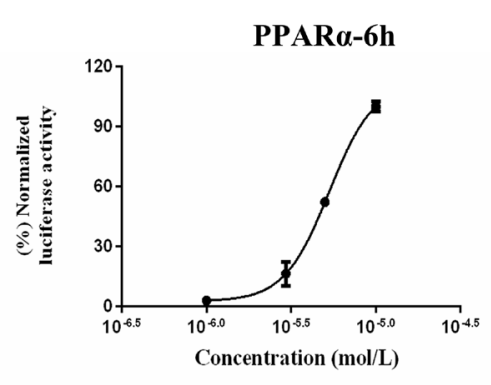

PPAR $\delta$-6e

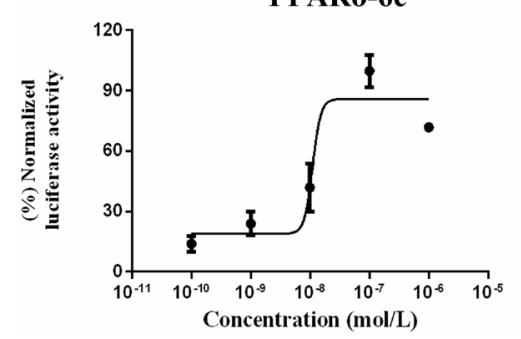

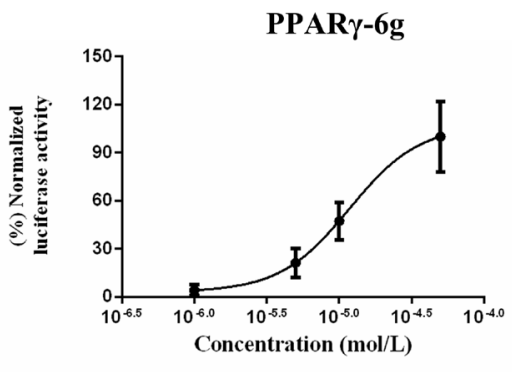

PPAR ס-61

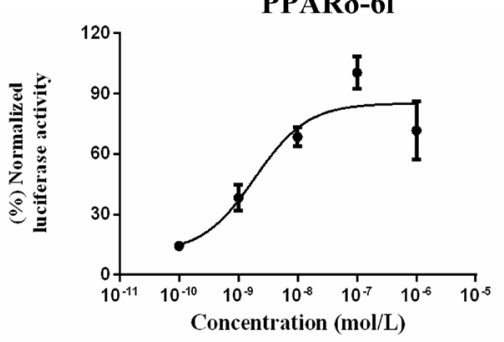

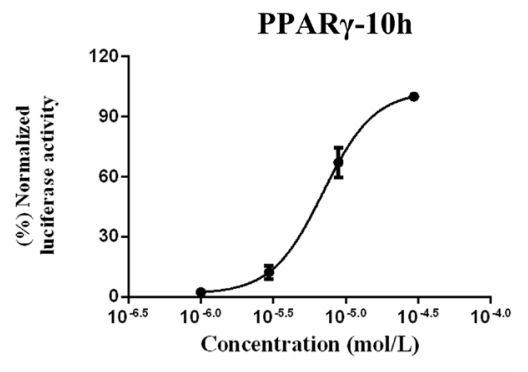

PPAR $\delta$-101

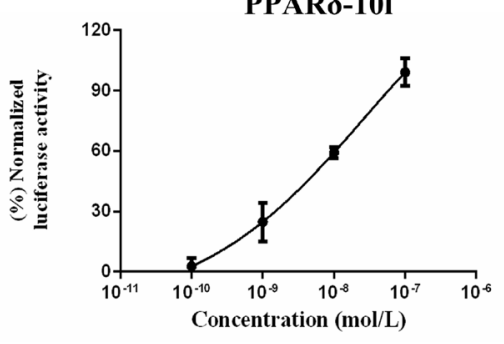

Figure 3: The concentration- relative activity curves of screened molecules activating PPARs. 
proteins. In PPAR $\alpha-\mathrm{LBD}, 6 \mathrm{~h}$ attained binding stability through the H-bonds interactions of the polar head with key amino acids (Tyr314, His440 and Tyr464) and other hydrophobic contacts. Equally with PPAR $\gamma-10 \mathrm{~h}, \mathrm{H}$-bonds interactions and hydrophobic contacts with larger fractions (Ser289, Tyr327, His449 and Tyr473) contributed to the stability. As for PPAR $\delta-6 e$, the higher interaction fractions of Thr289, His323, His449 and Tyr473 exactly explained the relatively higher PPAR $\delta$ agonistic activity as indicated in PPARs in vitro activation assays.

\section{MATERIALS AND METHODS}

\section{Chemistry}

All the reagents used in the experiments were analytically pure and purchased from assigned commercial suppliers. The X-6 micro melting point apparatus was ulitized to measure the melting points (m.p.). Through the thin-layer chromatography (TLC) method, the silica gel plates viewed under the box type automatic UV analyzer
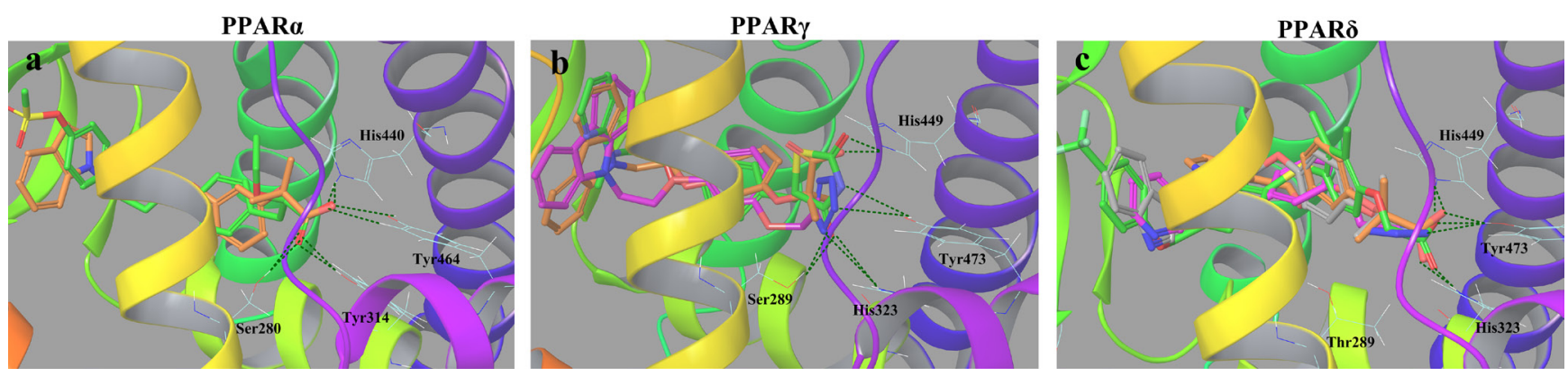

Figure 4: The putative binding behaviours from docking analysis. (A) AZ242 (green) and 6h (orange) in PPAR $\alpha$-LBD (PDB ID:1I7G). (B) rosiglitazone (green), $6 \mathrm{~g}$ (orange) and 10h (purple) in PPAR $\gamma$-LBD (PDB ID:2PRG). (C) D32 (green), $6 \mathrm{e}$ (gray), 61 (orange) and 101 (purple) in PPAR $\delta$-LBD (PDB ID:3GZ9).
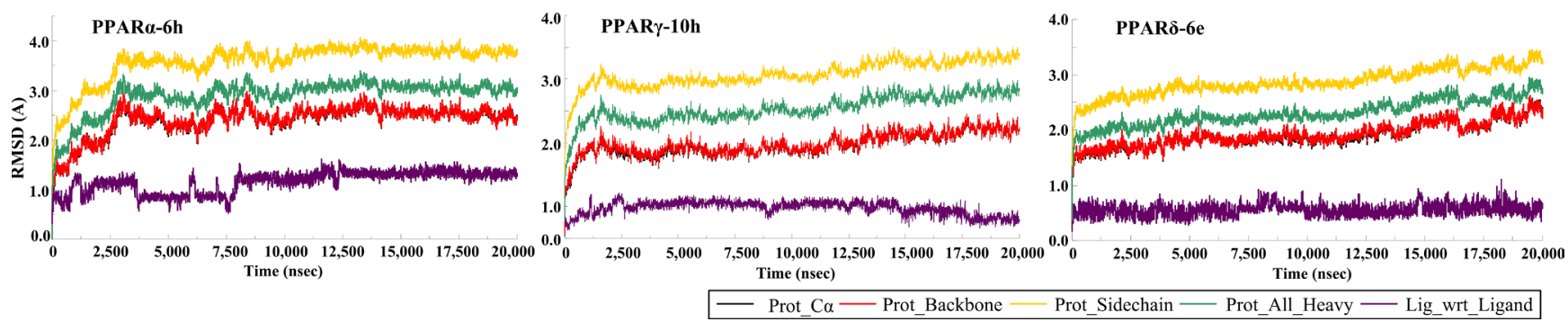

Figure 5: The RMSD trajectories of PPAR $\alpha-6 h$, PPAR $\gamma-10 h$ and PPAR $\delta-6 e$ complexes throughout 20 ns simulations. 'Lig_wrt_Ligand' meant the ligand aligned on itself.
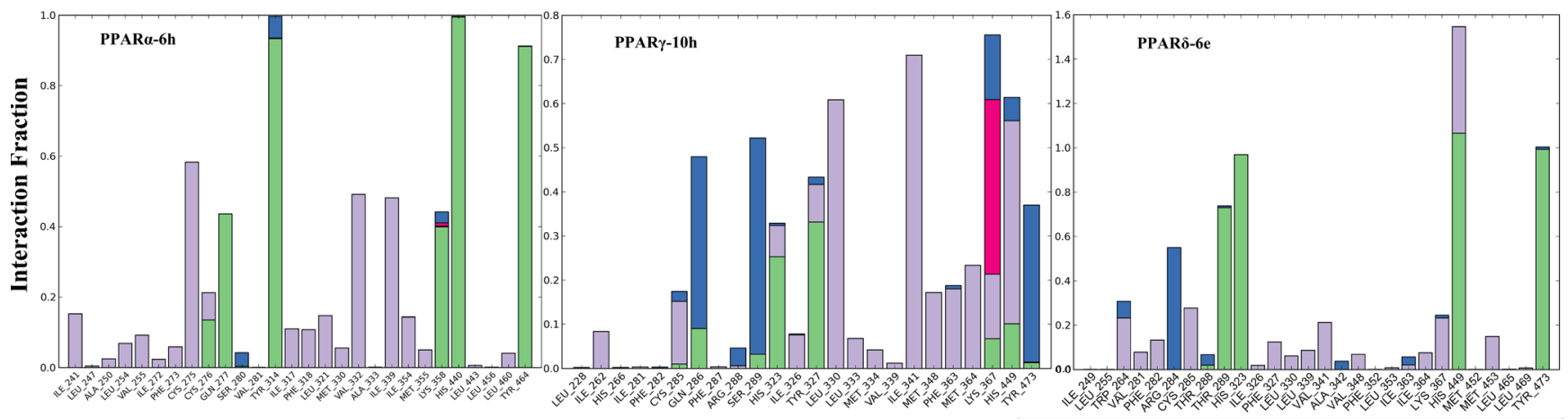

$\square$ H-bonds $\square$ Hydrophobic $\square$ lonic $\square$ Water bridges

Figure 6: The bar graphs of protein-ligand (PL) contacts (PPARa-6h, PPAR $\gamma$-10h and PPAR $\delta$-6e). Colored bar graphs of green, lavender, red and blue represented H-bonds, hydrophobic, ionic contacts and water bridges, respectively. 
(ZF-2C) (254 nm) was to determine the process of the reaction. The ${ }^{1} \mathrm{H}-\mathrm{NMR}$ and ${ }^{13} \mathrm{C}-\mathrm{NMR}$ spectra of new products that dissolved in $\mathrm{CDCl}_{3}$ or DMSO- $d_{6}$ solvent recorded the chemical shifts of $\mathrm{H}$ and $\mathrm{C}$ by a Bruker spectrometer with TMS as the standard material. The molecular weight of one compound was confirmed with the mass spectrometer.

\section{Para-/meta- monosubstituted intermediates (3)}

Hydroquinone / resorcinol 1 (2.2 g, $20 \mathrm{mmol})$ was dissolved in the solution of acetone $(50 \mathrm{ml})$, followed by $\mathrm{K}_{2} \mathrm{CO}_{3}(2.76 \mathrm{~g}, 20 \mathrm{mmol})$ and $\mathrm{NaI}$ (catalytic amounts). Then a mixed solution of ethyl 2-bromo-2methylpropanoate $2(1.95 \mathrm{~g}, 10 \mathrm{mmol})$ and acetone $(50 \mathrm{ml})$ was dripped slowly to the mixture above. The reaction was heated to reflux at $65^{\circ} \mathrm{C}$ for $48 \mathrm{~h}$ under stirring condition. The process of the reaction was detected through TLC method. After the reaction, crude products were obtained through the course of filtration and vacuum distillation to remove the solvent. The final products (3) were purified by flash column chromatography with petroleum ether/EtOAc as the mobile phase.

3a (Ethyl 2-(4-hydroxyphenoxy)-2-methyl propanoate): white solid (33\%), $\mathrm{R}_{\mathrm{f}}=0.70$ (developing agent: dichloromethane / acetone $=100: 1) ;{ }^{1} \mathrm{H}-\mathrm{NMR}$ $\left(\mathrm{CDCl}_{3}, 400 \mathrm{MHz}\right): \delta 6.78(2 \mathrm{H}, \mathrm{q}, J=2.98 \mathrm{~Hz}, \mathrm{Ar}-\mathrm{H}) ; 6.69$ $(2 \mathrm{H}, \mathrm{q}, J=2.98 \mathrm{~Hz}, \mathrm{Ar}-\mathrm{H}) ; 5.30(1 \mathrm{H}, \mathrm{s}, \mathrm{OH}) ; 4.24(2 \mathrm{H}, \mathrm{q}$, $\left.J=7.13 \mathrm{~Hz}, \mathrm{CH}_{2}\right) ; 1.53\left(6 \mathrm{H}, \mathrm{s}, \mathrm{CH}_{3}\right) ; 1.28(3 \mathrm{H}, \mathrm{t}, J=7.12$ $\left.\mathrm{Hz}, \mathrm{CH}_{3}\right)$. MS m/z: $470.93(2 \mathrm{M}+\mathrm{Na})$.

3b (Ethyl 2-(3-hydroxyphenoxy)-2-methyl propanoate): colorless oil $(11.35 \%), \mathrm{R}_{\mathrm{f}}=0.48$ (developing agent: dichloromethane / acetone $=20: 1)$; ${ }^{1} \mathrm{H}-\mathrm{NMR}$ $\left(\mathrm{CDCl}_{3}, 400 \mathrm{MHz}\right): \delta$ 7.050-7.029 $(1 \mathrm{H}, \mathrm{d}, J=8.4 \mathrm{~Hz}, \mathrm{Ar}-$ $\mathrm{H})$; 6.496-6.468 (1H, m, Ar-H); 6.396-6.375 (2H, m, Ar$\mathrm{H})$; 6.300-6.100 (1H, s, OH); 4.257-4.204 (2H, m, $\left.\mathrm{CH}_{2}\right)$; $1.585\left(6 \mathrm{H}, \mathrm{s}, \mathrm{CH}_{3}\right) ; 1.256-1.220\left(3 \mathrm{H}, \mathrm{m}, \mathrm{CH}_{3}\right) .{ }^{13} \mathrm{C}-\mathrm{NMR}$ $\left(\mathrm{CDCl}_{3}, \delta\right): 174.93(\mathrm{C}=\mathrm{O}), 156.73$ (C aro), 156.48 ( $\mathrm{C}$ aro), 129.74 (C aro), 111.16 (C aro), 109.52 (C aro), 106.71 (C aro), $\left.79.23\left(\mathrm{C}_{\left(\mathrm{CH}_{3}\right.}\right)_{2}\right), 61.76\left(\mathrm{CH}_{2}\right), 25.34\left(2 \times \mathrm{CH}_{3}\right)$, $13.98\left(\mathrm{CH}_{3}\right)$. MS m/z: $223.13(\mathrm{M}-1), 247.13(\mathrm{M}+\mathrm{Na})$, $447.07(2 \mathrm{M}-1), 470.93(2 \mathrm{M}+\mathrm{Na})$.

\section{Halogenated organic compounds (4)}

N-Heterocycle (15 mmol), KOH (8.4 g, $150 \mathrm{mmol})$, $\mathrm{K}_{2} \mathrm{CO}_{3}(20 \mathrm{~g}, 150 \mathrm{mmol})$, TBAB (0.48 g, $\left.1.5 \mathrm{mmol}\right)$ were dissolved in $100 \mathrm{ml} \mathrm{1,2-dihalogen} \mathrm{ethane} \mathrm{or} \mathrm{1,}$ 3 -dihalogen propane. The mixture was heated to reflux at $45^{\circ} \mathrm{C}$ for $24 \mathrm{~h}$. The process of the reaction was detected through TLC method. After the reaction, anhydrous $\mathrm{Na}_{2} \mathrm{SO}_{4}$ was used to dehydrate the organic layer from a separatory funnel. The crude products were obtained through the course of filtration and vacuum distillation to remove the solvent. The final products (4) were purified by flash column chromatography with petroleum ether/EtOAc as the mobile phase. 4a (1-(2-Chloroethyl)-1H-indole): colorless oil (24\%), $\mathrm{R}_{\mathrm{f}}=0.55$ (developing agent: petroleum ether/EtOAc $=20: 1) ;{ }^{1} \mathrm{H}-\mathrm{NMR}\left(\mathrm{CDCl}_{3}, 400 \mathrm{MHz}\right): \delta 8.136(1 \mathrm{H}, \mathrm{m}$, Ar-H); 7.688-7.583 (3H, m, Ar-H); 7.362 (1H, s, Ar-H); 6.964 (1H, s, Ar-H); 4.482-4.450 (2H, t, $\left.J=6.4 \mathrm{~Hz}, \mathrm{CH}_{2}\right)$; 3.915-3.884 (2H, t, $\left.J=6.4 \mathrm{~Hz}, \mathrm{CH}_{2}\right) .{ }^{13} \mathrm{C}-\mathrm{NMR}\left(\mathrm{CDCl}_{3}\right.$, $\delta): 136.12$ (C aro), 129.14 (C aro), 128.59 (C aro), 122.20 (C aro), 121.56 (C aro), 120.17 (C aro), 109.44 (C aro), 102.16 (C aro), $48.02\left(\mathrm{CH}_{2}\right), 43.04\left(\mathrm{CH}_{2}\right)$. MS m/z: 361.20 $(2 \mathrm{M}+1)$.

4b (9-(2-Chloroethyl)-9H-carbazole): white flocculus (30\%), m.p. $127.6-128.8^{\circ} \mathrm{C}, \mathrm{R}_{\mathrm{f}}=0.53$ (developing agent: petroleum ether / EtOAc $=10: 1)$; ${ }^{1} \mathrm{H}-\mathrm{NMR}\left(\mathrm{CDCl}_{3}\right.$, 400MHz): $\delta 8.106$ (2H, m, Ar-H); 7.501-7.425 (4H, m, Ar$\mathrm{H})$; 7.282-7.243 (2H, m, Ar-H); $4.646(2 \mathrm{H}, \mathrm{t}, J=7.2 \mathrm{~Hz}$, $\left.\mathrm{CH}_{2}\right) ; 3.860\left(2 \mathrm{H}, \mathrm{t}, J=7.2 \mathrm{~Hz}, \mathrm{CH}_{2}\right) .{ }^{13} \mathrm{C}-\mathrm{NMR}\left(\mathrm{CDCl}_{3}\right.$, $\delta): 140.13(2 \times \mathrm{C}$ aro $), 125.95(2 \times \mathrm{C}$ aro $), 123.13(2 \times \mathrm{C}$ aro $)$, $120.53(2 \times \mathrm{C}$ aro $), 119.54(2 \times \mathrm{C}$ aro $), 108.46(2 \times \mathrm{C}$ aro $)$, $44.73\left(\mathrm{CH}_{2}\right), 41.00\left(\mathrm{CH}_{2}\right)$.

4c (1-(3-Chloropropyl)-1H-indole): colorless oil $(44.52 \%), \mathrm{R}_{\mathrm{f}}=0.70$ (developing agent: petroleum ether / $\mathrm{EtOAc}=10: 1) ;{ }^{1} \mathrm{H}-\mathrm{NMR}\left(\mathrm{CDCl}_{3}, 400 \mathrm{MHz}\right): \delta 7.673-$ $7.632(1 \mathrm{H}, \mathrm{m}, \mathrm{Ar}-\mathrm{H})$; 7.363-7.393 $(1 \mathrm{H}, \mathrm{m},=\mathrm{CH})$; 7.256-7.199 (1H, m, Ar-H); 7.136-7.093 (2H, m, Ar-H); $6.511(1 \mathrm{H}, \mathrm{s},=\mathrm{CH}) ; 4.363-4.331\left(2 \mathrm{H}, \mathrm{t}, J=6.4 \mathrm{~Hz}, \mathrm{CH}_{2}\right)$; $3.470-3.440\left(2 \mathrm{H}, \mathrm{t}, J=6.0 \mathrm{~Hz}, \mathrm{CH}_{2}\right) ; 2.306-2.244(2 \mathrm{H}$, $\left.\mathrm{m}, \mathrm{CH}_{2}\right) .{ }^{13} \mathrm{C}-\mathrm{NMR}\left(\mathrm{CDCl}_{3}, \delta\right): 135.85(\mathrm{C}$ aro $), 128.72$ (C aro), 128.00 (=CH), 121.65 (C aro), 121.08 (C aro), 119.49 (C aro), 109.22 (C aro), $101.52(=\mathrm{CH}), 42.87$ $\left(\mathrm{CH}_{2}\right), 41.85\left(\mathrm{CH}_{2}\right), 32.64\left(\mathrm{CH}_{2}\right)$.

4d (9-(3-Chloropropyl)-9H-carbazole): colorless oil (40\%), $\mathrm{R}_{\mathrm{f}}=0.70$ (developing agent: dichloromethane/ acetone $=10: 1) ;{ }^{1} \mathrm{H}-\mathrm{NMR}\left(\mathrm{CDCl}_{3}, 400 \mathrm{MHz}\right): \delta 8.104-$ $8.085(2 \mathrm{H}, \mathrm{d}, J=7.6 \mathrm{~Hz}, \mathrm{Ar}-\mathrm{H}) ; 7.466(4 \mathrm{H}, \mathrm{s}, \mathrm{Ar}-\mathrm{H})$; 7.258-7.228 (2H, m, Ar-H); 4.509-4.477 (2H, t, $J=6.4 \mathrm{~Hz}$, $\left.\mathrm{CH}_{2}\right) ; 3.519-3.490\left(2 \mathrm{H}, \mathrm{t}, J=6.0 \mathrm{~Hz}, \mathrm{CH}_{2}\right) ; 2.362-2.300$ $\left(2 \mathrm{H}, \mathrm{m}, \mathrm{CH}_{2}\right) .{ }^{13} \mathrm{C}-\mathrm{NMR}\left(\mathrm{CDCl}_{3}, \delta\right): 140.40$ (C aro), $126.13(2 \times \mathrm{C}$ aro $), 123.00(\mathrm{C}$ aro $), 120.42(2 \times \mathrm{C}$ aro $)$, $119.15(3 \times \mathrm{C}$ aro $), 108.57(3 \times \mathrm{C}$ aro $), 55.07\left(\mathrm{CH}_{2}\right), 42.31$ $\left(\mathrm{CH}_{2}\right), 31.80\left(\mathrm{CH}_{2}\right)$.

4e (1-(3-Bromopropyl)-1H-indole): colorless oil (68.27\%), $\mathrm{R}_{\mathrm{f}}=0.55$ (developing agent: dichloromethane /acetone $=10: 1) ;{ }^{1} \mathrm{H}-\mathrm{NMR}\left(\mathrm{CDCl}_{3}, 400 \mathrm{MHz}\right): \delta 7.642-$ $7.623(1 \mathrm{H}, \mathrm{d}, J=7.6 \mathrm{~Hz}, \mathrm{Ar}-\mathrm{H}) ; 7.381-7.361(1 \mathrm{H}, \mathrm{d}$, $J=8.0 \mathrm{~Hz}, \mathrm{Ar}-\mathrm{H}) ; 7.234-7.178(1 \mathrm{H}, \mathrm{m},=\mathrm{CH}) ; 7.142-7.084$ $(2 \mathrm{H}, \mathrm{m}, \mathrm{Ar}-\mathrm{H}) ; 6.505$ (1H, s, =CH); 4.340-4.265 (2H, m, $\left.\mathrm{CH}_{2}\right) ; 3.308-3.277\left(2 \mathrm{H}, \mathrm{t}, J=6.4 \mathrm{~Hz}, \mathrm{CH}_{2}\right) ; 2.369-2.160$ $\left(2 \mathrm{H}, \mathrm{m}, \mathrm{CH}_{2}\right) .{ }^{13} \mathrm{C}-\mathrm{NMR}\left(\mathrm{CDCl}_{3}, \delta\right): 136.84$ (C aro), 128.74 (C aro), 128.05 (C aro), 121.67 (C aro), 120.95 (C aro), 119.53 (C aro), 109.58 (C aro), 101.55 (C aro), 43.98 $\left(\mathrm{CH}_{2}\right), 32.74\left(\mathrm{CH}_{2}\right), 30.96\left(\mathrm{CH}_{2}\right)$.

4f (9-(3-Bromopropyl)-9H-carbazole): colorless oil (73.7\%), $\mathrm{R}_{\mathrm{f}}=0.50$ (developing agent: dichloromethane/ acetone $=10: 1) ;{ }^{1} \mathrm{H}-\mathrm{NMR}\left(\mathrm{CDCl}_{3}, 400 \mathrm{MHz}\right): \delta 8.110$ $8.090(2 \mathrm{H}, \mathrm{d}, J=8.0 \mathrm{~Hz}, \mathrm{Ar}-\mathrm{H}) ; 7.497-7.483(4 \mathrm{H}, \mathrm{d}$, $J=5.6 \mathrm{~Hz}, \mathrm{Ar}-\mathrm{H}) ; 7.298-7.244$ (2H, m, Ar-H); 4.512-4.480 
$\left(2 \mathrm{H}, \mathrm{t}, J=6.4 \mathrm{~Hz}, \mathrm{CH}_{2}\right) ; 3.399-3.368(2 \mathrm{H}, \mathrm{t}, J=6.0 \mathrm{~Hz}$, $\left.\mathrm{CH}_{2}\right) ; 2.467-2.405\left(2 \mathrm{H}, \mathrm{m}, \mathrm{CH}_{2}\right) \cdot{ }^{13} \mathrm{C}-\mathrm{NMR}\left(\mathrm{CDCl}_{3}, \delta\right)$ : 140.38 (C aro), $132.37(2 \times \mathrm{C}$ aro $), 126.16(\mathrm{C}$ aro $), 123.01$ $(2 \times \mathrm{C}$ aro $), 120.47(2 \times \mathrm{C}$ aro $), 119.19(2 \times \mathrm{C}$ aro $), 108.82$ $(2 \times \mathrm{C}$ aro $), 45.30\left(\mathrm{CH}_{2}\right), 32.78\left(\mathrm{CH}_{2}\right), 30.98\left(\mathrm{CH}_{2}\right)$.

4g (1-(3-Chloropropyl)-1H-benzo[d]imidazole): colorless oil $(21.54 \%), \mathrm{R}_{\mathrm{f}}=0.48$ (developing agent: dichloromethane / acetone $=10: 1) ;{ }^{1} \mathrm{H}-\mathrm{NMR}\left(\mathrm{CDCl}_{3}\right.$, $400 \mathrm{MHz}): \delta 8.020(1 \mathrm{H}, \mathrm{s},=\mathrm{CH}) ; 7.845-7.823(1 \mathrm{H}, \mathrm{m}, \mathrm{Ar}-$ H); 7.461-7.428 (1H, m, Ar-H); 7.355-7.260 (2H, m, Ar$\mathrm{H}) ; 4.450-4.417\left(2 \mathrm{H}, \mathrm{t}, J=6.4 \mathrm{~Hz}, \mathrm{CH}_{2}\right) ; 3.506-3.476(2 \mathrm{H}$, $\left.\mathrm{t}, J=6.0 \mathrm{~Hz}, \mathrm{CH}_{2}\right) ; 2.369-2.306\left(2 \mathrm{H}, \mathrm{m}, \mathrm{CH}_{2}\right) .{ }^{13} \mathrm{C}-\mathrm{NMR}$ $\left(\mathrm{CDCl}_{3}, \delta\right): 143.48$ (C aro), 143.02 (C aro), 133.51 (C aro), 123.27 (C aro), 122.50 (C aro), 120.46 (C aro), 109.53 (C aro), $60.38\left(\mathrm{CH}_{2}\right), 41.22\left(\mathrm{CH}_{2}\right), 32.07\left(\mathrm{CH}_{2}\right)$.

\section{Ester compounds 5}

Monosubstituted intermediates $3(2.24 \mathrm{~g}, 10 \mathrm{mmol})$, halogenated organic compounds $4(10 \mathrm{mmol}), \mathrm{K}_{2} \mathrm{CO}_{3}$ (3.32 g, $24 \mathrm{mmol}$ ) and $\mathrm{NaI}$ (catalytic amounts) were added to $50 \mathrm{ml}$ acetone. The solution was heated to reflux at $65^{\circ} \mathrm{C}$ for $24 \mathrm{~h}$ under stirring condition. The process of the reaction was detected through TLC method. After the reaction, the crude esters were obtained through the course of filtration and vacuum distillation to remove the solvent. The final products 5 were purified by flash column chromatography with petroleum ether/EtOAc as the mobile phase.

5a (Ethyl 2-methyl-2-(4-(2-oxo-2-phenylethoxy) phenoxy)propanoate): colorless oil $(39.77 \%), R_{f}=0.45$ (developing agent: petroleum ether / EtOAc $=10: 1$ ); ${ }^{1} \mathrm{H}-\mathrm{NMR}\left(\mathrm{CDCl}_{3}, 400 \mathrm{MHz}\right): \delta 7.974(2 \mathrm{H}, \mathrm{m}, \mathrm{Ar}-\mathrm{H})$; $7.596(1 \mathrm{H}, \mathrm{d}, J=7.2 \mathrm{~Hz}, \mathrm{Ar}-\mathrm{H}) ; 7.478(2 \mathrm{H}, \mathrm{d}, J=7.6 \mathrm{~Hz}$, Ar-H); 6.829-6.772 (4H, m, Ar-H); $5.210\left(2 \mathrm{H}, \mathrm{s}, \mathrm{CH}_{2}\right)$; 4.248-4.194 (2H, m, $\left.\mathrm{CH}_{2}\right) ; 1.538\left(6 \mathrm{H}, \mathrm{s}, \mathrm{CH}_{3}\right) ; 1.277-$ $1.242\left(3 \mathrm{H}, \mathrm{m}, \mathrm{CH}_{3}\right) .{ }^{13} \mathrm{C}-\mathrm{NMR}\left(\mathrm{CDCl}_{3}, \delta\right): 194.67(\mathrm{C}=\mathrm{O})$, $174.13(\mathrm{C}=\mathrm{O}), 153.60$ ( $\mathrm{C}$ aro $), 149.80$ ( $\mathrm{C}$ aro $), 134.59$ (C aro), $133.86(\mathrm{C}$ aro $), 128.83(2 \times \mathrm{C}$ aro $), 128.13(2 \times \mathrm{C}$ aro $)$, $121.52(2 \times \mathrm{C}$ aro $), 115.40(2 \times \mathrm{C}$ aro $\left.), 79.65\left(\mathrm{C}^{\left(\mathrm{CH}_{3}\right.}\right)_{2}\right)$, $71.46\left(\mathrm{CH}_{2}\right), 61.41\left(\mathrm{CH}_{2}\right), 25.30\left(2 \times \mathrm{CH}_{3}\right), 14.11\left(\mathrm{CH}_{3}\right)$. MS $m / z: 365.13(\mathrm{M}+\mathrm{Na})$.

$5 b$ (Ethyl 2-(4-(2-(1H-indol-1-yl)ethoxy)phenoxy)2-methylpropanoate): colorless oil $(22.7 \%), R_{f}=0.40$ (developing agent: petroleum ether / EtOAc $=10: 1$ ); ${ }^{1} \mathrm{H}-\mathrm{NMR}\left(\mathrm{CDCl}_{3}, 400 \mathrm{MHz}\right): \delta$ 7.637-7.617 $(1 \mathrm{H}, \mathrm{d}$, $J=8.0 \mathrm{~Hz}, \mathrm{Ar}-\mathrm{H}) ; 7.399-7.377(1 \mathrm{H}, \mathrm{d}, J=8.4 \mathrm{~Hz},=\mathrm{CH})$; 7.248-7.198 (2H, m, Ar-H); 7.127-7.107 (1H, m, Ar-H); 6.802-6.708 (3H, m, Ar-H); 7.399-7.377 (1H, m, Ar-H); $6.509-6.500(1 \mathrm{H}, \mathrm{m},=\mathrm{CH}) ; 4.497-4.469(2 \mathrm{H}, \mathrm{t}, J=5.6 \mathrm{~Hz}$, $\left.\mathrm{CH}_{2}\right)$; 4.242-4.189 (4H, m, CH $) ; 1.579\left(6 \mathrm{H}, \mathrm{s}, \mathrm{CH}_{3}\right)$; 1.274-1.239 (3H, m, $\left.\mathrm{CH}_{3}\right) \cdot{ }^{13} \mathrm{C}-\mathrm{NMR}\left(\mathrm{CDCl}_{3}, \delta\right): 174.27$ $(\mathrm{C}=\mathrm{O}), 153.88$ ( $\mathrm{C}$ aro $), 149.38(\mathrm{C}$ aro $), 136.08(\mathrm{C}$ aro $)$, 128.67 (C aro), 128.40 (C aro), $121.59(2 \times \mathrm{C}$ aro $), 121.04$ (C aro), 120.08 (C aro), 119.49 (C aro), $114.95(2 \times \mathrm{C}$ aro), $109.20(\mathrm{C}$ aro $), 101.60(\mathrm{C}$ aro $), 79.69\left(\mathrm{C}\left(\mathrm{CH}_{3}\right)_{2}\right), 67.26$
$\left(\mathrm{CH}_{2}\right), 61.34\left(\mathrm{CH}_{2}\right), 45.72\left(\mathrm{CH}_{2}\right), 25.36\left(2 \times \mathrm{CH}_{3}\right), 14.13$ $\left(\mathrm{CH}_{3}\right)$. MS m/z: $390.20(\mathrm{M}+\mathrm{Na})$.

5c (Ethyl 2-(4-(2-(9H-carbazol-9-yl)ethoxy) phenoxy)-2-methylpropanoate): colorless oil $(6.2 \%), \mathrm{R}_{\mathrm{f}}=$ 0.47 (developing agent: petroleum ether/EtOAc $=10: 1$ ); ${ }^{1} \mathrm{H}-\mathrm{NMR}\left(\mathrm{CDCl}_{3}, 400 \mathrm{MHz}\right): \delta 8.100(1 \mathrm{H}, \mathrm{m}, \mathrm{Ar}-\mathrm{H}) ; 7.507-$ $7.450(3 \mathrm{H}, \mathrm{dd}, J=8.4 \mathrm{~Hz}, \mathrm{Ar}-\mathrm{H}) ; 7.260-7.225(5 \mathrm{H}, \mathrm{m}, \mathrm{Ar}-$ $\mathrm{H}) ; 6.780-6.758(1 \mathrm{H}, \mathrm{d}, J=8.8 \mathrm{~Hz}, \mathrm{Ar}-\mathrm{H}) ; 6.687-6.666(2 \mathrm{H}$, d, $J=8.4 \mathrm{~Hz}, \mathrm{Ar}-\mathrm{H}) ; 4.711-4.681\left(2 \mathrm{H}, \mathrm{t}, J=6.0 \mathrm{~Hz}, \mathrm{CH}_{2}\right)$; 4.310-4.116 (4H, m, $\left.\mathrm{CH}_{2}\right) ; 1.541\left(6 \mathrm{H}, \mathrm{s}, \mathrm{CH}_{3}\right) ; 1.278-$ $1.233\left(3 \mathrm{H}, \mathrm{m}, \mathrm{CH}_{3}\right) \cdot{ }^{13} \mathrm{C}-\mathrm{NMR}\left(\mathrm{CDCl}_{3}, \delta\right): 174.25(\mathrm{C}=\mathrm{O})$, 153.89 (C aro), 140.54 (C aro), $125.72(3 \times \mathrm{C}$ aro), 123.00 $(\mathrm{C}$ aro $), 121.54(2 \times \mathrm{C}$ aro $), 120.34(3 \times \mathrm{C}$ aro $), 119.16(3 \times \mathrm{C}$

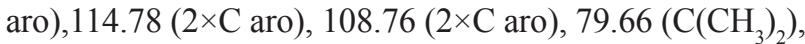
$66.25\left(\mathrm{CH}_{2}\right), 61.33\left(\mathrm{CH}_{2}\right), 42.56\left(\mathrm{CH}_{2}\right), 25.24\left(2 \times \mathrm{CH}_{3}\right)$, $14.11\left(\mathrm{CH}_{3}\right)$. MS m/z: $440.20(\mathrm{M}+\mathrm{Na})$.

$5 \mathrm{~d}$ (Ethyl 2-(4-(3-(1H-indol-1-yl)propoxy) phenoxy)-2-methylpropanoate): colorless oil (35.72\%), $\mathrm{R}_{\mathrm{f}}=0.36$ (developing agent: petroleum ether / EtOAc $=$ 10:1); ${ }^{1} \mathrm{H}-\mathrm{NMR}\left(\mathrm{CDCl}_{3}, 400 \mathrm{MHz}\right): \delta$ 7.628-7.609 $(1 \mathrm{H}, \mathrm{d}$, $J=7.6 \mathrm{~Hz}, \mathrm{Ar}-\mathrm{H}) ; 7.359-7.339(1 \mathrm{H}, \mathrm{d}, J=8.0 \mathrm{~Hz},=\mathrm{CH})$; 7.184-7.146 (1H, t, $J=7.2 \mathrm{~Hz}, \mathrm{Ar}-\mathrm{H}) ; 7.102-7.069(2 \mathrm{H}, \mathrm{m}$, Ar-H); 6.839-6.808 (2H, m, Ar-H); 6.758-6.736 (2H, m, Ar-H); 6.472-6.465 (1H, m, =CH); 4.372-4.339 (2H, t, $J=$ $\left.6.4 \mathrm{~Hz}, \mathrm{CH}_{2}\right) ; 4.265-4.212\left(2 \mathrm{H}, \mathrm{m}, \mathrm{CH}_{2}\right) ; 3.835-3.807(2 \mathrm{H}$, $\left.\mathrm{t}, J=5.6 \mathrm{~Hz}, \mathrm{CH}_{2}\right) ; 2.283-2.060\left(2 \mathrm{H}, \mathrm{m}, \mathrm{CH}_{2}\right) ; 1.538(6 \mathrm{H}$, $\left.\mathrm{s}, \mathrm{CH}_{3}\right) ; 1.296-1.261\left(3 \mathrm{H}, \mathrm{t}, J=6.8 \mathrm{~Hz}, \mathrm{CH}_{3}\right) .{ }^{13} \mathrm{C}-\mathrm{NMR}$ $\left(\mathrm{CDCl}_{3}, \delta\right): 174.28(\mathrm{C}=\mathrm{O}), 154.31$ ( $\mathrm{C}$ aro $), 149.21(\mathrm{C}$ aro $)$, 135.95 (C aro), 128.84 (C aro), 128.07 (C aro), 127.69 $(=\mathrm{CH}), 121.63(2 \times \mathrm{C}$ aro $), 120.97(\mathrm{C}$ aro $), 119.41(\mathrm{C}$ aro $)$, $114.91(2 \times \mathrm{C}$ aro $), 109.30(\mathrm{C}$ aro $), 101.49(=\mathrm{CH}), 79.71$

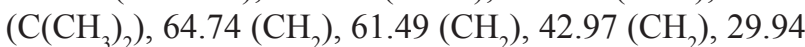
$\left(\mathrm{CH}_{2}\right), 25.31\left(2 \times \mathrm{CH}_{3}\right), 14.11\left(\mathrm{CH}_{3}\right) . \mathrm{MS} \mathrm{m} / \mathrm{z}: 382.27$ $(\mathrm{M}+1), 404.27(\mathrm{M}+\mathrm{Na})$.

5e (Ethyl 2-(4-(3-(9H-carbazol-9-yl)propoxy) phenoxy)-2-methylpropanoate): colorless oil (15.84\%), $\mathrm{R}_{\mathrm{f}}$ $=0.39$ (developing agent: petroleum ether $/ \mathrm{EtOAc}=5: 1)$; ${ }^{1} \mathrm{H}-\mathrm{NMR}\left(\mathrm{CDCl}_{3}, 400 \mathrm{MHz}\right): \delta 8.132-8.098(2 \mathrm{H}, \mathrm{m}, \mathrm{Ar}-\mathrm{H})$; 7.580-7.560 (2H, d, $J=8.0 \mathrm{~Hz}$, Ar-H); 7.407-7.369 $(2 \mathrm{H}, \mathrm{t}$, $J=7.2 \mathrm{~Hz}, \mathrm{Ar}-\mathrm{H}) ; 7.197-7.159$ (2H, t, $J=7.6 \mathrm{~Hz}, \mathrm{Ar}-\mathrm{H})$; 6.813-6.737 (4H, m, Ar-H); 4.569-4.536 (2H, t, $J=6.8 \mathrm{~Hz}$, $\left.\mathrm{CH}_{2}\right) ; 3.882-3.853\left(2 \mathrm{H}, \mathrm{t}, J=5.6 \mathrm{~Hz}, \mathrm{CH}_{2}\right) ; 3.695(2 \mathrm{H}$, $\left.\mathrm{s}, \mathrm{CH}_{2}\right) ; 2.400-2.100\left(2 \mathrm{H}, \mathrm{m}, \mathrm{CH}_{2}\right) ; 1.446\left(6 \mathrm{H}, \mathrm{s}, \mathrm{CH}_{3}\right)$; $1.164\left(3 \mathrm{H}, \mathrm{s}, \mathrm{CH}_{3}\right) \cdot{ }^{13} \mathrm{C}-\mathrm{NMR}\left(\mathrm{CDCl}_{3}, \delta\right): 173.70(\mathrm{C}=\mathrm{O})$, 153.89(C aro), 148.49 (C aro), $139.91(2 \times \mathrm{C}$ aro), 125.62 $(2 \times \mathrm{C}$ aro $), 122.05(2 \times \mathrm{C}$ aro $), 121.38(2 \times \mathrm{C}$ aro $), 121.25$ $(2 \times \mathrm{C}$ aro $), 120.22(2 \times \mathrm{C}$ aro $), 118.72(\mathrm{C}$ aro $), 114.99(\mathrm{C}$

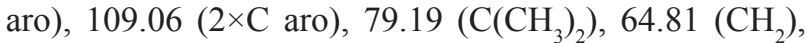
$60.83\left(\mathrm{CH}_{2}\right), 52.17\left(\mathrm{CH}_{2}\right), 28.14\left(\mathrm{CH}_{2}\right), 24.90\left(2 \times \mathrm{CH}_{3}\right)$, $13.89\left(\mathrm{CH}_{3}\right)$. MS m/z: $432.13(\mathrm{M}+1), 454.20(\mathrm{M}+\mathrm{Na})$.

$5 f$ (Ethyl 2-(4-(3-(1H-benzo[d]imidazol-1-yl) propoxy)phenoxy)-2-methylpropanoate): colorless oil (33.23\%), $\mathrm{R}_{\mathrm{f}}=0.65$ (developing agent: dichloromethane/ acetone $=10: 1) ;{ }^{1} \mathrm{H}-\mathrm{NMR}\left(\mathrm{CDCl}_{3}, 400 \mathrm{MHz}\right): \delta 7.925(1 \mathrm{H}, \mathrm{s}$, $=\mathrm{CH}) ; 7.818-7.802(1 \mathrm{H}, \mathrm{q}, J=4.4 \mathrm{~Hz}, \mathrm{Ar}-\mathrm{H}) ; 7.423-7.407$ $(1 \mathrm{H}, \mathrm{t}, J=7.2 \mathrm{~Hz}, \mathrm{Ar}-\mathrm{H}) ; 7.291-7.265(2 \mathrm{H}, \mathrm{m}, \mathrm{Ar}-\mathrm{H})$; 
6.847-6.813 (2H, d, $J=8.8 \mathrm{~Hz}, \mathrm{Ar}-\mathrm{H}) ; 6.761-6.739(2 \mathrm{H}$, $\mathrm{d}, J=8.8 \mathrm{~Hz}, \mathrm{Ar}-\mathrm{H}) ; 4.449-4.411\left(2 \mathrm{H}, \mathrm{m}, \mathrm{CH}_{2}\right) ; 4.269-$ $4.215\left(2 \mathrm{H}, \mathrm{m}, \mathrm{CH}_{2}\right) ; 3.869-3.783\left(2 \mathrm{H}, \mathrm{m}, \mathrm{CH}_{2}\right) ; 2.308-$ $2.294\left(2 \mathrm{H}, \mathrm{m}, \mathrm{CH}_{2}\right) ; 1.541\left(6 \mathrm{H}, \mathrm{s}, \mathrm{CH}_{3}\right) ; 1.300-1.255(3 \mathrm{H}$, $\left.\mathrm{m}, \mathrm{CH}_{3}\right) \cdot{ }^{13} \mathrm{C}-\mathrm{NMR}\left(\mathrm{CDCl}_{3}, \delta\right): 174.26(\mathrm{C}=\mathrm{O}), 154.08(\mathrm{C}$ aro), 149.38 (C aro), $143.72(=\mathrm{CH}), 143.18$ (C aro), 133.71 (C aro), 123.05 (C aro), 123.01 (C aro), $122.20(2 \times \mathrm{C}$ aro), 120.54 (C aro), $114.92(2 \times \mathrm{C}$ aro), 109.59 (C aro), 79.77 $\left(\mathrm{C}\left(\mathrm{CH}_{3}\right)_{2}\right), 64.19\left(\mathrm{CH}_{2}\right), 61.33\left(\mathrm{CH}_{2}\right), 41.53\left(\mathrm{CH}_{2}\right), 30.90$ $\left(\mathrm{CH}_{2}\right), 25.29\left(2 \times \mathrm{CH}_{3}\right), 14.12\left(\mathrm{CH}_{3}\right) . \mathrm{MS} \mathrm{m} / z: 383.33$ $(\mathrm{M}+1), 405.19(\mathrm{M}+\mathrm{Na}), 765.87(2 \mathrm{M}+1)$.

$5 \mathrm{~g}$ (Ethyl 2-methyl-2-(4-(3-phenylpropoxy) phenoxy)propanoate): colorless oil (29.24\%), $\mathrm{R}_{\mathrm{f}}=0.52$ (developing agent: dichloromethane); ${ }^{1} \mathrm{H}-\mathrm{NMR}\left(\mathrm{CDCl}_{3}\right.$, 400MHz): $\delta 7.247(2 \mathrm{H}, \mathrm{m}, \mathrm{Ar}-\mathrm{H}) ; 7.195(3 \mathrm{H}, \mathrm{dd}, J=$ 8.0Hz, Ar-H); 6.821 (2H, m, Ar-H); 6.762 (2H, m, Ar-H); $4.258\left(2 \mathrm{H}, \mathrm{m}, \mathrm{CH}_{2}\right) ; 3.901\left(2 \mathrm{H}, \mathrm{t}, J=6.4 \mathrm{~Hz}, \mathrm{CH}_{2}\right) ; 2.790$ $\left(2 \mathrm{H}, \mathrm{t}, J=7.2 \mathrm{~Hz}, \mathrm{CH}_{2}\right) ; 2.075\left(2 \mathrm{H}, \mathrm{m}, \mathrm{CH}_{2}\right) ; 1.531(6 \mathrm{H}, \mathrm{s}$, $\left.\mathrm{CH}_{3}\right) ; 1.273\left(3 \mathrm{H}, \mathrm{t}, J=7.2 \mathrm{~Hz}, \mathrm{CH}_{3}\right) .{ }^{13} \mathrm{C}-\mathrm{NMR}\left(\mathrm{CDCl}_{3}, \delta\right)$ : $174.31(\mathrm{C}=\mathrm{O}), 154.72$ (C aro), 148.96 (C aro), 141.58 (C aro $), 128.52(2 \times \mathrm{C}$ aro $), 128.42(2 \times \mathrm{C}$ aro $), 125.93(\mathrm{C}$ aro $)$, $121.63(2 \times \mathrm{C}$ aro $), 114.91(2 \times \mathrm{C}$ aro $), 79.69\left(\mathrm{C}\left(\mathrm{CH}_{3}\right)_{2}\right)$, $67.34\left(\mathrm{CH}_{2}\right), 61.28\left(\mathrm{CH}_{2}\right), 32.20\left(\mathrm{CH}_{2}\right), 30.94\left(\mathrm{CH}_{2}\right)$, $25.33\left(2 \times \mathrm{CH}_{3}\right), 14.14\left(\mathrm{CH}_{3}\right) . \mathrm{MS} \mathrm{m} / z: 343.07(\mathrm{M}+1)$, $706.93(2 \mathrm{M}+\mathrm{Na})$.

5 h (Ethyl 2-methyl-2-(3-(2-oxo-2-phenylethoxy) phenoxy)propanoate): achromatous oil (58.93\%), $\mathrm{R}_{\mathrm{f}}=$ 0.60 (developing agent: petroleum ether / EtOAc = 10:1); ${ }^{1} \mathrm{H}-\mathrm{NMR}\left(\mathrm{CDCl}_{3}, 400 \mathrm{MHz}\right): \delta$ 8.093-7.974 (2H, m, Ar$\mathrm{H}) ; 7.593$ (1H, m, Ar-H); 7.512-7.474 (2H, t, $J=7.6 \mathrm{~Hz}$, Ar-H); 7.137-7.096 (1H, t, $J=8.0 \mathrm{~Hz}, \mathrm{Ar}-\mathrm{H}) ; 6.597-6.571$ $(1 \mathrm{H}, \mathrm{m}, \mathrm{Ar}-\mathrm{H}) ; 6.485-6.436(2 \mathrm{H}, \mathrm{m}, \mathrm{Ar}-\mathrm{H}) ; 5.217(2 \mathrm{H}$, $\left.\mathrm{s}, \mathrm{CH}_{2}\right) ; 4.231-4.177\left(2 \mathrm{H}, \mathrm{m}, \mathrm{CH}_{2}\right) ; 1.581\left(6 \mathrm{H}, \mathrm{s}, \mathrm{CH}_{3}\right)$; 1.242-1.185 (3H, m, $\left.\mathrm{CH}_{3}\right) .{ }^{13} \mathrm{C}-\mathrm{NMR}\left(\mathrm{CDCl}_{3}, \delta\right): 194.41$ $(\mathrm{C}=\mathrm{O}), 174.14(\mathrm{C}=\mathrm{O}), 158.95(\mathrm{C}$ aro $), 156.69$ ( $\mathrm{C}$ aro), 134.62 (C aro), 133.83 (C aro), 129.58 (C aro), 128.81 $(2 \times \mathrm{C}$ aro $), 128.15(2 \times \mathrm{C}$ aro $), 111.88(\mathrm{C}$ aro $), 108.61(\mathrm{C}$ aro), 106.32 (C aro), $79.23\left(\mathrm{C}\left(\mathrm{CH}_{3}\right)_{2}\right), 70.93\left(\mathrm{CH}_{2}\right), 61.42$ $\left(\mathrm{CH}_{2}\right), 25.37\left(2 \times \mathrm{CH}_{3}\right), 14.04\left(\mathrm{CH}_{3}\right) . \mathrm{MS} \mathrm{m} / z: 365.20$ $(\mathrm{M}+\mathrm{Na}), 706.87(2 \mathrm{M}+\mathrm{Na})$.

5i (Ethyl 2-(3-(2-(1H-indol-1-yl)ethoxy)phenoxy)2-methylpropanoate): achromatous oil $(32.24 \%), \mathrm{R}_{\mathrm{f}}=$ 0.54 (developing agent: petroleum ether / EtOAc = 10:1); ${ }^{1} \mathrm{H}-\mathrm{NMR}\left(\mathrm{CDCl}_{3}, 400 \mathrm{MHz}\right): \delta$ 7.633-7.614 $(1 \mathrm{H}, \mathrm{d}$, $J=7.6 \mathrm{~Hz}, \mathrm{Ar}-\mathrm{H}) ; 7.402-7.382(1 \mathrm{H}, \mathrm{d}, J=8.0 \mathrm{~Hz}, \mathrm{Ar}-\mathrm{H})$; 7.257-7.193 (4H, m, Ar-H); 7.125-7.055 (1H, m, =CH); 6.508-6.392 (3H, m, Ar-H and $=\mathrm{CH}) ; 4.511-4.483(2 \mathrm{H}, \mathrm{t}$, $\left.J=5.6 \mathrm{~Hz}, \mathrm{CH}_{2}\right) ; 4.243-4.176\left(4 \mathrm{H}, \mathrm{m}, \mathrm{CH}_{2}\right) ; 1.569(6 \mathrm{H}$, $\left.\mathrm{s}, \mathrm{CH}_{3}\right) ; 1.249-1.195\left(3 \mathrm{H}, \mathrm{m}, \mathrm{CH}_{3}\right) .{ }^{13} \mathrm{C}-\mathrm{NMR}\left(\mathrm{CDCl}_{3}, \delta\right)$ : $174.19(\mathrm{C}=\mathrm{O}), 159.17$ (C aro), 156.67 (C aro), 136.10 (C aro), $129.50(2 \times \mathrm{C}$ aro $), 128.32(=\mathrm{CH}), 121.60$ (C aro), 121.02 (C aro), 119.48 (C aro), 111.50 (C aro), 109.15 (C aro), 108.26 (C aro), 106.09 (C aro), $101.64(=\mathrm{CH}), 79.18$ $\left(\mathrm{C}\left(\mathrm{CH}_{3}\right)_{2}\right), 66.82\left(\mathrm{CH}_{2}\right), 61.40\left(\mathrm{CH}_{2}\right), 45.61\left(\mathrm{CH}_{2}\right), 25.36$ $\left(2 \times \mathrm{CH}_{3}\right), 14.03\left(\mathrm{CH}_{3}\right)$. MS m/z: $368.27(\mathrm{M}+1), 390.27$ $(\mathrm{M}+\mathrm{Na}), 756.93(2 \mathrm{M}+\mathrm{Na})$.
$5 \mathrm{j}$ (Ethyl 2-(3-(2-(9H-carbazol-9-yl)ethoxy) phenoxy)-2-methylpropanoate): white solid (13.70\%), m.p. $57.6-60.1^{\circ} \mathrm{C}, \mathrm{R}_{\mathrm{f}}=0.58$ (developing agent: petroleum ether / EtOAc $=10: 1) ;{ }^{1} \mathrm{H}-\mathrm{NMR}\left(\mathrm{CDCl}_{3}, 400 \mathrm{MHz}\right): \delta$ 8.136-8.097 (2H, m, Ar-H); 7.505-7.495 (4H, m, Ar-H); 7.241-7.217 (2H, m, Ar-H); 7.071-7.025 (1H, m, Ar-H); 6.450-6.347 (3H, m, Ar-H); 4.693-4.664 (2H, t, $J=6.0 \mathrm{~Hz}$, $\left.\mathrm{CH}_{2}\right) ; 4.302-4.272\left(2 \mathrm{H}, \mathrm{t}, J=6.0 \mathrm{~Hz}, \mathrm{CH}_{2}\right) ; 4.192-4.139$ $\left(2 \mathrm{H}, \mathrm{m}, \mathrm{CH}_{2}\right) ; 1.562\left(6 \mathrm{H}, \mathrm{s}, \mathrm{CH}_{3}\right) ; 1.191-1.156(3 \mathrm{H}, \mathrm{t}$, $\left.J=7.2 \mathrm{~Hz}, \mathrm{CH}_{3}\right) .{ }^{13} \mathrm{C}-\mathrm{NMR}\left(\mathrm{CDCl}_{3}, \delta\right): 174.21(\mathrm{C}=\mathrm{O})$, 159.25 (C aro), 156.61 (C aro), $140.55(2 \times \mathrm{C}$ aro $), 129.58$ (C aro), 129.48 (C aro), $125.76(2 \times \mathrm{C}$ aro $), 123.04$ (C aro), $120.43(2 \times \mathrm{C}$ aro $), 119.28(2 \times \mathrm{C}$ aro $), 111.33(\mathrm{C}$ aro $), 108.05$ $(2 \times \mathrm{C}$ aro $), 106.01(\mathrm{C}$ aro $), 105.95(\mathrm{C}$ aro $), 79.24\left(\mathrm{C}\left(\mathrm{CH}_{3}\right)_{2}\right)$, $65.90\left(\mathrm{CH}_{2}\right), 61.42\left(\mathrm{CH}_{2}\right), 52.48\left(\mathrm{CH}_{2}\right), 25.39\left(2 \times \mathrm{CH}_{3}\right)$, $14.03\left(\mathrm{CH}_{3}\right)$. MS m/z: $440.20(\mathrm{M}+\mathrm{Na}), 856.93(2 \mathrm{M}+\mathrm{Na})$.

5k (Ethyl 2-(3-(3-(1H-indol-1-yl)propoxy)phenoxy)2-methylpropanoate): achromatous oil (40.70\%), $\mathrm{R}_{\mathrm{f}}$ $=0.44$ (developing agent: petroleum ether / EtOAc $=$ 10:1); ${ }^{1} \mathrm{H}-\mathrm{NMR}\left(\mathrm{CDCl}_{3}, 400 \mathrm{MHz}\right): \delta$ 7.626-7.607 $(1 \mathrm{H}$, $\mathrm{d}, J=7.6 \mathrm{~Hz}, \mathrm{Ar}-\mathrm{H}) ; 7.358-7.338(1 \mathrm{H}, \mathrm{d}, J=8.0 \mathrm{~Hz}$, $=\mathrm{CH})$; 7.251-7.061 (4H, m, Ar-H); 6.533-6.406 (4H, m, Ar-H and $=\mathrm{CH})$; 4.366-4.333 $\left(2 \mathrm{H}, \mathrm{t}, \mathrm{J}=6.4 \mathrm{~Hz}, \mathrm{CH}_{2}\right)$; 4.254-4.193 (2H, m, $\left.\mathrm{CH}_{2}\right)$; 3.840-3.749 (2H, m, $\left.\mathrm{CH}_{2}\right)$; 2.270-2.240 (2H, t, $\left.J=6.0 \mathrm{~Hz}, \mathrm{CH}_{2}\right) ; 1.595\left(6 \mathrm{H}, \mathrm{s}, \mathrm{CH}_{3}\right)$; 1.254-1.219 (3H, t, $\left.J=6.8 \mathrm{~Hz}, \mathrm{CH}_{3}\right) .{ }^{13} \mathrm{C}-\mathrm{NMR}\left(\mathrm{CDCl}_{3}\right.$, $\delta): 174.25(\mathrm{C}=\mathrm{O}), 159.65$ ( $\mathrm{C}$ aro $), 156.69$ (C aro), 135.93 (C aro), 129.59 (C aro), 128.66 (C aro), 127.70 (C aro), 121.66 (C aro), 120.97 (C aro), 119.49 (C aro), 109.28 (C aro), 108.38 (C aro), 106.00 (C aro), 101.62 (C aro),

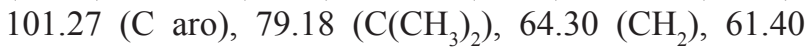
$\left(\mathrm{CH}_{2}\right), 52.47\left(\mathrm{CH}_{2}\right), 29.82\left(\mathrm{CH}_{2}\right), 25.40\left(2 \times \mathrm{CH}_{3}\right), 14.07$ $\left(\mathrm{CH}_{3}\right)$. MS $m / z: 404.27(\mathrm{M}+\mathrm{Na})$.

51 (Ethyl 2-(3-(3-(9H-carbazol-9-yl)propoxy) phenoxy)-2-methylpropanoate): white solid (33.20\%), m.p. $94.8-97.5^{\circ} \mathrm{C}, \quad \mathrm{R}_{\mathrm{f}}=0.64$ (developing agent: dichloromethane); ${ }^{1} \mathrm{H}-\mathrm{NMR}\left(\mathrm{CDCl}_{3}, 400 \mathrm{MHz}\right): \delta 8.092-$ 8.073 (2H, d, $J=7.6 \mathrm{~Hz}, \mathrm{Ar}-\mathrm{H}) ; 7.419-7.388$ (4H, t, $J=$ 6.4Hz, Ar-H); 7.244-7.104 (3H, m, Ar-H); 6.526-6.419 $(3 \mathrm{H}, \mathrm{m}, \mathrm{Ar}-\mathrm{H}) ; 4.543-4.511\left(2 \mathrm{H}, \mathrm{t}, J=6.4 \mathrm{~Hz}, \mathrm{CH}_{2}\right)$; 4.237-4.198 (2H, m, $\left.\mathrm{CH}_{2}\right) ; 3.874-3.846(2 \mathrm{H}, \mathrm{t}, J=5.6 \mathrm{~Hz}$, $\left.\mathrm{CH}_{2}\right) ; 2.327-2.297\left(2 \mathrm{H}, \mathrm{t}, J=6.0 \mathrm{~Hz}, \mathrm{CH}_{2}\right) ; 1.587(6 \mathrm{H}, \mathrm{s}$, $\left.\mathrm{CH}_{3}\right) ; 1.248-1.210\left(3 \mathrm{H}, \mathrm{m}, \mathrm{CH}_{3}\right) .{ }^{13} \mathrm{C}-\mathrm{NMR}\left(\mathrm{CDCl}_{3}, \delta\right)$ : $174.28(\mathrm{C}=\mathrm{O}), 159.54(\mathrm{C}$ aro $), 156.65$ ( $\mathrm{C}$ aro $), 140.44$ $(2 \times \mathrm{C}$ aro $), 129.50(\mathrm{C}$ aro $), 125.73(2 \times \mathrm{C}$ aro $), 122.88(2 \times \mathrm{C}$ aro $), 120.30(2 \times \mathrm{C}$ aro $), 118.93(2 \times \mathrm{C}$ aro $), 111.31$ (C aro), $108.58(2 \times \mathrm{C}$ aro $), 108.42$ (C aro), 106.05 (C aro), 79.18 $\left(\mathrm{C}\left(\mathrm{CH}_{3}\right)_{2}\right), 64.48\left(\mathrm{CH}_{2}\right), 61.40\left(\mathrm{CH}_{2}\right), 39.38\left(\mathrm{CH}_{2}\right), 28.77$ $\left(\mathrm{CH}_{2}\right), 25.38\left(2 \times \mathrm{CH}_{3}\right), 14.07\left(\mathrm{CH}_{3}\right) . \mathrm{MS} \mathrm{m} / z: 432.20$ $(\mathrm{M}+1), 454.27(\mathrm{M}+\mathrm{Na})$.

$5 \mathrm{~m}$ (Ethyl 2-(3-(3-(1H-benzo[d]imidazol-1-yl) propoxy)phenoxy)-2-methylpropanoate): achromatous oil (40.12\%), $\mathrm{R}_{\mathrm{f}}=0.58$ (developing agent: dichloromethane / acetone $=10: 1) ;{ }^{1} \mathrm{H}-\mathrm{NMR}\left(\mathrm{CDCl}_{3}, 400 \mathrm{MHz}\right): \delta 7.922(1 \mathrm{H}$, $\mathrm{s},=\mathrm{CH}) ; 7.825-7.803(1 \mathrm{H}, \mathrm{m}, \mathrm{Ar}-\mathrm{H}) ; 7.430-7.407(1 \mathrm{H}, \mathrm{m}$, Ar-H); 7.295-7.264 (2H, m, Ar-H); 7.140-7.099 (1H, t, 
$J=8.4 \mathrm{~Hz}, \mathrm{Ar}-\mathrm{H}) ; 6.527-6.419(3 \mathrm{H}, \mathrm{m}, \mathrm{Ar}-\mathrm{H}) ; 4.445-$ $4.412\left(2 \mathrm{H}, \mathrm{t}, J=6.8 \mathrm{~Hz}, \mathrm{CH}_{2}\right) ; 4.254-4.201\left(2 \mathrm{H}, \mathrm{m}, \mathrm{CH}_{2}\right)$; 3.883-3.855 (2H, t, $\left.J=5.6 \mathrm{~Hz}, \mathrm{CH}_{2}\right) ; 2.331-2.301(2 \mathrm{H}, \mathrm{t}$, $\left.J=6.0 \mathrm{~Hz}, \mathrm{CH}_{2}\right) ; 1.601\left(6 \mathrm{H}, \mathrm{s}, \mathrm{CH}_{3}\right) ; 1.259-1.223(3 \mathrm{H}$, $\left.\mathrm{t}, J=7.2 \mathrm{~Hz}, \mathrm{CH}_{3}\right) \cdot{ }^{13} \mathrm{C}-\mathrm{NMR}\left(\mathrm{CDCl}_{3}, \delta\right): 174.24(\mathrm{C}=\mathrm{O})$, 159.36 (C aro), 156.73 (C aro), $143.10(=\mathrm{CH}), 133.69$ (C aro), 129.70 (C aro), 123.07 (C aro), 122.25 (C aro), 120.38 (C aro), 111.34 (C aro), 109.58 (C aro), 108.36 (C aro), 108.22 (C aro), $105.88(\mathrm{C}$ aro $), 79.17\left(\mathrm{C}\left(\mathrm{CH}_{3}\right)_{2}\right)$, $63.77\left(\mathrm{CH}_{2}\right), 61.43\left(\mathrm{CH}_{2}\right), 41.52\left(\mathrm{CH}_{2}\right), 30.90\left(\mathrm{CH}_{2}\right), 25.38$ $\left(2 \times \mathrm{CH}_{3}\right), 14.07\left(\mathrm{CH}_{3}\right)$. MS m/z: $383.40(\mathrm{M}+1), 405.27$ $(\mathrm{M}+\mathrm{Na}), 787.20(2 \mathrm{M}+\mathrm{Na})$.

5n (Ethyl 2-methyl-2-(3-(3-phenylpropoxy) phenoxy)propanoate): achromatous oil (12.66\%), $\mathrm{R}_{\mathrm{f}}=$ 0.55 (developing agent: petroleum ether / EtOAc = 10:1); ${ }^{1} \mathrm{H}-\mathrm{NMR}\left(\mathrm{CDCl}_{3}, 400 \mathrm{MHz}\right): \delta$ 7.294-7.186 (6H, m, Ar-H); 7.116-7.075 (1H, t, $J=8.4 \mathrm{~Hz}, \mathrm{Ar}-\mathrm{H}) ; 6.544-6.518(1 \mathrm{H}, \mathrm{m}$, Ar-H); 6.439-6.393 (1H, m, Ar-H); 4.247-4.194 (2H, m, $\left.\mathrm{CH}_{2}\right) ; 3.919-3.888\left(2 \mathrm{H}, \mathrm{t}, \mathrm{J}=6.0 \mathrm{~Hz}, \mathrm{CH}_{2}\right) ; 2.803-2.765$ $\left(2 \mathrm{H}, \mathrm{m}, \mathrm{CH}_{2}\right) ; 2.093-2.055\left(2 \mathrm{H}, \mathrm{m}, \mathrm{CH}_{2}\right) ; 1.592(6 \mathrm{H}, \mathrm{s}$, $\left.\mathrm{CH}_{3}\right)$; $1.255-1.219\left(3 \mathrm{H}, \mathrm{t}, J=7.2 \mathrm{~Hz}, \mathrm{CH}_{3}\right) .{ }^{13} \mathrm{C}-\mathrm{NMR}$ $\left(\mathrm{CDCl}_{3}, \delta\right): 174.29(\mathrm{C}=\mathrm{O}), 160.00(\mathrm{C}$ aro $), 156.65$ (C aro), 141.51 (C aro), 129.39 (C aro), $128.54(2 \times \mathrm{C}$ aro), 128.49 $(2 \times \mathrm{C}$ aro), 125.92 (C aro), 110.98 (C aro), $108.55(\mathrm{C}$

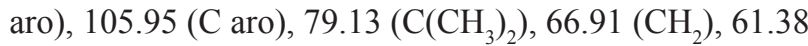
$\left(\mathrm{CH}_{2}\right), 32.16\left(\mathrm{CH}_{2}\right), 30.80\left(\mathrm{CH}_{2}\right), 25.41\left(2 \times \mathrm{CH}_{3}\right) ; 14.07$ $\left(\mathrm{CH}_{3}\right)$. MS m/z: $365.13(\mathrm{M}+\mathrm{Na}), 706.93(2 \mathrm{M}+\mathrm{Na})$.

5o (Ethyl 2-methyl-2-(3-(pyridin-3-ylmethoxy) phenoxy)propanoate): achromatous oil (31.17\%), $\mathrm{R}_{\mathrm{f}}=$ 0.24 (developing agent: dichloromethane / acetone $=$ 100:1); ${ }^{1} \mathrm{H}-\mathrm{NMR}\left(\mathrm{CDCl}_{3}, 400 \mathrm{MHz}\right): \delta 8.673-8.581(2 \mathrm{H}$, m, Ar-H); 7.774 (1H, s, Ar-H); 7.359-7.327 (1H, m, Ar$\mathrm{H})$; 7.161-7.120 (1H, t, $J=8.4 \mathrm{~Hz}, \mathrm{Ar}-\mathrm{H})$; 6.627-6.601 $(1 \mathrm{H}, \mathrm{m}, \mathrm{Ar}-\mathrm{H}) ; 6.522-6.510\left(1 \mathrm{H}, \mathrm{m}, \mathrm{CH}_{2}\right) ; 6.463-6.436$ $\left(1 \mathrm{H}, \mathrm{d}, J=8.8 \mathrm{~Hz}, \mathrm{CH}_{2}\right) ; 5.040\left(2 \mathrm{H}, \mathrm{s}, \mathrm{CH}_{2}\right) ; 4.255-4.202$ $\left(2 \mathrm{H}, \mathrm{m}, \mathrm{CH}_{2}\right) ; 1.595\left(6 \mathrm{H}, \mathrm{s}, \mathrm{CH}_{3}\right) ; 1.263-1.228(3 \mathrm{H}, \mathrm{t}, J=$ $\left.6.8 \mathrm{~Hz}, \mathrm{CH}_{3}\right) .{ }^{13} \mathrm{C}-\mathrm{NMR}\left(\mathrm{CDCl}_{3}, \delta\right): 174.20(\mathrm{C}=\mathrm{O}), 159.23$ (C aro), 156.72 (C aro), 149.07 (C aro), 148.61 (C aro), 135.57 (C aro), 132.72 (C aro), 129.63 (C aro), 123.67 (C aro), 111.62 (C aro), 108.58 (C aro), 106.17 (C aro), 79.20 $\left(\mathrm{C}\left(\mathrm{CH}_{3}\right)_{2}\right), 67.45\left(\mathrm{CH}_{2}\right), 61.46\left(\mathrm{CH}_{2}\right), 25.38\left(2 \times \mathrm{CH}_{3}\right)$, $14.07\left(\mathrm{CH}_{3}\right)$. MS m/z: $338.20(\mathrm{M}+\mathrm{Na})$.

\section{Carboxylic acid compounds (6)}

Method 1: esters $(5,10 \mathrm{mmol})$ were dissolved in the solution of THF- $\mathrm{CH}_{3} \mathrm{OH}$-water $(3: 1: 1,100 \mathrm{ml})$. The reaction was beginning by adding $1 \mathrm{M} \mathrm{LiOH}(30 \mathrm{ml}, 30 \mathrm{mmol})$ dropwise to the mixture and stirred at room temperature for $1 \mathrm{~h}$, followed by $6 \mathrm{M}$ hydrochloric acid to acidify. The crude products were extracted with ethyl acetate, washed with water and saturated $\mathrm{Na}_{2} \mathrm{CO}_{3}$ solution and dehydrated with anhydrous $\mathrm{Na}_{2} \mathrm{SO}_{4}$. The solvent was removed by vacuum distillation to afford carboxylic acids (6a-1).

$6 a$ (2-(4-(2-(1H-indol-1-yl)ethoxy)phenoxy)-2methylpropanoic acid): colorless oil $(25.83 \%), \mathrm{R}_{\mathrm{f}}=0.20$ (developing agent: petroleum ether / EtOAc $=5: 1)$; MS $m / z: 338.13$ (M-1), 340.20(M+1), 362.07(M+Na).

$6 \mathrm{~b}$ (2-(4-(2-(9H-carbazol-9-yl)ethoxy)phenoxy)-2methylpropanoic acid): colorless oil $(16.83 \%), \mathrm{R}_{\mathrm{f}}=0.40$ (developing agent: petroleum ether / EtOAc $=1: 1$ ); MS $m / z: 388.20$ (M-1), $412.13(\mathrm{M}+\mathrm{Na})$.

$6 c$ (2-(4-(3-(1H-indol-1-yl)propoxy)phenoxy)-2methylpropanoic acid): colorless oil $(36.75 \%), \mathrm{R}_{\mathrm{f}}=$ 0.36 (developing agent: petroleum ether / EtOAc $=$ $1: 1) ;{ }^{1} \mathrm{H}-\mathrm{NMR}\left(\mathrm{CDCl}_{3}, 400 \mathrm{MHz}\right): \delta 7.631-7.611(1 \mathrm{H}, \mathrm{d}$, $J=8.0 \mathrm{~Hz}, \mathrm{Ar}-\mathrm{H}) ; 7.358-7.338(1 \mathrm{H}, \mathrm{d}, J=8.0 \mathrm{~Hz},=\mathrm{CH})$; 7.186-7.069 (3H, m, Ar-H); 6.920-6.897 (2H, m, Ar-H); 6.791-6.770 (2H, m, Ar-H); 6.477 (1H, s, =CH); 4.375$4.342\left(2 \mathrm{H}, \mathrm{t}, J=6.8 \mathrm{~Hz}, \mathrm{CH}_{2}\right) ; 3.838-3.810(2 \mathrm{H}, \mathrm{t}, J=$ $\left.5.6 \mathrm{~Hz}, \mathrm{CH}_{2}\right) ; 2.276-2.245\left(2 \mathrm{H}, \mathrm{t}, J=6.0 \mathrm{~Hz}, \mathrm{CH}_{2}\right) ; 1.549$ $\left(6 \mathrm{H}, \mathrm{s}, \mathrm{CH}_{3}\right) \cdot{ }^{13} \mathrm{C}-\mathrm{NMR}\left(\mathrm{CDCl}_{3}, \delta\right): 175.96(\mathrm{C}=\mathrm{O}), 155.37$ (C aro), 147.25 (C aro), 135.92 (C aro), $128.63(=\mathrm{CH})$, $128.05(=\mathrm{CH}), 123.23(2 \times \mathrm{C}$ aro $), 121.53(\mathrm{C}$ aro $), 121.00$ (C aro), 119.36 (C aro), $115.04(2 \times \mathrm{C}$ aro), 109.29 (C aro), $101.30(=\mathrm{CH}), 80.66\left(\mathrm{C}\left(\mathrm{CH}_{3}\right)_{2}\right), 64.70\left(\mathrm{CH}_{2}\right), 42.72\left(\mathrm{CH}_{2}\right)$, $29.87\left(\mathrm{CH}_{2}\right), 24,75\left(2 \times \mathrm{CH}_{3}\right)$. MS m/z: $352.13(\mathrm{M}-1)$.

6d (2-(4-(3-(9H-carbazol-9-yl)propoxy)phenoxy)-2methylpropanoic acid): colorless oil $(25.46 \%), \mathrm{R}_{\mathrm{f}}=$ 0.33 (developing agent: petroleum ether / EtOAc $=1: 1$ ); ${ }^{1} \mathrm{H}-\mathrm{NMR}\left(\mathrm{CDCl}_{3}, 400 \mathrm{MHz}\right): \delta$ 8.099-8.080 (2H, d, $J=$ 7.6Hz, Ar-H); 7.421-7.361 (4H, m, Ar-H); 7.258-7.189 (2H, m, Ar-H); 6.912-6.890 (2H, m, Ar-H); 6.787-6.764 $(2 \mathrm{H}, \mathrm{m}, \mathrm{Ar}-\mathrm{H}) ; 4.567-4.534\left(2 \mathrm{H}, \mathrm{t}, J=6.8 \mathrm{~Hz}, \mathrm{CH}_{2}\right)$; $3.873-3.845\left(2 \mathrm{H}, \mathrm{t}, J=5.6 \mathrm{~Hz}, \mathrm{CH}_{2}\right) ; 2.348-2.318(2 \mathrm{H}, \mathrm{t}$, $\left.J=6.0 \mathrm{~Hz}, \mathrm{CH}_{2}\right) ; 1.536\left(6 \mathrm{H}, \mathrm{s}, \mathrm{CH}_{3}\right) \cdot{ }^{13} \mathrm{C}-\mathrm{NMR}\left(\mathrm{CDCl}_{3}\right.$, $\delta): 176.06(\mathrm{C}=\mathrm{O}), 155.13(\mathrm{C}$ aro $), 147.56(\mathrm{C}$ aro $), 140.42$ $(2 \times \mathrm{C}$ aro $), 125.71(2 \times \mathrm{C}$ aro $), 122.98(2 \times \mathrm{C}$ aro $), 122.86$ $(2 \times \mathrm{C}$ aro $), 120.32(2 \times \mathrm{C}$ aro $), 118.94(2 \times \mathrm{C}$ aro $), 115.02$ $(2 \times \mathrm{C}$ aro $), 108.59(2 \times \mathrm{C}$ aro $\left.), 97.48\left(\mathrm{C}_{\left(\mathrm{CH}_{3}\right.}\right)_{2}\right), 64.87$ $\left(\mathrm{CH}_{2}\right), 55.06\left(\mathrm{CH}_{2}\right), 39.34\left(\mathrm{CH}_{2}\right), 30.92\left(2 \times \mathrm{CH}_{3}\right) . \mathrm{MS} m / z$ : 402.13 (M-1), 805.07 (2M-1).

6e (2-(4-(3-(1H-benzo[d]imidazol-1-yl)propoxy) phenoxy)-2-methylpropanoic acid): colorless oil $(31.25 \%), \mathrm{R}_{\mathrm{f}}=0.35$ (developing agent: dichloromethane / acetone $=1: 1) ;{ }^{1} \mathrm{H}-\mathrm{NMR}\left(\mathrm{CDCl}_{3}, 400 \mathrm{MHz}\right): \delta 7.637-7.617$ $(1 \mathrm{H}, \mathrm{d}, J=8.0 \mathrm{~Hz},=\mathrm{CH}) ; 7.403-7.383(1 \mathrm{H}, \mathrm{d}, J=8.0 \mathrm{~Hz}$, Ar-H); 7.256-7.198 (3H, m, Ar-H); 6.875-6.843 (2H, m, Ar-H); 6.748-6.726 (2H, d, J=8.0Hz, Ar-H); 4.515-4.487 $\left(2 \mathrm{H}, \mathrm{t}, J=5.6 \mathrm{~Hz}, \mathrm{CH}_{2}\right) ; 4.247-4.219(2 \mathrm{H}, \mathrm{t}, J=5.6 \mathrm{~Hz}$, $\left.\mathrm{CH}_{2}\right) ; 3.486\left(2 \mathrm{H}, \mathrm{s}, \mathrm{CH}_{2}\right) ; 1.507\left(6 \mathrm{H}, \mathrm{s}, \mathrm{CH}_{3}\right) .{ }^{13} \mathrm{C}-\mathrm{NMR}$ $\left(\mathrm{CDCl}_{3}, \delta\right): 174.96(\mathrm{C}=\mathrm{O}), 154.06(\mathrm{C}$ aro $), 149.29$ (C aro), $143.05(=\mathrm{CH}), 130.88$ (C aro), 123.15 (C aro), $122.38(\mathrm{C}$ aro $), 121.74(2 \times \mathrm{C}$ aro $), 120.29(\mathrm{C}$ aro $), 114.93(2 \times \mathrm{C}$ aro $)$, 109.64 (C aro), 106.74 ( $\mathrm{C}$ aro), $79.78\left(\mathrm{C}\left(\mathrm{CH}_{3}\right)_{2}\right), 64.21$ $\left(\mathrm{CH}_{2}\right), 52.39\left(\mathrm{CH}_{2}\right), 30.88\left(\mathrm{CH}_{2}\right), 25.38\left(2 \times \mathrm{CH}_{3}\right) . \mathrm{MS} \mathrm{m} / \mathrm{z}$ : $353.13(\mathrm{M}-1)$.

6f (2-Methyl-2-(3-(2-oxo-2-phenylethoxy)phenoxy) propanoic acid): achromatous oil $(10.48 \%), \mathrm{R}_{\mathrm{f}}=0.20$ (developing agent: petroleum ether / EtOAc = 1:1); ${ }^{1} \mathrm{H}-\mathrm{NMR}\left(\mathrm{CDCl}_{3}, 400 \mathrm{MHz}\right): \delta 8.043-7.976(2 \mathrm{H}, \mathrm{m}, \mathrm{Ar}-\mathrm{H})$; 7.636-7.599 (1H, t, $J=7.2 \mathrm{~Hz}, \mathrm{Ar}-\mathrm{H}) ; 7.518-7.479(2 \mathrm{H}, \mathrm{t}$, 
$J=8.0 \mathrm{~Hz}, \mathrm{Ar}-\mathrm{H}) ; 7.173-7.132(1 \mathrm{H}, \mathrm{t}, J=8.0 \mathrm{~Hz}, \mathrm{Ar}-\mathrm{H})$; 6.642-6.545 (3H, m, Ar-H); $5.233\left(2 \mathrm{H}, \mathrm{s}, \mathrm{CH}_{2}\right) ; 1.596(6 \mathrm{H}$, $\left.\mathrm{s}, \mathrm{CH}_{3}\right)$. MS m/z: 313.07 (M-1), $337.13(\mathrm{M}+\mathrm{Na})$.

$6 \mathrm{~g}$ (2-(3-(2-(9H-carbazol-9-yl)ethoxy)phenoxy)-2methylpropanoic acid): white solid (45.28\%), m.p. 111.9$114.5^{\circ} \mathrm{C}, \mathrm{R}_{\mathrm{f}}=0.28$ (developing agent: petroleum ether/ EtOAc = 1:1); MS m/z: $388.20(\mathrm{M}-1), 777.07$ (2M-1).

$6 \mathrm{~h}$ (2-(3-(3-(1H-indol-1-yl)propoxy)phenoxy)-2methylpropanoic acid): achromatous oil (19.48\%), $\mathrm{R}_{\mathrm{f}}$ $=0.24$ (developing agent: dichloromethane / acetone $=$ 10:1); ${ }^{1} \mathrm{H}-\mathrm{NMR}\left(\mathrm{CDCl}_{3}, 400 \mathrm{MHz}\right): \delta$ 7.627-7.608 $(1 \mathrm{H}$, $\mathrm{d}, J=7.6 \mathrm{~Hz}, \mathrm{Ar}-\mathrm{H}) ; 7.353-7.253(1 \mathrm{H}, \mathrm{m},=\mathrm{CH}) ; 7.184-$ 7.060 (4H, m, Ar-H); 6.604-6.466 (4H, m, Ar-H and =CH); 4.367-4.334 (2H, t, $\left.J=6.4 \mathrm{~Hz}, \mathrm{CH}_{2}\right) ; 3.845-3.817(2 \mathrm{H}, \mathrm{t}, J$ $\left.=5.6 \mathrm{~Hz}, \mathrm{CH}_{2}\right) ; 2.277-2.247\left(2 \mathrm{H}, \mathrm{t}, J=6.0 \mathrm{~Hz}, \mathrm{CH}_{2}\right) ; 1.598$ $\left(6 \mathrm{H}, \mathrm{s}, \mathrm{CH}_{3}\right) .{ }^{13} \mathrm{C}-\mathrm{NMR}\left(\mathrm{CDCl}_{3}, \delta\right): 176.79(\mathrm{C}=\mathrm{O}), 159.65$ (C aro), 155.64 (C aro), 135.93 (C aro), 129.71 (C aro), 128.65 (C aro), 128.05 (=CH), 121.53 (C aro), 120.99 (C aro), 119.34 (C aro), 112.69 (C aro), 109.41 (C aro), 109.28 (C aro), $107.38(\mathrm{C}$ aro $), 101.30(=\mathrm{CH}), 79.75\left(\mathrm{C}\left(\mathrm{CH}_{3}\right)_{2}\right)$, $64.42\left(\mathrm{CH}_{2}\right), 42.72\left(\mathrm{CH}_{2}\right), 30.89\left(\mathrm{CH}_{2}\right), 25.09\left(2 \times \mathrm{CH}_{3}\right)$. MS $m / z$ : $352.13(\mathrm{M}-1), 354.20(\mathrm{M}+1), 376.13(\mathrm{M}+\mathrm{Na})$.

6 i (2-(3-(3-(9H-carbazol-9-yl)propoxy)phenoxy)2-methylpropanoic acid): achromatous oil $(33.2 \%), \mathrm{R}_{\mathrm{f}}$ $=0.34$ (developing agent: dichloromethane / acetone $=$ 10:1); ${ }^{1} \mathrm{H}-\mathrm{NMR}\left(\mathrm{CDCl}_{3}, 400 \mathrm{MHz}\right): \delta 8.092-8.073(2 \mathrm{H}, \mathrm{d}$, $J=7.6 \mathrm{~Hz}, \mathrm{Ar}-\mathrm{H}) ; 7.413-7.362$ (4H, m, Ar-H); 7.251-7.119 (3H, m, Ar-H); 6.592-6.475 (3H, m, Ar-H); 4.548-4.515 $\left(2 \mathrm{H}, \mathrm{t}, J=6.4 \mathrm{~Hz}, \mathrm{CH}_{2}\right) ; 3.869-3.841(2 \mathrm{H}, \mathrm{t}, J=5.6 \mathrm{~Hz}$, $\left.\mathrm{CH}_{2}\right) ; 2.337-2.307\left(2 \mathrm{H}, \mathrm{t}, J=6.0 \mathrm{~Hz}, \mathrm{CH}_{2}\right) ; 1.585(6 \mathrm{H}$, $\left.\mathrm{s}, \mathrm{CH}_{3}\right) \cdot{ }^{13} \mathrm{C}-\mathrm{NMR}\left(\mathrm{CDCl}_{3}, \delta\right): 176.92(\mathrm{C}=\mathrm{O}), 159.59(\mathrm{C}$ aro), 155.59 (C aro), $140.43(2 \times \mathrm{C}$ aro $), 129.70(\mathrm{C}$ aro), $125.74(2 \times \mathrm{C}$ aro $), 122.89(2 \times \mathrm{C}$ aro $), 120.32(2 \times \mathrm{C}$ aro $)$, $118.95(2 \times \mathrm{C}$ aro $), 112.81$ (C aro), 109.52 (C aro), 108.58 $(2 \times \mathrm{C}$ aro $), 107.49(\mathrm{C}$ aro $\left.), 79.79\left(\mathrm{C}_{\left(\mathrm{CH}_{3}\right.}\right)_{2}\right), 64.62\left(\mathrm{CH}_{2}\right)$, $39.35\left(\mathrm{CH}_{2}\right), 30.89\left(\mathrm{CH}_{2}\right), 25.38\left(2 \times \mathrm{CH}_{3}\right) . \mathrm{MS} \mathrm{m} / z: 402.13$ (M-1), $426.13(\mathrm{M}+\mathrm{Na})$.

$6 j$ (2-(3-(3-(1H-benzo[d]imidazol-1-yl)propoxy) phenoxy)-2-methylpropanoic acid): achromatous oil (16.43\%), $\mathrm{R}_{\mathrm{f}}=0.38$ (developing agent: dichloromethane); MS m/z: 353.20 (M-1), 355.13 (M+1).

$6 \mathrm{k}$ (2-Methyl-2-(3-(3-phenylpropoxy)phenoxy) propanoic acid): achromatous oil form things (32.75\%), $\mathrm{R}_{\mathrm{f}}=0.25$ (developing agent: petroleum ether / EtOAc $=$ 1:1); ${ }^{1} \mathrm{H}-\mathrm{NMR}\left(\mathrm{CDCl}_{3}, 400 \mathrm{MHz}\right): \delta$ 7.305-7.257 $(2 \mathrm{H}$, $\mathrm{m}, \mathrm{Ar}-\mathrm{H}) ; 7.213-7.142$ (4H, m, Ar-H); 6.644-6.503 (3H, $\mathrm{m}, \mathrm{Ar}-\mathrm{H})$; 3.944-3.913 (2H, t, $\left.J=6.4 \mathrm{~Hz}, \mathrm{CH}_{2}\right) ; 2.816-$ $2.778\left(2 \mathrm{H}, \mathrm{t}, J=7.2 \mathrm{~Hz}, \mathrm{CH}_{2}\right) ; 2.126-2.057\left(2 \mathrm{H}, \mathrm{m}, \mathrm{CH}_{2}\right)$; $1.599\left(6 \mathrm{H}, \mathrm{s}, \mathrm{CH}_{3}\right) .{ }^{13} \mathrm{C}-\mathrm{NMR}\left(\mathrm{CDCl}_{3}, \delta\right): 176.07(\mathrm{C}=\mathrm{O})$, 160.03 (C aro), 155.38 (C aro), 141.43 (C aro), 129.62 (C aro), $128.49(2 \times \mathrm{C}$ aro $), 128.41(2 \times \mathrm{C}$ aro $), 125.94(\mathrm{C}$ aro), 112.60 (C aro), 109.63 (C aro), 107.59 (C aro), 79.93 $\left(\mathrm{C}\left(\mathrm{CH}_{3}\right)_{2}\right), 67.03\left(\mathrm{CH}_{2}\right), 32.13\left(\mathrm{CH}_{2}\right), 30.88\left(\mathrm{CH}_{2}\right), 25.10$ $\left(2 \times \mathrm{CH}_{3}\right)$. MS m/z: $313.07(\mathrm{M}-1), 337.07(\mathrm{M}+\mathrm{Na})$.

61 (2-Methyl-2-(3-(pyridin-3-ylmethoxy)phenoxy) propanoic acid): achromatous oil $(14.63 \%), \mathrm{R}_{\mathrm{f}}=0.42$ (developing agent: petroleum ether / EtOAc $=1: 1)$; MS m/z: 286.07 (M-1), $288.20(\mathrm{M}+1), 597.00(2 \mathrm{M}+\mathrm{Na})$.

Method 2: esters $(5,10 \mathrm{mmol})$ were dissolved in $\mathrm{CH}_{3} \mathrm{OH}(25 \mathrm{ml})$, adding $1 \mathrm{M} \mathrm{NaOH}(10 \mathrm{ml}, 10 \mathrm{mmol})$ under the stirring condition in ice bath. With the solution up to the room temperature, the reaction was heated to reflux at $50^{\circ} \mathrm{C}$ for $24 \mathrm{~h}$ under stirring condition, followed by $1 \mathrm{M}$ hydrochloric acid $(10 \mathrm{ml}, 10 \mathrm{mmol})$ for $5 \mathrm{~h}$. The crude products were obtained after filtration and the solvent removed by vacuum distillation. The purification was washed for three times with $\mathrm{CH}_{3} \mathrm{OH}$-water (1:1) to afford carboxylic acids (6m-o).

$6 \mathrm{~m}$ (2-Methyl-2-(4-(3-phenylpropoxy)phenoxy) propanoic acid): white solid (31.85\%), m.p. 112.1$114.2^{\circ} \mathrm{C}, \mathrm{R}_{\mathrm{f}}=0.75$ (developing agent: dichloromethane / acetone $=1: 1) ;{ }^{1} \mathrm{H}-\mathrm{NMR}\left(\mathrm{CDCl}_{3}, 400 \mathrm{MHz}\right): \delta 7.288-7.178$ $(5 \mathrm{H}, \mathrm{m}, \mathrm{Ar}-\mathrm{H}) ; 6.906(2 \mathrm{H}, \mathrm{d}, J=8.8 \mathrm{~Hz}, \mathrm{Ar}-\mathrm{H}) ; 6.802(2 \mathrm{H}$, $\mathrm{d}, J=9.2 \mathrm{~Hz}, \mathrm{Ar}-\mathrm{H}) ; 4.758(1 \mathrm{H}, \mathrm{s}, \mathrm{OH}) ; 3.924(2 \mathrm{H}, \mathrm{t}, J=$ $\left.6.0 \mathrm{~Hz}, \mathrm{CH}_{2}\right) ; 2.803\left(2 \mathrm{H}, \mathrm{t}, J=7.6 \mathrm{~Hz}, \mathrm{CH}_{2}\right) ; 2.127-2.058$ $\left(2 \mathrm{H}, \mathrm{m}, \mathrm{CH}_{2}\right) ; 1.535\left(6 \mathrm{H}, \mathrm{s}, \mathrm{CH}_{3}\right) .{ }^{13} \mathrm{C}-\mathrm{NMR}\left(\mathrm{CDCl}_{3}, \delta\right)$ : $176.72(\mathrm{C}=\mathrm{O}), 155.68(\mathrm{C}$ aro $), 147.13(\mathrm{C}$ aro $), 141.48(\mathrm{C}$ aro $), 128.51(2 \times \mathrm{C}$ aro $), 128.43(2 \times \mathrm{C}$ aro $), 125.96(\mathrm{C}$ aro $)$, $121.69(2 \times \mathrm{C}$ aro $), 115.0(2 \times \mathrm{C}$ aro $\left.), 80.53\left(\mathrm{C}_{\left(\mathrm{CH}_{3}\right.}\right)_{2}\right), 67.32$ $\left(\mathrm{CH}_{2}\right), 32.15\left(\mathrm{CH}_{2}\right), 30.85\left(\mathrm{CH}_{2}\right), 24.79\left(2 \times \mathrm{CH}_{3}\right) . \mathrm{MS} \mathrm{m} / \mathrm{z}$ : $313.20(\mathrm{M}-1)$.

6n (2-Methyl-2-(4-(2-oxo-2-phenylethoxy)pheno xy)propanoic acid): colorless oil $(32.41 \%), \mathrm{R}_{\mathrm{f}}=0.42$ (developing agent: petroleum ether / EtOAc $=1: 1$ ); ${ }^{1} \mathrm{H}-\mathrm{NMR}\left(\mathrm{CDCl}_{3}, 400 \mathrm{MHz}\right): \delta 8.081-7.982(2 \mathrm{H}, \mathrm{m}, \mathrm{Ar}-$ $\mathrm{H}) ; 7.641-7.604(1 \mathrm{H}, \mathrm{d}, J=7.2 \mathrm{~Hz}, \mathrm{Ar}-\mathrm{H}) ; 7.523-7.468$ $(2 \mathrm{H}, \mathrm{m}, \mathrm{Ar}-\mathrm{H}) ; 6.932-6.848$ (4H, m, Ar-H); 5.243 (2H, s, $\left.\mathrm{CH}_{2}\right) ; 1.561\left(6 \mathrm{H}, \mathrm{s}, \mathrm{CH}_{3}\right)$. MS m/z: $313.20(\mathrm{M}-1) ; 337.13$ $(\mathrm{M}+\mathrm{Na})$.

60 (2-(3-(2-(1H-indol-1-yl)ethoxy)phenoxy)-2methylpropanoic acid): achromatous oil $(36.47 \%), \mathrm{R}_{\mathrm{f}}$ $=0.34$ (developing agent: dichloromethane); ${ }^{1} \mathrm{H}-\mathrm{NMR}$ $\left(\mathrm{CDCl}_{3}, 400 \mathrm{MHz}\right): \delta 7.636-7.617(1 \mathrm{H}, \mathrm{d}, J=7.6 \mathrm{~Hz}, \mathrm{Ar}-$ $\mathrm{H})$; 7.401-7.380 (1H, d, $J=8.4 \mathrm{~Hz},=\mathrm{CH}) ; 7.255-7.189$ $(2 \mathrm{H}, \mathrm{m}, \mathrm{Ar}-\mathrm{H}) ; 7.135-7.090$ (2H, m, Ar-H); 6.551-6.438 $(4 \mathrm{H}, \mathrm{m}, \mathrm{Ar}-\mathrm{H}$ and $=\mathrm{CH}) ; 4.507-4.479(2 \mathrm{H}, \mathrm{t}, J=5.6 \mathrm{~Hz}$, $\left.\mathrm{CH}_{2}\right) ; 4.242-4.214\left(2 \mathrm{H}, \mathrm{t}, J=5.6 \mathrm{~Hz}, \mathrm{CH}_{2}\right) ; 1.570(6 \mathrm{H}, \mathrm{s}$, $\left.\mathrm{CH}_{3}\right) \cdot{ }^{13} \mathrm{C}-\mathrm{NMR}\left(\mathrm{CDCl}_{3}, \delta\right): 173.19(\mathrm{C}=\mathrm{O}), 159.25$ ( $\mathrm{C}$ aro $)$, 136.04 (C aro), 129.76 (C aro), 128.68 (C aro), 128.36 $(=\mathrm{CH}), 121.64$ (C aro), $121.07(2 \times \mathrm{C}$ aro $), 119.53(\mathrm{C}$ aro $)$, 109.57 (C aro), $109.17(2 \times \mathrm{C}$ aro $), 107.60$ (C aro), 101.69 $\left.(=\mathrm{CH}), 79.18\left(\mathrm{C}_{\left(\mathrm{CH}_{3}\right.}\right)_{2}\right), 66.95\left(\mathrm{CH}_{2}\right), 45.62\left(\mathrm{CH}_{2}\right), 25.36$ $\left(2 \times \mathrm{CH}_{3}\right)$. MS m/z: 338.20 (M-1), 677.00 (2M-1).

\section{Para-/meta- monosubstituted intermediates (8)}

Hydroquinone / resorcinol 1 (2.2 g, $20 \mathrm{mmol})$ was dissolved in the solution of acetone $(50 \mathrm{ml})$, followed by $\mathrm{K}_{2} \mathrm{CO}_{3}(2.76 \mathrm{~g}, 20 \mathrm{mmol})$ and $\mathrm{NaI}$ (catalytic amounts). Then a mixed solution of chloride acetonitrile 7 (0.755 g, $10 \mathrm{mmol})$ and acetone $(50 \mathrm{ml})$ was dripped slowly to the mixture above. The reaction was heated to reflux at 
$65^{\circ} \mathrm{C}$ for $16 \mathrm{~h}$ under the stirring condition. The process of the reaction was detected through TLC method. After the reaction, crude products were obtained through the course of filtration and vacuum distillation to remove the solvent. The intermediates 8 were purified by flash column chromatography with petroleum ether/EtOAc as the mobile phase.

8a(2-(4-Hydroxyphenoxy)acetonitrile): achromatous oil $(80.62 \%), \quad \mathrm{R}_{\mathrm{f}}=0.38$ (developing agent: dichloromethane / methanol = 50:1); ${ }^{1} \mathrm{H}-\mathrm{NMR}\left(\mathrm{CDCl}_{3}\right.$, $400 \mathrm{MHz}): \delta$ 6.914-6.882 (2H, m, Ar-H); 6.828-6.787 $(2 \mathrm{H}, \mathrm{m}, \mathrm{Ar}-\mathrm{H}) ; 4.702\left(2 \mathrm{H}, \mathrm{s}, \mathrm{CH}_{2}\right) .{ }^{13} \mathrm{C}-\mathrm{NMR}\left(\mathrm{CDCl}_{3}\right.$, 101MHz): 151.54 (C aro), $150.80(\mathrm{C}$ aro $), 117.02(2 \times \mathrm{C}$ aro), $116.41(2 \times \mathrm{C}$ aro $), 115.33(\mathrm{C} \equiv \mathrm{N}), 55.04\left(\mathrm{CH}_{2}\right) . \mathrm{MS}$ $m / z: 147.93$ (M-1), 296.80 (2M-1).

8 b (2-(3-Hydroxyphenoxy)acetonitrile): white solid (84.7\%), $\mathrm{R}_{\mathrm{f}}=0.46$ (developing agent: dichloromethane / methanol $=50: 1) ;{ }^{1} \mathrm{H}-\mathrm{NMR}\left(\mathrm{CDCl}_{3}, 400 \mathrm{MHz}\right): \delta 7.262$ $(1 \mathrm{H}, \mathrm{s}, \mathrm{Ar}-\mathrm{H}) ; 7.217-7.176(1 \mathrm{H}, \mathrm{t}, J=8.2 \mathrm{~Hz}, \mathrm{Ar}-\mathrm{H})$; 6.583-6.539 (2H, t, $J=8.8 \mathrm{~Hz}, \mathrm{Ar}-\mathrm{H}) ; 4.743\left(2 \mathrm{H}, \mathrm{s}, \mathrm{CH}_{2}\right)$. ${ }^{13} \mathrm{C}-\mathrm{NMR}\left(\mathrm{CDCl}_{3}, 101 \mathrm{MHz}\right): 158.69$ (C aro), 157.49 (C aro), 130.15 ( $\mathrm{C}$ aro), $116.70(\mathrm{C} \equiv \mathrm{N}), 109.61$ (C aro), 105.17 (C aro), 102.15 (C aro), $53.26\left(\mathrm{CH}_{2}\right)$.

\section{Nitrile intermediates (9)}

Monosubstituted intermediates 8 (1.49 g, $10 \mathrm{mmol})$, halogenated organic compounds 4 (10 mmol), $\mathrm{K}_{2} \mathrm{CO}_{3}$ (3.32 g, $24 \mathrm{mmol}$ ) and $\mathrm{NaI}$ (catalytic amounts) were added to $50 \mathrm{ml}$ acetone. The solution was heated to reflux at $65^{\circ} \mathrm{C}$ for $12 \mathrm{~h}$ under stirring condition. The process of the reaction was detected through TLC method. After the reaction, the final products were obtained through the course of filtration and vacuum distillation to remove the solvent. Nitrile intermediates (9) were purified by flash column chromatography with petroleum ether/EtOAc as the mobile phase.

9a (2-(4-(2-(1H-indol-1-yl)ethoxy)phenoxy)aceto nitrile): achromatous oil $(20.90 \%), \mathrm{R}_{\mathrm{f}}=0.60$ (developing agent: petroleum ether / EtOAc $=3: 1) ;{ }^{1} \mathrm{H}-\mathrm{NMR}\left(\mathrm{CDCl}_{3}\right.$, $400 \mathrm{MHz}$ ): $\delta 7.643-7.624(1 \mathrm{H}, \mathrm{d}, J=7.6 \mathrm{~Hz}, \mathrm{Ar}-\mathrm{H}) ; 7.405-$ $7.385(1 \mathrm{H}, \mathrm{d}, J=8.0 \mathrm{~Hz}, \mathrm{Ar}-\mathrm{H}) ; 7.248-7.188$ (2H, m, Ar$\mathrm{H}) ; 7.115(1 \mathrm{H}, \mathrm{s}, \mathrm{Ar}-\mathrm{H}), 6.888-6.852$ (2H, m, Ar-H); $6.797-$ 6.762 (2H, m, Ar-H); 6.518-6.504 (1H, t, $J=2.8 \mathrm{~Hz}, \mathrm{Ar}-\mathrm{H})$; $4.654\left(2 \mathrm{H}, \mathrm{s}, \mathrm{CH}_{2}\right)$; 4.511-4.497 (2H, t, $\left.J=2.8 \mathrm{~Hz}, \mathrm{CH}_{2}\right)$; 4.239-4.226 (2H, t, $\left.J=2.6 \mathrm{~Hz}, \mathrm{CH}_{2}\right) .{ }^{13} \mathrm{C}-\mathrm{NMR}\left(\mathrm{CDCl}_{3}\right.$, $101 \mathrm{MHz}$ ): $\delta 154.41$ (C aro), 151.03 (C aro), 137.05 (C aro), 128.67 (C aro), $128.37(=\mathrm{C}-\mathrm{N}), 127.03$ (C aro), 121.63 (C aro), 121.48 (C aro), 119.52 (C aro), 115.78 $(\mathrm{C} \equiv \mathrm{N}), 115.33$ ( $\mathrm{C}$ aro), 115.30 (C aro), 109.19 (C aro), $109.02(\mathrm{C}$ aro $), 101.66(=\mathrm{CH}), 67.53\left(\mathrm{CH}_{2}\right), 54.78\left(\mathrm{CH}_{2}\right)$, $45.68\left(\mathrm{CH}_{2}\right)$. MS m/z: 293.20(M+1), 585.27(2M+1).

$9 \mathrm{~b}$ (2-(4-(2-(9H-carbazol-9-yl)ethoxy)phenoxy) acetonitrile): white solid (12.63\%), m.p. 99.8-102.1 ${ }^{\circ} \mathrm{C}, \mathrm{R}_{\mathrm{f}}$ $=0.62$ (developing agent: petroleum ether $/$ EtOAc $=3: 1$ ); ${ }^{1} \mathrm{H}-\mathrm{NMR}$ (DMSO-d, $\left.400 \mathrm{MHz}\right): \delta 8.154-8.135(2 \mathrm{H}, \mathrm{d}$,
$J=7.6 \mathrm{~Hz}, \mathrm{Ar}-\mathrm{H}) ; 7.686-7.665(2 \mathrm{H}, \mathrm{d}, J=8.4 \mathrm{~Hz}, \mathrm{Ar}-\mathrm{H})$; 7.504-7.439 (2H, m, Ar-H); 7.224-7.187 (2H, t, $J=7.4$ $\mathrm{Hz}, \mathrm{Ar}-\mathrm{H}) ; 6.824-6.696$ (4H, m, Ar-H); 4.785-4.759 (2H, $\left.\mathrm{t}, J=5.2 \mathrm{~Hz}, \mathrm{CH}_{2}\right)$; 4.323-4.287 (4H, t, $\left.J=7.2 \mathrm{~Hz}, \mathrm{CH}_{2}\right)$. ${ }^{13} \mathrm{C}-\mathrm{NMR}$ (DMSO-d, $\left.101 \mathrm{MHz}\right): \delta 152.55$ (C aro), 151.89 (C aro), $140.21(2 \times \mathrm{C}$ aro $), 125.60(2 \times \mathrm{C}$ aro $), 122.09(2 \times \mathrm{C}$ aro), $120.11(2 \times \mathrm{C}$ aro $), 118.84(2 \times \mathrm{C}$ aro $), 115.56(\mathrm{C}$ aro, $\mathrm{C} \equiv \mathrm{N}), 115.09(2 \times \mathrm{C}$ aro $), 114.81(\mathrm{C}$ aro $), 109.58(2 \times \mathrm{C}$ aro), $67.29\left(\mathrm{CH}_{2}\right), 66.81\left(\mathrm{CH}_{2}\right), 42.13\left(\mathrm{CH}_{2}\right)$. MS $m / z$ : 341.00 (M-1).

9c (2-(4-(3-(1H-indol-1-yl)propoxy)phenoxy) acetonitrile): achromatous oil $(36.75 \%), \mathrm{R}_{\mathrm{f}}=0.46$ (developing agent: petroleum ether / EtOAc = 3:1); ${ }^{1} \mathrm{H}-\mathrm{NMR}\left(\mathrm{CDCl}_{3}, 400 \mathrm{MHz}\right): \delta$ 7.638-7.618 (1H, d, $J=$ $8.0 \mathrm{~Hz}, \mathrm{Ar}-\mathrm{H})$; 7.369-7.348 (1H, d, $J=8.4 \mathrm{~Hz}, \mathrm{Ar}-\mathrm{H})$; 7.201-7.160 (1H, m, Ar-H); 7.115-7.077 (2H, m, Ar-H); 6.945-6.866 (2H, m, Ar-H); 6.857-6.835 (2H, m, Ar-H); 6.481 (1H, s, Ar-H); $4.710\left(2 \mathrm{H}, \mathrm{s}, \mathrm{CH}_{2}\right) ; 4.390-4.357(2 \mathrm{H}$, $\left.\mathrm{t}, J=6.6 \mathrm{~Hz}, \mathrm{CH}_{2}\right) ; 3.845-3.817\left(2 \mathrm{H}, \mathrm{t}, J=5.6 \mathrm{~Hz}, \mathrm{CH}_{2}\right)$; 2.305-2.244 (2H, m, CH $) .{ }^{13} \mathrm{C}-\mathrm{NMR}\left(\mathrm{CDCl}_{3}, 101 \mathrm{MHz}\right)$ : $\delta 154.80$ (C aro), 150.84 (C aro), 136.88 (C aro), 128.12 (C aro), $126.90(=\mathrm{CH}), 121.54$ (C aro), 120.92 (C aro), 119.36 (C aro), 118.07 (C aro), 116.77 (C aro), 115.63 $(\mathrm{C} \equiv \mathrm{N}), 115.61(\mathrm{C}$ aro $), 115.34(\mathrm{C}$ aro $), 109.30(=\mathrm{CH})$, $101.30(\mathrm{C}$ aro $), 64.94\left(\mathrm{CH}_{2}\right), 54.90\left(\mathrm{CH}_{2}\right), 42.70\left(\mathrm{CH}_{2}\right)$, $30.95\left(\mathrm{CH}_{2}\right)$. MS m/z: $329.13(\mathrm{M}+\mathrm{Na})$.

9d (2-(4-(3-(9H-carbazol-9-yl)propoxy)phenoxy) acetonitrile): achromatous oil (70.60\%), $\mathrm{R}_{\mathrm{f}}=0.50$ (developing agent: petroleum ether / EtOAc = 3:1); ${ }^{1} \mathrm{H}-\mathrm{NMR}\left(\mathrm{CDCl}_{3}, 400 \mathrm{MHz}\right): \delta$ 8.105-8.086 (2H, d, J = $7.6 \mathrm{~Hz}, \mathrm{Ar}-\mathrm{H}) ; 7.432-7.378$ (4H, m, Ar-H); 7.258-7.196 (2H, m, Ar-H); 6.935-6.903 (2H, m, Ar-H); 6.854-6.823 $(2 \mathrm{H}, \mathrm{m}, \mathrm{Ar}-\mathrm{H}) ; 4.709$ (2H, s, $\left.\mathrm{CH}_{2}\right) ; 4.573-4.541$ (2H, t, $\left.J=6.4 \mathrm{~Hz}, \mathrm{CH}_{2}\right) ; 3.880-3.852\left(2 \mathrm{H}, \mathrm{t}, J=5.6 \mathrm{~Hz}, \mathrm{CH}_{2}\right)$; 2.370-2.325 (2H, m, $\left.\mathrm{CH}_{2}\right) .{ }^{13} \mathrm{C}-\mathrm{NMR}\left(\mathrm{CDCl}_{3}, 101 \mathrm{MHz}\right): \delta$ 154.66 (C aro), 150.82 (C aro), $140.43(2 \times \mathrm{C}$ aro $), 125.75$ $(2 \times \mathrm{C}$ aro $), 122.87(2 \times \mathrm{C}$ aro $), 120.35(2 \times \mathrm{C}$ aro $), 118.97$ $(2 \times \mathrm{C}$ aro $), 116.73(2 \times \mathrm{C}$ aro $), 115.65(2 \times \mathrm{C}$ aro $), 115.34$ $(\mathrm{C} \equiv \mathrm{N}), 108.57(2 \times \mathrm{C}$ aro $), 65.02\left(\mathrm{CH}_{2}\right), 54.89\left(\mathrm{CH}_{2}\right), 39.34$ $\left(\mathrm{CH}_{2}\right), 30.96\left(\mathrm{CH}_{2}\right)$. MS m/z: $379(\mathrm{M}+\mathrm{Na}), 712.47$ (2M).

9e (2-(4-(3-Phenylpropoxy)phenoxy)acetonitrile): achromatous oil $(15.84 \%), \mathrm{R}_{\mathrm{f}}=0.52$ (developing agent: petroleum ether / EtOAc = 3:1); ${ }^{1} \mathrm{H}-\mathrm{NMR}\left(\mathrm{CDCl}_{3}\right.$, $400 \mathrm{MHz}): \delta$ 7.307-7.177 (5H, m, Ar-H); 6.949-6.838 $(4 \mathrm{H}, \mathrm{m}, \mathrm{Ar}-\mathrm{H}) ; 4.697$ (2H, s, $\left.\mathrm{CH}_{2}\right) ; 3.938-3.906(2 \mathrm{H}, \mathrm{t}$, $\left.J=6.4 \mathrm{~Hz}, \mathrm{CH}_{2}\right) ; 2.822-2.784\left(2 \mathrm{H}, \mathrm{t}, J=7.6 \mathrm{~Hz}, \mathrm{CH}_{2}\right)$; 2.166-2.041(2H, m, $\left.\mathrm{CH}_{2}\right) .{ }^{13} \mathrm{C}-\mathrm{NMR}\left(\mathrm{CDCl}_{3}, 101 \mathrm{MHz}\right)$ : 155.10 (C aro), 150.66 (C aro), 141.46 (C aro), 128.52 $(2 \times \mathrm{C}$ aro $), 128.44(2 \times \mathrm{C}$ aro $), 125.97(\mathrm{C}$ aro $), 116.74$ $(2 \times \mathrm{C}$ aro $), 115.64(2 \times \mathrm{C}$ aro $), 115.41(\mathrm{C} \equiv \mathrm{N}), 67.43\left(\mathrm{CH}_{2}\right)$, $54.96\left(\mathrm{CH}_{2}\right), 32.13\left(\mathrm{CH}_{2}\right), 30.84\left(\mathrm{CH}_{2}\right) . \mathrm{MS} m / z: 290.07$ $(\mathrm{M}+\mathrm{Na}), 535.00(2 \mathrm{M}+1), 556.93(2 \mathrm{M}+\mathrm{Na})$.

9f (2-(4-(Pyridin-3-ylmethoxy)phenoxy)aceto nitrile): achromatous oil $(32.10 \%), \mathrm{R}_{\mathrm{f}}=0.34$ (developing agent: petroleum ether / $\mathrm{EtOAc}=3: 1) ;{ }^{1} \mathrm{H}-\mathrm{NMR}\left(\mathrm{CDCl}_{3}\right.$, 400MHz): $\delta 8.680$ (1H, s, Ar-H); 8.599-8.587 (1H, d, $J$ 
$=4.8 \mathrm{~Hz}, \mathrm{Ar}-\mathrm{H}) ; 7.790-7.771(1 \mathrm{H}, \mathrm{d}, J=7.6 \mathrm{~Hz}, \mathrm{Ar}-\mathrm{H})$; 7.355-7.324 (1H, dd, $J=7.6 \mathrm{~Hz}, \mathrm{Ar}-\mathrm{H}) ; 6.977(4 \mathrm{H}, \mathrm{s}$, Ar-H); $5.052\left(2 \mathrm{H}, \mathrm{s}, \mathrm{CH}_{2}\right) ; 4.720\left(2 \mathrm{H}, \mathrm{s}, \mathrm{CH}_{2}\right) .{ }^{13} \mathrm{C}-\mathrm{NMR}$ $\left(\mathrm{CDCl}_{3}, 101 \mathrm{MHz}\right): \delta 154.31(\mathrm{C}$ aro $), 151.14(\mathrm{C}$ aro $)$, 149.37 (C aro), 148.85 (C aro), 135.41 (C aro), 132.47 (C aro), $123.59(\mathrm{C}$ aro $), 116.75(2 \times \mathrm{C}$ aro $), 116.05(2 \times \mathrm{C}$ aro), $115.29(\mathrm{C} \equiv \mathrm{N}), 68.10\left(\mathrm{CH}_{2}\right), 54.78\left(\mathrm{CH}_{2}\right)$. MS $m / z$ : $263.13(\mathrm{M}+\mathrm{Na}), 479.07(2 \mathrm{M}-1), 480.87(2 \mathrm{M}+1), 502.93$ $(2 \mathrm{M}+\mathrm{Na})$.

9g (2-(3-(2-(1H-indol-1-yl)ethoxy)phenoxy)aceto nitrile): corlorless oil (18.21\%), $\mathrm{R}_{\mathrm{f}}=0.43$ (developing agent: petroleum ether / $\mathrm{EtOAc}=3: 1) ;{ }^{1} \mathrm{H}-\mathrm{NMR}\left(\mathrm{CDCl}_{3}\right.$, $400 \mathrm{MHz}): \delta 7.643-7.624(1 \mathrm{H}, \mathrm{d}, J=7.6 \mathrm{~Hz}, \mathrm{Ar}-\mathrm{H})$; 7.412-7.391 (1H, d, $J=8.4 \mathrm{~Hz}, \mathrm{Ar}-\mathrm{H}) ; 7.253-7.102(4 \mathrm{H}$, m, Ar-H); 6.569-6.507 (3H, m, Ar-H); 6.384-6.372 (1H, t, $J=2.4 \mathrm{~Hz}, \mathrm{Ar}-\mathrm{H}) ; 4.614\left(2 \mathrm{H}, \mathrm{s}, \mathrm{CH}_{2}\right) ; 4.523-4.496(2 \mathrm{H}$, $\left.\mathrm{t}, J=5.4 \mathrm{~Hz}, \mathrm{CH}_{2}\right) ; 4.276-4.248\left(2 \mathrm{H}, \mathrm{t}, J=5.6 \mathrm{~Hz}, \mathrm{CH}_{2}\right)$. ${ }^{13} \mathrm{C}-\mathrm{NMR}\left(\mathrm{CDCl}_{3}, 101 \mathrm{MHz}\right): \delta 159.70(\mathrm{C}$ aro $), 157.67$ (C aro), 136.03 (C aro), 130.42 (C aro), 128.82 (C aro), $128.40(=\mathrm{C}-\mathrm{N}), 121.72(\mathrm{C}$ aro $), 121.11(\mathrm{C}$ aro $), 119.60$ (C aro), $115.02(\mathrm{C} \equiv \mathrm{N}), 109.22(\mathrm{C}$ aro $), 109.19(\mathrm{C}$ aro), 107.39 (C aro), $102.22(\mathrm{C}$ aro $), 101.76(=\mathrm{CH}), 67.09$ $\left(\mathrm{CH}_{2}\right), 53.51\left(\mathrm{CH}_{2}\right), 45.68\left(\mathrm{CH}_{2}\right)$. MS m/z: $293.13(\mathrm{M}+1)$, $315.20(\mathrm{M}+\mathrm{Na})$.

9h (2-(3-(2-(9H-carbazol-9-yl)ethoxy)phenoxy) acetonitrile): corlorless oil $(12.66 \%), \mathrm{R}_{\mathrm{f}}=0.60$ (developing agent: petroleum ether / EtOAc $=3: 1)$; $1 \mathrm{H}-\mathrm{NMR}\left(\mathrm{CDCl}_{3}\right.$, $400 \mathrm{MHz}$ ): $\delta 8.099-8.079(2 \mathrm{H}, \mathrm{d}, J=8.0 \mathrm{~Hz}, \mathrm{Ar}-\mathrm{H}) ; 7.501-$ 7.431 (4H, m, Ar-H); 7.266-7.227 (2H, m, Ar-H); 7.159$7.117(1 \mathrm{H}, \mathrm{t}, J=8.4 \mathrm{~Hz}, \mathrm{Ar}-\mathrm{H}) ; 6.520-6.482(2 \mathrm{H}, \mathrm{m}, \mathrm{Ar}-\mathrm{H})$; 6.363-6.352 (1H, t, $J=2.2 \mathrm{~Hz}, \mathrm{Ar}-\mathrm{H}) ; 4.708-4.679(2 \mathrm{H}, \mathrm{t}$, $J=5.8 \mathrm{~Hz}, \mathrm{CH} 2) ; 4.626-4.595$ (2H, t, $J=6.2 \mathrm{~Hz}, \mathrm{CH} 2$ ); 4.338-4. 308 (2H, t, $J=6.0 \mathrm{~Hz}, \mathrm{CH} 2)$. 13C-NMR (CDCl3, $101 \mathrm{MHz}): \delta 159.68$ (C aro), 157.61 (C aro), 140.51 (C aro), 140.14 (C aro),130.34 (C aro), 125.94 (C aro), 125.81 (C aro), 123.12 (C aro), 123.04 (C aro), 120.51 (C aro), 120.30 (C aro), 119.53 (C aro), 119.36 (C aro), 115.01 $(\mathrm{C} \equiv \mathrm{N}), 109.09(\mathrm{C}$ aro $), 108.76(\mathrm{C}$ aro $), 108.49(\mathrm{C}$ aro $)$, 107.19 (C aro), 102.19 (C aro), 66.16 (CH2), 53.49 (CH2), $44.71(\mathrm{CH} 2)$. MS m/z: $343.07(\mathrm{M}+1)$.

9i (2-(3-(3-(1H-indol-1-yl)propoxy)phenoxy) acetonitrile): corlorless oil $(19.10 \%), \mathrm{R}_{\mathrm{f}}=0.52$ (developing agent: petroleum ether / $\mathrm{EtOAc}=3: 1) ;{ }^{1} \mathrm{H}-\mathrm{NMR}\left(\mathrm{CDCl}_{3}\right.$, $400 \mathrm{MHz}): \delta 7.636-7.617(1 \mathrm{H}, \mathrm{d}, J=7.6 \mathrm{~Hz}, \mathrm{Ar}-\mathrm{H})$; 7.367-7.346 (1H, d, $J=8.4 \mathrm{~Hz},=\mathrm{CH}) ; 7.182-7.164(2 \mathrm{H}, \mathrm{d}$, $J=7.2 \mathrm{~Hz}, \mathrm{Ar}-\mathrm{H}) ; 7.114-7.094$ (2H, d, $J=8.0 \mathrm{~Hz}, \mathrm{Ar}-\mathrm{H})$; 6.609-6.559 (2H, m, Ar-H); 6.495-6.477 (2H, m, Ar-H and $=\mathrm{CH}) ; 4.714\left(2 \mathrm{H}, \mathrm{s}, \mathrm{CH}_{2}\right) ; 4.384-4.351(2 \mathrm{H}, \mathrm{t}, J=6.6 \mathrm{~Hz}$, $\left.\mathrm{CH}_{2}\right) ; 3.872-3.844\left(2 \mathrm{H}, \mathrm{t}, J=5.6 \mathrm{~Hz}, \mathrm{CH}_{2}\right) ; 2.297-2.267$ $\left(2 \mathrm{H}, \mathrm{t}, J=6.0 \mathrm{~Hz}, \mathrm{CH}_{2}\right) \cdot{ }^{13} \mathrm{C}-\mathrm{NMR}\left(\mathrm{CDCl}_{3}, 101 \mathrm{MHz}\right): \delta$ 154.86 (C aro), 152.47 (C aro), 131.66 (C aro), 130.66 ( $\mathrm{C}$ aro), 125.17 ( $\mathrm{C}$ aro), $125.13(=\mathrm{CH}), 123.41$ ( $\mathrm{C}$ aro), $119.24(\mathrm{C}$ aro $), 118.96(\mathrm{C}$ aro $), 115.99(\mathrm{C} \equiv \mathrm{N}), 109.84$ (C aro), 104.04 (C aro), 103.97 (C aro), $101.85(=\mathrm{CH})$, $101.72(\mathrm{C}$ aro $), 59.46\left(\mathrm{CH}_{2}\right), 59.28\left(\mathrm{CH}_{2}\right), 48.33\left(\mathrm{CH}_{2}\right)$, $29.37\left(\mathrm{CH}_{2}\right)$. MS m/z: $307.27(\mathrm{M}+1)$. 9j (2-(3-(3-(9H-carbazol-9-yl)propoxy)phenoxy) acetonitrile): corlorless oil $(32.11 \%), \mathrm{R}_{\mathrm{f}}=0.54$ (developing agent: petroleum ether / EtOAc $=3: 1) ;{ }^{1} \mathrm{H}-\mathrm{NMR}\left(\mathrm{CDCl}_{3}\right.$, $400 \mathrm{MHz}): \delta 8.090-8.071(2 \mathrm{H}, \mathrm{d}, J=7.6 \mathrm{~Hz}, \mathrm{Ar}-\mathrm{H}) ; 7.401-$ 7.369 (4H, t, $J=6.4 \mathrm{~Hz}, \mathrm{Ar}-\mathrm{H}) ; 7.233-7.168$ (3H, m, ArH); 6.561-6.528 (2H, m, Ar-H); 6.458 (1H, s, Ar-H); 4.667 $\left(2 \mathrm{H}, \mathrm{s}, \mathrm{CH}_{2}\right) ; 4.537-4.505\left(2 \mathrm{H}, \mathrm{t}, J=6.4 \mathrm{~Hz}, \mathrm{CH}_{2}\right) ; 3.872-$ $3.845\left(2 \mathrm{H}, \mathrm{t}, J=5.4 \mathrm{~Hz}, \mathrm{CH}_{2}\right) ; 2.330-2.252\left(2 \mathrm{H}, \mathrm{m}, \mathrm{CH}_{2}\right)$. ${ }^{13} \mathrm{C}-\mathrm{NMR}\left(\mathrm{CDCl}_{3}, 101 \mathrm{MHz}\right): \delta 154.78(\mathrm{C}$ aro $), 152.46(\mathrm{C}$ aro $), 135.19(3 \times \mathrm{C}$ aro $), 125.15(2 \times \mathrm{C}$ aro $), 120.59(4 \times \mathrm{C}$ aro), $120.54(2 \times \mathrm{C}$ aro $), 117.66(\mathrm{C} \equiv \mathrm{N}), 109.87(2 \times \mathrm{C}$ aro $)$, 103.40 (C aro), 103.36 (C aro), 101.70 (C aro), 59.53 $\left(\mathrm{CH}_{2}\right), 55.14\left(\mathrm{CH}_{2}\right), 34.11\left(\mathrm{CH}_{2}\right), 25.66\left(\mathrm{CH}_{2}\right)$.

9k (2-(3-(3-Phenylpropoxy)phenoxy)acetonitrile): corlorless oil $(32.40 \%), \mathrm{R}_{\mathrm{f}}=0.55$ (developing agent: petroleum ether / EtOAc $=3: 1) ;{ }^{1} \mathrm{H}-\mathrm{NMR}\left(\mathrm{CDCl}_{3}\right.$, 400MHz): $\delta$ 7.312-7.249 (3H, m, Ar-H); 7.228-7.182 (3H, m, Ar-H); 6.633-6.607 (1H, m, Ar-H); 6.571-6.512 $(2 \mathrm{H}, \mathrm{m}, \mathrm{Ar}-\mathrm{H}) ; 4.741\left(2 \mathrm{H}, \mathrm{s}, \mathrm{CH}_{2}\right) ; 3.966-3.935(2 \mathrm{H}, \mathrm{t}$, $\left.J=6.2 \mathrm{~Hz}, \mathrm{CH}_{2}\right) ; 2.828-2.790\left(2 \mathrm{H}, \mathrm{t}, J=7.6 \mathrm{~Hz}, \mathrm{CH}_{2}\right)$; 2.140-2.071 (2H, m, $\left.\mathrm{CH}_{2}\right) .{ }^{13} \mathrm{C}-\mathrm{NMR}\left(\mathrm{CDCl}_{3}, 101 \mathrm{MHz}\right)$ : 160.46 (C aro), 157.71 (C aro), 141.38 (C aro), 130.31 (C aro), $128.52(2 \times \mathrm{C}$ aro $), 128.45(2 \times \mathrm{C}$ aro $), 125.98(\mathrm{C}$ aro $)$, $115.13(\mathrm{C} \equiv \mathrm{N}), 109.19(\mathrm{C}$ aro $), 106.60(\mathrm{C}$ aro $), 102.24(\mathrm{C}$ aro), $67.06\left(\mathrm{CH}_{2}\right), 53.58\left(\mathrm{CH}_{2}\right), 32.11\left(\mathrm{CH}_{2}\right), 30.92\left(\mathrm{CH}_{2}\right)$.

91 (2-(3-(Pyridin-3-ylmethoxy)phenoxy)aceto nitrile): corlorless oil (19.51\%), $\mathrm{R}_{\mathrm{f}}=0.45$ (developing agent: petroleum ether / EtOAc $=1: 1) ;{ }^{1} \mathrm{H}-\mathrm{NMR}\left(\mathrm{CDCl}_{3}\right.$, 400MHz): $\delta 8.687(1 \mathrm{H}, \mathrm{s}, \mathrm{Ar}-\mathrm{H}) ; 8.597(1 \mathrm{H}, \mathrm{s}, \mathrm{Ar}-\mathrm{H})$; 7.799-7.779 (1H, d, $J=8 \mathrm{~Hz}, \mathrm{Ar}-\mathrm{H})$; 7.363-7.335 (1H, m, Ar-H); 7.292-7.249 (1H, m, Ar-H); 6.720-6.699 (1H, d, $J$ $=8.4 \mathrm{~Hz}, \mathrm{Ar}-\mathrm{H})$; 6.615-6.610 (2H, d, $J=2.0 \mathrm{~Hz}, \mathrm{Ar}-\mathrm{H})$; $5.076\left(2 \mathrm{H}, \mathrm{s}, \mathrm{CH}_{2}\right) ; 4.757\left(2 \mathrm{H}, \mathrm{s}, \mathrm{CH}_{2}\right) \cdot{ }^{13} \mathrm{C}-\mathrm{NMR}\left(\mathrm{CDCl}_{3}\right.$, $101 \mathrm{MHz}): \delta 159.74$ (C aro), $157.76(\mathrm{C}$ aro), 149.43 (C aro), 148.84 (C aro), 135.43 (C aro), 132.22 (C aro), $130.53(\mathrm{C}$ aro $), 123.60(\mathrm{C}$ aro $), 115.01(\mathrm{C} \equiv \mathrm{N}), 109.34(\mathrm{C}$ aro), 107.39 (C aro), 102.73 (C aro), $67.69\left(\mathrm{CH}_{2}\right), 53.61$ $\left(\mathrm{CH}_{2}\right)$. MS m/z: $241.13(\mathrm{M}+1), 263.07(\mathrm{M}+\mathrm{Na}), 480.60$ $(\mathrm{M}+1), 502.73(2 \mathrm{M}+\mathrm{Na})$.

\section{Tetrazole compounds (10)}

The mixture of toluene $(24 \mathrm{ml})$, nitrile intermediates 9 $(10 \mathrm{mmol})$, triethylamine hydrochloride $(2.48 \mathrm{~g}, 18 \mathrm{mmol})$ and sodium azide $(1.12 \mathrm{~g}, 16 \mathrm{mmol})$ was heated at $120^{\circ} \mathrm{C}$ for $48 \mathrm{~h}$. The process of the reaction was detected through TLC method. After the reaction, on cooling to room temperature, ice-water was added to the solution. Solid was precipitated after the $\mathrm{pH}$ of water layer adjusted to 1.0 with diluted hydrochloric acid. The solid products were further purified by flash column chromatography with dichloromethane/ methanol as the mobile phase.

10a (1-(2-(4-((2H-tetrazol-5-yl)methoxy)phenoxy) ethyl)-1H-indole): white solid (61.03\%), m.p. 132.3$136.1^{\circ} \mathrm{C}, \mathrm{R}_{\mathrm{f}}=0.39$ (developing agent: dichloromethane / methanol = 10:1); ${ }^{1} \mathrm{H}-\mathrm{NMR}\left(\mathrm{DMSO}_{6}, 400 \mathrm{MHz}\right): \delta$ 
7.551-7.529 (2H, m, Ar-H); 7.419-7.411 (1H, d, $J=3.2$ $\mathrm{Hz}, \mathrm{Ar}-\mathrm{H}) ; 7.137-7.113(1 \mathrm{H}, \mathrm{m}, \mathrm{Ar}-\mathrm{H}) ; 7.034-7.013$ (1H, $\mathrm{dd}, J=3.8 \mathrm{~Hz}, \mathrm{Ar}-\mathrm{H})$; 6.964-6.942 (2H, dd, $J=3.4 \mathrm{~Hz}, \mathrm{Ar}-$ $\mathrm{H})$; 6.847-6.824 (2H, dd, $J=3.4 \mathrm{~Hz}, \mathrm{Ar}-\mathrm{H})$; 6.433-6.431 $(1 \mathrm{H}, \mathrm{d}, J=0.8 \mathrm{~Hz}, \mathrm{Ar}-\mathrm{H}) ; 5.378\left(2 \mathrm{H}, \mathrm{d}, \mathrm{CH}_{2}\right) ; 4.552-4.426$ $\left(2 \mathrm{H}, \mathrm{t}, J=5.2 \mathrm{~Hz}, \mathrm{CH}_{2}\right) ; 4.246-4.219(2 \mathrm{H}, \mathrm{t}, J=5.4 \mathrm{~Hz}$, $\left.\mathrm{CH}_{2}\right) \cdot{ }^{13} \mathrm{C}-\mathrm{NMR}\left(\mathrm{DMSO}-\mathrm{d}_{6}, 101 \mathrm{MHz}\right): \delta 158.16(\mathrm{C}=\mathrm{N})$, 156.81 (C aro), 141.11 (C aro), 134.26 (C aro), 133.31 (C aro), $126.22(=\mathrm{CH}-\mathrm{N}), 125.55$ (C aro), 124.20 (C aro), 121.19 (C aro), $120.60(2 \times \mathrm{C}$ aro $), 115.16(2 \times \mathrm{C}$ aro $)$, $105.92\left(=\mathrm{CH}, \mathrm{C}\right.$ aro), $72.60\left(\mathrm{CH}_{2}\right), 65.11\left(\mathrm{CH}_{2}\right), 50.28$ $\left(\mathrm{CH}_{2}\right)$. MS m/z: 334.13(M-1); 335.13(M); 336.13(M+1).

$10 b$ (9-(2-(4-((2H-tetrazol-5-yl)methoxy)phenoxy) ethyl)-9H-carbazole): white solid (30.70\%), m.p. 131.4$139.8^{\circ} \mathrm{C}, \mathrm{R}_{\mathrm{f}}=0.42$ (developing agent: dichloromethane/ methanol $=10: 1) ;{ }^{1} \mathrm{H}-\mathrm{NMR}\left(\mathrm{DMSO}_{6}, 400 \mathrm{MHz}\right): \delta$ 8.170-8.128 (2H, t, $J=8.4 \mathrm{~Hz}, \mathrm{Ar}-\mathrm{H}) ; 7.684-7.663(2 \mathrm{H}$, $\mathrm{d}, J=8.4 \mathrm{~Hz}, \mathrm{Ar}-\mathrm{H})$; 7.478-7.440 (2H, t, $J=7.6 \mathrm{~Hz}, \mathrm{Ar}-$ $\mathrm{H})$; 7.226-7.189 (2H, t, $J=7.4 \mathrm{~Hz}, \mathrm{Ar}-\mathrm{H})$; 6.929-6.897 $(2 \mathrm{H}, \mathrm{t}, J=6.4 \mathrm{~Hz}, \mathrm{Ar}-\mathrm{H}) ; 6.764-6.741(2 \mathrm{H}, \mathrm{d}, J=9.2 \mathrm{~Hz}$, $\mathrm{Ar}-\mathrm{H}) ; 5.357\left(2 \mathrm{H}, \mathrm{s}, \mathrm{CH}_{2}\right) ; 4.786-4.760(2 \mathrm{H}, \mathrm{t}, J=5.2$ $\left.\mathrm{Hz}, \mathrm{CH}_{2}\right)$; 4.314-4.288 (2H, t, $\left.J=5.2 \mathrm{~Hz}, \mathrm{CH}_{2}\right) .{ }^{13} \mathrm{C}-\mathrm{NMR}$ $\left(\mathrm{DMSO}-\mathrm{d}_{6}, 101 \mathrm{MHz}\right): \delta 152.94(\mathrm{C}=\mathrm{N}, \mathrm{C}$ aro $), 151.48(\mathrm{C}$ aro $), 140.21(2 \times \mathrm{C}$ aro $), 125.60(2 \times \mathrm{C}$ aro $), 122.09(2 \times \mathrm{C}$ aro $), 120.11(2 \times \mathrm{C}$ aro $), 118.85(2 \times \mathrm{C}$ aro $), 115.91(2 \times \mathrm{C}$ aro), 115.68 (C aro), 114.19 (C aro), $109.58(2 \times \mathrm{C}$ aro), $66.80\left(\mathrm{CH}_{2}\right), 59.83\left(\mathrm{CH}_{2}\right), 54.87\left(\mathrm{CH}_{2}\right)$. MS m/z: 384.07 (M-1); 385.07(M); 386.14(M+1); 407.73(M+Na).

10c (1-(3-(4-((2H-tetrazol-5-yl)methoxy)phenoxy) propyl)-1H-indole): yellowish solid (57.77\%), m.p. 148.5$153.7^{\circ} \mathrm{C}, \mathrm{R}_{\mathrm{f}}=0.42$ (developing agent: dichloromethane / methanol $=30: 1) ;{ }^{1} \mathrm{H}-\mathrm{NMR}\left(\mathrm{DMSO}_{6}, 400 \mathrm{MHz}\right): \delta$ 7.543-7.523 (1H, d, $J=8.0 \mathrm{~Hz}, \mathrm{Ar}-\mathrm{H}) ; 7.469-7.449(1 \mathrm{H}$, $\mathrm{d}, J=8.0 \mathrm{~Hz}, \mathrm{Ar}-\mathrm{H})$; 7.345-7.338 (1H, d, $J=2.8 \mathrm{~Hz}$, ArH); 7.110-7.072 (1H, m, Ar-H); 7.016-6.897 (3H, m, Ar$\mathrm{H})$; 6.888-6.856 (2H, m, Ar-H); 6.423-6.416 (1H, d, $J=$ $2.8 \mathrm{~Hz}, \mathrm{Ar}-\mathrm{H}) ; 5.402\left(2 \mathrm{H}, \mathrm{s}, \mathrm{CH}_{2}\right) ; 4.356-4.322(2 \mathrm{H}, \mathrm{t}, J=$ $\left.6.8 \mathrm{~Hz}, \mathrm{CH}_{2}\right) ; 3.842-3.812\left(2 \mathrm{H}, \mathrm{t}, J=6.0 \mathrm{~Hz}, \mathrm{CH}_{2}\right) ; 2.199$ $2.135\left(2 \mathrm{H}, \mathrm{m}, \mathrm{CH}_{2}\right) .{ }^{13} \mathrm{C}-\mathrm{NMR}$ (DMSO-d, $\left.101 \mathrm{MHz}\right)$ : $\delta 153.23(\mathrm{C}$ aro, $\mathrm{C}=\mathrm{N}), 151.45(\mathrm{C}$ aro $), 135.61$ ( $\mathrm{C}$ aro), 128.60 (C aro), 128.05 (=CH), 120.97 (C aro), 120.39 (C aro), 118.87 (C aro), $115.94(2 \times \mathrm{C}$ aro $), 115.38(2 \times \mathrm{C}$ aro $)$, 109.62 (C aro), $100.59(=\mathrm{CH}), 64.94\left(\mathrm{CH}_{2}\right), 59.87\left(\mathrm{CH}_{2}\right)$, $42.18\left(\mathrm{CH}_{2}\right), 30.66\left(\mathrm{CH}_{2}\right)$. MS m/z: $348.00(\mathrm{M}-1), 349.20$ (M), $350.13(\mathrm{M}+1)$.

10d (9-(3-(4-((2H-tetrazol-5-yl)methoxy)phenoxy) propyl)-9H-carbazole): white solid (66.18\%), m.p. 168.2$171.3^{\circ} \mathrm{C}, \mathrm{R}_{\mathrm{f}}=0.30$ (developing agent: dichloromethane/ methanol = 30:1); ${ }^{1} \mathrm{H}-\mathrm{NMR}\left(\mathrm{DMSO}-\mathrm{d}_{6}, 400 \mathrm{MHz}\right): \delta$ 8.157-8.137 (2H, d, $J=8.0 \mathrm{~Hz}, \mathrm{Ar}-\mathrm{H}) ; 7.592-7.572(2 \mathrm{H}$, $\mathrm{d}, J=8.0 \mathrm{~Hz}, \mathrm{Ar}-\mathrm{H}) ; 7.413-7.375(2 \mathrm{H}, \mathrm{dd}, J=8.0 \mathrm{~Hz}$ ArH); 7.201-7.164 (2H, t, $J=7.4 \mathrm{~Hz}, \mathrm{Ar}-\mathrm{H})$; 6.984-6.961 $(2 \mathrm{H}, \mathrm{d}, J=8.4 \mathrm{~Hz}, \mathrm{Ar}-\mathrm{H}) ; 6.872-6.850(2 \mathrm{H}, \mathrm{d}, J=8.0 \mathrm{~Hz}$, Ar-H); $5.401\left(2 \mathrm{H}, \mathrm{s}, \mathrm{CH}_{2}\right) ; 4.577-4.544(2 \mathrm{H}, \mathrm{t}, J=6.6 \mathrm{~Hz}$, $\left.\mathrm{CH}_{2}\right) ; 3.880-3.852\left(2 \mathrm{H}, \mathrm{t}, J=5.6 \mathrm{~Hz}, \mathrm{CH}_{2}\right) ; 2.245-2.171$ $\left(2 \mathrm{H}, \mathrm{m}, \mathrm{CH}_{2}\right) .{ }^{13} \mathrm{C}-\mathrm{NMR}$ (DMSO-d, $\left.101 \mathrm{MHz}\right): \delta 152.06$
$(\mathrm{C}$ aro, $\mathrm{C}=\mathrm{N}), 151.12(\mathrm{C}$ aro $), 139.92(2 \times \mathrm{C}$ aro $), 125.65$ $(2 \times \mathrm{C}$ aro $), 122.04(2 \times \mathrm{C}$ aro $), 120.24(2 \times \mathrm{C}$ aro $), 118.73$ $(2 \times \mathrm{C}$ aro $), 115.91(2 \times \mathrm{C}$ aro $), 115.38(2 \times \mathrm{C}$ aro $), 109.07$ $(2 \times \mathrm{C}$ aro $), 64.93\left(2 \times \mathrm{CH}_{2}\right), 59.89\left(\mathrm{CH}_{2}\right), 30.66\left(\mathrm{CH}_{2}\right) . \mathrm{MS}$ $\mathrm{m} / z$ : 398.13 (M-1), 797.07 (2M-1).

10e (5-((4-(3-Phenylpropoxy)phenoxy)methyl)-2Htetrazole): white solid $(64.52 \%)$, m.p. $142.5-147.8^{\circ} \mathrm{C}, \mathrm{R}_{\mathrm{f}}$ $=0.37$ (developing agent: dichloromethane / methanol $=30: 1) ;{ }^{1} \mathrm{H}-\mathrm{NMR}\left(\mathrm{DMSO}_{6}, 400 \mathrm{MHz}\right): \delta$ 7.302-7.159 (5H, m, Ar-H); 6.966-6.943 (2H, d, $J=9.2 \mathrm{~Hz}, \mathrm{Ar}-\mathrm{H})$; 6.841-6.818 (2H, d, $J=9.2 \mathrm{~Hz}, \mathrm{Ar}-\mathrm{H}) ; 5.052\left(2 \mathrm{H}, \mathrm{s}, \mathrm{CH}_{2}\right)$; 3.902-3.870 (2H, t, $\left.J=6.4 \mathrm{~Hz}, \mathrm{CH}_{2}\right) ; 2.744-2.670(2 \mathrm{H}$, $\left.\mathrm{m}, \mathrm{CH}_{2}\right) ; 2.012-1.942\left(2 \mathrm{H}, \mathrm{m}, \mathrm{CH}_{2}\right) .{ }^{13} \mathrm{C}-\mathrm{NMR}$ (DMSO-d, 101MHz): $152.67(\mathrm{C}$ aro, $\mathrm{C}=\mathrm{N}), 152.48(\mathrm{C}$ aro $), 141.44(\mathrm{C}$ aro $), 128.32(2 \times \mathrm{C}$ aro $), 128.29(2 \times \mathrm{C}$ aro $), 125.76(\mathrm{C}$ aro $)$, $115.44(2 \times \mathrm{C}$ aro $), 115.18(2 \times \mathrm{C}$ aro $), 67.07\left(\mathrm{CH}_{2}\right), 61.95$ $\left(\mathrm{CH}_{2}\right), 31.48\left(\mathrm{CH}_{2}\right), 30.66\left(\mathrm{CH}_{2}\right)$. MS m/z: $309.13(\mathrm{M}-1)$.

10f (3-((4-((2H-tetrazol-5-yl)methoxy)phenoxy) methyl)pyridine): yellowish solid (97.67\%), m.p. 190.7$192.2^{\circ} \mathrm{C}, \mathrm{R}_{\mathrm{f}}=0.30$ (developing agent: dichloromethane / methanol $=30: 1) ;{ }^{1} \mathrm{H}-\mathrm{NMR}\left(\mathrm{DMSO}-\mathrm{d}_{6}, 400 \mathrm{MHz}\right): \delta 8.656$ (1H, s, Ar-H); 8.549-8.533 (1H, dd, $J=4.8 \mathrm{~Hz}, \mathrm{Ar}-\mathrm{H})$; 7.867-7.847 (1H, d, $J=8.0 \mathrm{~Hz}, \mathrm{Ar}-\mathrm{H}) ; 7.440-7.409(1 \mathrm{H}$, $\mathrm{dd}, J=7.6 \mathrm{~Hz}, \mathrm{Ar}-\mathrm{H}) ; 7.026-6.976$ (4H, m, Ar-H); 5.415 $\left(2 \mathrm{H}, \mathrm{s}, \mathrm{CH}_{2}\right) ; 5.097\left(2 \mathrm{H}, \mathrm{s}, \mathrm{CH}_{2}\right) .{ }^{13} \mathrm{C}-\mathrm{NMR}$ (DMSO-d, 101MHz): $152.88(\mathrm{C}$ aro, $\mathrm{C}=\mathrm{N}), 151.66(\mathrm{C}$ aro $), 149.05$ (C aro), 148.99 (C aro), 135.65 (C aro), 132.71 (C aro), $123.56(\mathrm{C}$ aro $), 115.97(2 \times \mathrm{C}$ aro $), 115.78(2 \times \mathrm{C}$ aro $), 67.30$ $\left(\mathrm{CH}_{2}\right), 59.87\left(\mathrm{CH}_{2}\right)$. MS m/z: $282.07(\mathrm{M}-1), 283.93(\mathrm{M}+1)$.

$10 \mathrm{~g}$ (1-(2-(3-((2H-tetrazol-5-yl)methoxy)phenoxy) ethyl)-1H-indole): yellowish solid (50.24\%), m.p. 150.0$154.5^{\circ} \mathrm{C}, \mathrm{R}_{\mathrm{f}}=0.39$ (developing agent: dichloromethane / methanol $=10: 1) ;{ }^{1} \mathrm{H}-\mathrm{NMR}\left(\mathrm{DMSO}-\mathrm{d}_{6}, 400 \mathrm{MHz}\right): \delta$ 7.562-7.527 (2H, m, Ar-H); 7.423-7.415 (1H, d, $J=3.2$ $\mathrm{Hz}, \mathrm{Ar}-\mathrm{H}) ; 7.200-7.141$ (2H, m, Ar-H); 7.037-7.017 (1H, t, $J=4 \mathrm{~Hz}, \mathrm{Ar}-\mathrm{H}) ; 6.629-6.592$ (2H, m, Ar-H); 6.586-6.527 $(1 \mathrm{H}, \mathrm{m}, \mathrm{Ar}-\mathrm{H}) ; 6.446(1 \mathrm{H}, \mathrm{s}, \mathrm{Ar}-\mathrm{H}) ; 5.422\left(2 \mathrm{H}, \mathrm{s}, \mathrm{CH}_{2}\right)$; 4.577-4.551 (2H, t, $\left.J=5.2 \mathrm{~Hz}, \mathrm{CH}_{2}\right) ; 4.299-4.273(2 \mathrm{H}$, $\left.\mathrm{t}, J=5.2 \mathrm{~Hz}, \mathrm{CH}_{2}\right) .{ }^{13} \mathrm{C}-\mathrm{NMR}$ (DMSO-d, $\left.101 \mathrm{MHz}\right): \delta$ $159.27(2 \times \mathrm{C}$ aro $), 158.53(\mathrm{C}=\mathrm{N}), 135.84(\mathrm{C}$ aro $), 130.15$ (C aro), 129.02 (C aro), $128.08(=\mathrm{C}-\mathrm{N}), 121.00$ (C aro), 120.32 (C aro), 118.98 (C aro), 109.91 (C aro), 107.83 (C aro), 107.38 (C aro), 101.52 (C aro), $100.72(=\mathrm{CH}), 66.97$ $\left(\mathrm{CH}_{2}\right), 59.30\left(\mathrm{CH}_{2}\right), 44.94\left(\mathrm{CH}_{2}\right)$. MS m/z: 334.13(M-1), 335.07(M), 336.13(M+1).

10h (9-(2-(3-((2H-tetrazol-5-yl)methoxy)phenoxy) ethyl)-9H-carbazole): white solid (10.70\%), m.p. 199.8$202.1^{\circ} \mathrm{C}, \mathrm{R}_{\mathrm{f}}=0.42$ (developing agent: dichloromethane/ methanol = 10:1); ${ }^{1} \mathrm{H}-\mathrm{NMR}\left(\mathrm{DMSO}-\mathrm{d}_{6}, 400 \mathrm{MHz}\right): \delta$ 8.155-8.136 (2H, d, $J=7.6 \mathrm{~Hz}, \mathrm{Ar}-\mathrm{H}) ; 7.693-7.672(2 \mathrm{H}$, d, $J=8.4 \mathrm{~Hz}, \mathrm{Ar}-\mathrm{H})$; 7.484-7.443 (2H, m, Ar-H); 7.2287.190 (2H, m, Ar-H); 7.161-7.120 (1H, t, J=8.2 Hz, Ar$\mathrm{H})$; 6.602-6.576 (1H, m, Ar-H); 6.523-6.511 (1H, t, $J=2.4$ $\mathrm{Hz}, \mathrm{Ar}-\mathrm{H}) ; 6.472-6.446$ (1H, dd, $J=8.4 \mathrm{~Hz}, \mathrm{Ar}-\mathrm{H}) ; 5.391$ $\left(2 \mathrm{H}, \mathrm{s}, \mathrm{CH}_{2}\right) ; 4.812-4.786\left(2 \mathrm{H}, \mathrm{t}, J=5.2 \mathrm{~Hz}, \mathrm{CH}_{2}\right) ; 4.370-$ $4.344\left(2 \mathrm{H}, \mathrm{t}, J=5.2 \mathrm{~Hz}, \mathrm{CH}_{2}\right) .{ }^{13} \mathrm{C}-\mathrm{NMR}$ (DMSO-d, 
101MHz): $\delta 159.28(\mathrm{C}$ aro, $\mathrm{C}=\mathrm{N}), 158.48(\mathrm{C}$ aro $), 140.20$ $(2 \times \mathrm{C}$ aro $), 130.11(\mathrm{C}$ aro $), 125.62(2 \times \mathrm{C}$ aro $), 122.11(2 \times \mathrm{C}$ aro $), 120.12(2 \times \mathrm{C}$ aro $), 118.88(2 \times \mathrm{C}$ aro $), 109.57(2 \times \mathrm{C}$ aro), 107.85 (C aro), 107.23 (C aro), 101.41 (C aro), 66.45 $\left(\mathrm{CH}_{2}\right), 59.30\left(\mathrm{CH}_{2}\right), 42.00\left(\mathrm{CH}_{2}\right)$. MS m/z: $384.13(\mathrm{M}-1)$, $385.20(\mathrm{M}), 386.07(\mathrm{M}+1)$.

$10 \mathrm{i}$ (1-(3-(3-((2H-tetrazol-5-yl)methoxy)phenoxy) propyl)-1H-indole): yellowish solid (42.17\%), m.p. 112.5$116.1^{\circ} \mathrm{C}, \mathrm{R}_{\mathrm{f}}=0.28$ (developing agent: dichloromethane / methanol $=30: 1)$; ${ }^{1} \mathrm{H}-\mathrm{NMR}\left(\mathrm{DMSO}_{6}, 400 \mathrm{MHz}\right): \delta$ 7.546-7.527 (1H, d, $J=7.6 \mathrm{~Hz}, \mathrm{Ar}-\mathrm{H}) ; 7.479-7.458$ (1H, d, $J=8.4 \mathrm{~Hz}, \mathrm{Ar}-\mathrm{H}) ; 7.352-7.344(1 \mathrm{H}, \mathrm{d}, J=3.2 \mathrm{~Hz},=\mathrm{CH})$; 7.226-7.183 (1H, t, $J=8.6 \mathrm{~Hz}, \mathrm{Ar}-\mathrm{H}) ; 7.118-7.080(1 \mathrm{H}, \mathrm{t}$, $J=7.6 \mathrm{~Hz}, \mathrm{Ar}-\mathrm{H}) ; 7.099-7.081$ (1H, d, $J=7.2 \mathrm{~Hz}, \mathrm{Ar}-\mathrm{H})$; 7.019-7.000 (1H, d, $J=7.6 \mathrm{~Hz}, \mathrm{Ar}-\mathrm{H}) ; 6.652-6.561(2 \mathrm{H}$, $\mathrm{m}, \mathrm{Ar}-\mathrm{H}) ; 6.431-6.424(1 \mathrm{H}, \mathrm{d}, J=2.8 \mathrm{~Hz},=\mathrm{CH}) ; 5.457$ $\left(2 \mathrm{H}, \mathrm{s}, \mathrm{CH}_{2}\right)$; 4.364-4.330 (2H, t, $\left.J=6.8 \mathrm{~Hz}, \mathrm{CH}_{2}\right)$; 3.894$3.864\left(2 \mathrm{H}, \mathrm{t}, J=6.0 \mathrm{~Hz}, \mathrm{CH}_{2}\right) ; 2.225-2.160\left(2 \mathrm{H}, \mathrm{m}, \mathrm{CH}_{2}\right)$. ${ }^{13} \mathrm{C}-\mathrm{NMR}\left(\mathrm{DMSO}-\mathrm{d}_{6}, 101 \mathrm{MHz}\right): \delta 159.61(\mathrm{C}$ aro, $\mathrm{C}=\mathrm{N})$, 158.54 (C aro), 135.61 (C aro), 130.13 (C aro), 128.59 (C aro), $128.06(=\mathrm{CH}), 121.00$ (C aro), 120.40 (C aro), 118.88 (C aro), 109.62 (C aro), 107.75 (C aro), 107.13 (C aro), $101.68(\mathrm{C}$ aro $), 100.63(=\mathrm{CH}), 64.62\left(\mathrm{CH}_{2}\right), 59.28$ $\left(\mathrm{CH}_{2}\right), 42.16\left(\mathrm{CH}_{2}\right), 30.65\left(\mathrm{CH}_{2}\right)$. MS m/z: $348.13(\mathrm{M}-1)$, $350.13(\mathrm{M}+1), 372.13(\mathrm{M}+\mathrm{Na}), 697.00$ (2M-1), 720.67 $(2 \mathrm{M}+\mathrm{Na})$.

$10 \mathrm{j}$ (9-(3-(3-((2H-tetrazol-5-yl)methoxy)phenoxy) propyl)-9H-carbazole): white solid (34.79\%), m.p. 157.0$160.3^{\circ} \mathrm{C}, \mathrm{R}_{\mathrm{f}}=0.30$ (developing agent: dichloromethane/ methanol $=30: 1) ;{ }^{1} \mathrm{H}-\mathrm{NMR}\left(\mathrm{DMSO}-\mathrm{d}_{6}, 400 \mathrm{MHz}\right): \delta 7.600$ $7.580(2 \mathrm{H}, \mathrm{d}, J=8.0 \mathrm{~Hz}, \mathrm{Ar}-\mathrm{H})$; 7.421-7.380 (2H, m, ArH); 7.216-7.164 (3H, m, Ar-H); 6.999-6.981 (2H, d, $J=7.2$ $\mathrm{Hz}, \mathrm{Ar}-\mathrm{H}) ; 6.650-6.628$ (2H, m, Ar-H); 6.582-6.560 (1H, $\mathrm{m}, \mathrm{Ar}-\mathrm{H}) ; 5.454\left(2 \mathrm{H}, \mathrm{s}, \mathrm{CH}_{2}\right) ; 4.364-4.330(2 \mathrm{H}, \mathrm{t}, J=6.8$ $\left.\mathrm{Hz}, \mathrm{CH}_{2}\right) ; 3.894-3.864\left(2 \mathrm{H}, \mathrm{t}, J=6.0 \mathrm{~Hz}, \mathrm{CH}_{2}\right) ; 2.241-$ $2.208\left(2 \mathrm{H}, \mathrm{m}, \mathrm{CH}_{2}\right) .{ }^{13} \mathrm{C}-\mathrm{NMR}\left(\mathrm{DMSO}-\mathrm{d}_{6}, 101 \mathrm{MHz}\right): \delta$ $159.55(\mathrm{C}$ aro, $\mathrm{C}=\mathrm{N}), 158.53(\mathrm{C}$ aro $), 139.92(2 \times \mathrm{C}$ aro $)$, $130.10(\mathrm{C}$ aro $), 125.67(2 \times \mathrm{C}$ aro $), 122.06(2 \times \mathrm{C}$ aro $), 120.24$ $(2 \times \mathrm{C}$ aro $), 118.74(2 \times \mathrm{C}$ aro $), 109.07(2 \times \mathrm{C}$ aro $), 107.72(\mathrm{C}$ aro), 107.13 (C aro), 101.73 (C aro), $64.63\left(2 \times \mathrm{CH}_{2}\right), 59.28$ $\left(\mathrm{CH}_{2}\right), 30.65\left(\mathrm{CH}_{2}\right)$. MS m/z: 398.13 (M-1), 797.00 (2M-1).

10k (5-((3-(3-Phenylpropoxy)phenoxy)methyl)-2Htetrazole): white solid (44.36\%), m.p. $121.1-124.9^{\circ} \mathrm{C}, \mathrm{R}_{\mathrm{f}}$ $=0.33$ (developing agent: dichloromethane / methanol $=$ 30:1); ${ }^{1} \mathrm{H}-\mathrm{NMR}$ (DMSO-d , 400MHz): $\delta$ 7.306-7.270 $(2 \mathrm{H}$, m, Ar-H); 7.240-7.166 (4H, m, Ar-H); 6.636-6.593 (2H, m, Ar-H); 6.591-6.567 (1H, m, Ar-H); 5.459 (2H, s, $\left.\mathrm{CH}_{2}\right)$; 3.964-3.932 (2H, t, $\left.J=6.4 \mathrm{~Hz}, \mathrm{CH}_{2}\right) ; 2.752-2.713(2 \mathrm{H}, \mathrm{t}$, $\left.J=7.8 \mathrm{~Hz}, \mathrm{CH}_{2}\right) ; 2.086-1.986\left(2 \mathrm{H}, \mathrm{m}, \mathrm{CH}_{2}\right) .{ }^{13} \mathrm{C}-\mathrm{NMR}$ $\left(\mathrm{DMSO}_{6}, 101 \mathrm{MHz}\right): 159.82(\mathrm{C}$ aro, $\mathrm{C}=\mathrm{N}), 158.57(\mathrm{C}$ aro), 141.32 (C aro), $130.11(2 \times \mathrm{C}$ aro $), 128.31(2 \times \mathrm{C}$ aro $)$, $125.81(2 \times \mathrm{C}$ aro $), 107.77$ (C aro), 107.03 (C aro), 101.66 (C aro), $66.73\left(\mathrm{CH}_{2}\right), 59.29\left(\mathrm{CH}_{2}\right), 31.43\left(\mathrm{CH}_{2}\right), 30.65$ $\left(\mathrm{CH}_{2}\right)$. MS m/z: 309.07 (M-1), $310.20(\mathrm{M}), 311.07(\mathrm{M}+1)$.

101 (3-((3-((2H-tetrazol-5-yl)methoxy)phenoxy) methyl)pyridine): white solid $(94.82 \%)$, m.p. 172.4- $175.1^{\circ} \mathrm{C}, \mathrm{R}_{\mathrm{f}}=0.36$ (developing agent: dichloromethane/ methanol $=30: 1) ;{ }^{1} \mathrm{H}-\mathrm{NMR}\left(\mathrm{DMSO}_{6}, 400 \mathrm{MHz}\right): \delta$ $8.671(1 \mathrm{H}, \mathrm{s}, \mathrm{Ar}-\mathrm{H}) ; 8.558-8.548(1 \mathrm{H}, \mathrm{d}, J=4.0 \mathrm{~Hz}, \mathrm{Ar}-$ $\mathrm{H})$; 7.878-7.859 (1H, d, $J=7.6 \mathrm{~Hz}, \mathrm{Ar}-\mathrm{H})$; 7.449-7.417 (1H, m, Ar-H); 7.261-7.220 (1H, t, $J=8.2 \mathrm{~Hz}, \mathrm{Ar}-\mathrm{H})$; 6.751-6.657 (3H, m, Ar-H); $5.460\left(2 \mathrm{H}, \mathrm{s}, \mathrm{CH}_{2}\right) ; 5.145$ $\left(2 \mathrm{H}, \mathrm{s}, \mathrm{CH}_{2}\right) \cdot{ }^{13} \mathrm{C}-\mathrm{NMR}\left(\mathrm{DMSO}-\mathrm{d}_{6}, 101 \mathrm{MHz}\right): \delta 159.30$ $(2 \times \mathrm{C}$ aro $), 158.60(\mathrm{C}=\mathrm{N}), 149.14(\mathrm{C}$ aro $), 149.04(\mathrm{C}$ aro $)$, 135.70 (C aro), 132.46 (C aro), 130.20 (C aro), 123.59 (C aro), 108.05 (C aro), 107.45 (C aro), 102.06 (C aro), $66.97\left(\mathrm{CH}_{2}\right), 59.34\left(\mathrm{CH}_{2}\right) . \mathrm{MS} \mathrm{m} / \mathrm{z}: 241.13(\mathrm{M}+1), 263.07$ $(\mathrm{M}+\mathrm{Na}), 480.60(\mathrm{M}+1), 502.73(2 \mathrm{M}+\mathrm{Na}) . \mathrm{MS} m / z$ : 282.03(M-1), 283.03(M), 284.22(M+1), 305.98(M+Na).

\section{In vitro $\mathrm{PPAR} \alpha / \gamma / \delta$ transactivation assays}

PPAR $\alpha$ agonist GW7647 and $\operatorname{PPAR} \delta$ agonist GW501516 were obtained from Sigma-Aldrich while PPAR $\gamma$ agonist rosiglitazone was from Zhejiang Hisun Pharmaceutical Company Limited. These reported agonists were regarded as positive controls (pc). The solvent DMSO with the same volume was added to the cell incubation solution and acted as the negative control (nc). The synthetic compounds and the positive controls were dissolved in DMSO. 293E cell and transfection reagents used in the biological assays were purchased from American type culture collection (ATCC) and Invitrogen Corporation, respectively.

Initially, synthetic molecules and the positive controls $\left(10^{-5} \mathrm{M}\right)$ were incubated with $293 \mathrm{E}$ cells which transfected with PPAR plasmid system (pcDNA3.1hPPARLBD-Gal4DB and Peak12-6×Gal4UAS-luci) for $24 \mathrm{~h}$. Then the values of normalized luciferase activities in cells incubated with synthetic molecules and controls were detected. With the activation folds of positive controls defined as the max, the relative activity (\%) expressed as (mean $\pm \mathrm{SEM}$ ) could be calculated as fomular (1):

Relative activity $(\%)=\left(\right.$ Fold $_{\text {sample }}-$ Fold $\left._{\text {nc }}\right) /\left(\right.$ Fold $_{\mathrm{pc}}-$ Fold $\left._{\mathrm{nc}}\right) \times 100 \%$

Where sample means the synthetic compounds, pc and nc refer to the positive control and the negative control, respectively.

Based on the relative activity ( $\%$ activity), six compounds (6e, 6g, 6h, 6l, 10h and 101) were further screened with specific PPAR activity.

Furthermore, compounds $6 \mathrm{~h}$ and GW7647 in multiple concentration gradients were incubated with $293 \mathrm{E}$ cells transfected with PPAR $\alpha$ plasmid system (pcDNA3.1hPPAR $\alpha$ LBD-Gal4DB and Peak12-6 $\times$ Gal4UAS-luci) for $24 \mathrm{~h}$. Compounds $6 \mathrm{~g}, 10 \mathrm{~h}$ and rosiglitazone in multiple concentration gradients were incubated with 293E cells transfected with PPAR $\gamma$ plasmid system (pcDNA3.1hPPAR $\gamma$ LBD-Gal4DB and Peak12-6×Gal4UAS-luci) for 24 h. Compounds 6e, 61, 101 and GW501516 in multiple concentration gradients were incubated with $293 \mathrm{E}$ cells 
transfected with PPAR $\delta$ plasmid system (pcDNA3.1hPPAR $\delta$ LBD-Gal4DB and Peak12-6×Gal4UAS-luci) for $24 \mathrm{~h}$. The solvent DMSO with the same volume was added to the cell incubation solution and acted as the negative control. Then the values of normalized luciferase activities in cells incubated with these six molecules and controls in various concentrations could be detected. The relative activity (\%) expressed as (mean \pm SEM) could be calculated as fomular (2):

Relative activity $(\%)=\left(\right.$ Fold $_{\text {sample }}-$ Fold $\left._{\text {nc }}\right) /\left(\right.$ Fold $_{\text {max }}-$ Fold $\left._{\text {nc }}\right) \times 100 \%$

Where sample means the synthetic compounds, max means the maximum activation fold of the synthetic compounds (Max \%), nc refers to the negative control.

Through the concentration-activity curves by GraphPad Prism 6 tool, the median effective concentration $\left(\mathrm{EC}_{50}\right)$ and concentrations at maximum efficiency percentage $\left(\mathrm{C}_{\max }\right)$ of molecules in activating PPARs would be deduced.

\section{Molecular docking}

The crystal structures of PPARs (117G.pdb for PPAR $\alpha$ [22], 2PRG.pdb [23] for PPAR $\gamma$ and 3GZ9.pdb for PPAR $\delta$ [24], respectively) were retrieved from RCSB PROTEIN DATA BANK (RCSB PDB, http://www.rcsb.org/).

The reference structures of proteins were subjected to Protein Preparation Wizard (Prep Wiz) [25-27] panel implemented in Maestro v10.2 (Schrödinger, LLC, New York, 2015) for optimization in several steps. Preliminarily, the preparation was preprocessed to assign bond orders to all bonds, add hygrogens to all atoms, creat disulfide bonds within $3.2 \AA$, cap termini to fill up ACE (N-acetyl) and NMA (N-methyl amide) and delete all unrelated waters [28]. Hydrogen bonding network and the orientation of Asn, Gln and His residues were optimized with H-bond assignment section [29]. A restraint minimization of the protein structure was performed with the root mean square deviation (RMSD) regulated to 0.5 and the force field set to Optimize Potentials for Liquid Simulations 2005 (OPLS_2005) $[30,31]$.

Ligand preparation was calculated with the LigPrep panel (Schrödinger, LLC, New York, 2015) to produce the corresponding low-energy 3D structures [32-34], which generated possible ionization states (at target PH: 7.0+/-2.0) [31], stereoisomers, tautomers and ring conformations [28].

With the preparation of protein and molecules completed, SP (standard precision) option in Ligand Docking protocol was utilized to dock ligands into the enclosing box $[35,36]$, which was generated with the original ligand centered. Finally, the docking quality would be evaluated by the glide scores, the binding interactions and the matching degree to the active cavity [37].

\section{Molecular dynamics simulations}

For detailed dynamics behaviour of small molecules, 20 ns molecular dynamics (MD) of best docked complexes were simulated with Desmond v4.3 suite (D.E. Shaw Research, New York, NY, 2015), running CentOS7.1 Linux operating system. The operation was mainly conducted on well-prepared structures in several phases [38]. Initially, a model system for generating a solvated system was built with the solvent model set to predefined SPC [33], box shape to orthorhombic and box size calculation to Buffer method through the System Builder panel [39, 40]. The protein was reoriented to minimize the box volume. As the prepared structure was charged, it was necessary to be neutralized with counter ions. Additionally, ionic strength was enhanced via adding default salt of $0.15 \mathrm{M}$ sodium chloride $(\mathrm{NaCl})$ [41]. $20 \mathrm{~ns}$ MD task that simulated Newtonian dynamics to the built model system was performed with the model system loaded from workspace. For modeling convenience, the recording interval of trajectory was set to $5.0 \mathrm{ps}$ [42] and the recording interval of the checkpoint file improved to 2000 ps. The checkfile was used to restart the simulation if interrupted and should be saved infrequently. Furthermore, the stage to relax model system before simulation was critical in case that the model system built by the System Builder was not optimal [33].

Before the simulation officially started, several stages [43, 44] were performed to relax the model system. After the MD simulation successfully completed, Simulation Interaction Diagram and Simulation Event Analysis panels were used to run the results analysis and investigate the binding stability.

\section{CONCLUSION}

Motivated by the concept of multi-targets agents to avoid of the severe side effects, 27 molecules with the main structural skeleton of 3- or 4-alkoxy substituted phenoxyl were designed and synthesized successfully based on the combination principle and the bioisosterism principle. Preliminary in vitro PPAR $\alpha / \gamma / \delta$ transactivation assays yielded six compounds with potential PPARs activation. With the aid of molecular docking and molecular dynamics simulation of $20 \mathrm{~ns}$, the interaction modes and binding stability of the representatives with PPARs were validated visually. The potential structures could be valuable references with further optimization for better PPARs activities.

\section{Abbreviations}

PPAR, peroxisome proliferators-activated receptors; T2DM, type 2 diabetes mellitus; MD, molecular dynamic; $\mathrm{EC}_{50}$, median effective concentration; $\mathrm{C}_{\text {max }}$, concentration at maximum efficiency percentage; LBD, ligand binding domain; PL contacts, protein-ligand contacts; m.p., 
melting points; TLC, thin-layer chromatography; pc, positive control; nc, negative control; ATCC, American type culture collection; PDB, PROTEIN DATA BANK; Prep Wiz, Protein Preparation Wizard; ACE, N-acetyl; NMA, N-methyl amide; RMSD, root mean square deviation; OPLS_2005, Optimize Potentials for Liquid Simulations 2005; SP, standard precision; NVT, constant Number of particles, Volume and Temperature; NPT, constant Number of particles, Pressure and Temperature.

\section{ACKNOWLEDGMENTS AND FUNDING}

This study was supported by the National Natural Science Foundation of China (Grant No. 21202120) and China Postdoctoral Science Foundation funded project (2012T50237).

\section{CONFLICTS OF INTEREST}

Authors declare no conflicts of interest.

\section{REFERENCES}

1. Pal T, Joshi H, Ramaa CS. Design and development of oxazol-5-ones as potential partial PPAR-gamma agonist against cancer cell lines. Anticancer Agents Med Chem. 2014; 14:872-83.

2. Ohashi M, Oyama T, Putranto EW, Waku T, Nobusada H, Kataoka K, Matsuno K, Yashiro M, Morikawa K, Huh NH, Miyachi H. Design and synthesis of a series of alphabenzyl phenylpropanoic acid-type peroxisome proliferatoractivated receptor (PPAR) gamma partial agonists with improved aqueous solubility. Bioorg Med Chem. 2013; 21:2319-32.

3. Gim HJ, Li H, Lee E, Ryu JH, Jeon R. Design and synthesis of alkoxyindolyl-3-acetic acid analogs as peroxisome proliferator-activated receptor-gamma/delta agonists. Bioorg Med Chem Lett. 2013; 23:513-7.

4. Gim HJ, Li H, Lee E, Ryu JH, Jeon R. Design and synthesis of alkoxyindolyl-3-acetic acid analogs as peroxisome proliferator-activated receptor- $\gamma / \delta$ agonists. Bioorganic \& Medicinal Chemistry Letters. 2013; 23:513-7.

5. Gathiaka S, Nanayakkara G, Boncher T, Acevedo O, Wyble J, Patel S, Patel A, Shane ME, Bonkowski B, Wieczorek J, Rong Y, Huggins K, Smith F, et al. Design, development and evaluation of novel dual PPARdelta/ PPARgamma agonists. Bioorg Med Chem Lett. 2013; 23:873-9.

6. Zhou L, Zhong Y, Xue MZ, Kuang D, Cao XW, Zhao ZJ, Li HL, Xu YF, Wang R. Design, synthesis and evaluation of PPAR gamma binding activity of 2-thioxo-4-thiazolidinone derivatives. Chinese Chemical Letters. 2015; 26:63-8.

7. Behl T, Kaur I, Goel H, Kotwani A. Implications of endogenous PPAR-gamma ligand, 15-Deoxy-Delta-12, 14-prostaglandin J2, in diabetic retinopathy. Life Sci. 2016.
8. Massaro M, Scoditti E, Pellegrino M, Carluccio MA, Calabriso N, Wabitsch M, Storelli C, Wright M, De Caterina R. Therapeutic potential of the dual peroxisome proliferator activated receptor (PPAR)alpha/gamma agonist aleglitazar in attenuating TNF-alpha-mediated inflammation and insulin resistance in human adipocytes. Pharmacol Res. 2016; 107:125-36.

9. Gao D, Zhang Y, Yang F, Lin Y, Zhang Q, Xia Z. In vitro Screening and Evaluation of 37 Traditional Chinese Medicines for Their Potential to Activate Peroxisome Proliferator-Activated Receptors-gamma. Pharmacogn Mag. 2016; 12:120-7.

10. Gim HJ, Li H, Jeong JH, Lee SJ, Sung MK, Song MY, Park BH, Oh SJ, Ryu JH, Jeon R. Design, synthesis, and biological evaluation of a series of alkoxy-3-indolylacetic acids as peroxisome proliferator-activated receptor gamma/ delta agonists. Bioorg Med Chem. 2015; 23:3322-36.

11. Garbacz WG, Huang JT, Higgins LG, Wahli W, Palmer CN. PPARalpha Is Required for PPARdelta Action in Regulation of Body Weight and Hepatic Steatosis in Mice. PPAR Res. 2015; 2015:927057.

12. Maltarollo VG, Togashi M, Nascimento AS, Honorio KM. Structure-based virtual screening and discovery of New PPARdelta/gamma dual agonist and PPARdelta and gamma agonists. PLoS One. 2015; 10:e0118790.

13. Liu C, Feng T, Zhu N, Liu P, Han X, Chen M, Wang X, Li N, Li Y, Xu Y, Si S. Identification of a novel selective agonist of PPAR $\gamma$ with no promotion of adipogenesis and less inhibition of osteoblastogenesis. Scientific Reports. 2015; 5:9530.

14. Jadhav R, Gupta-Rajoria R, Pal T, Subramanian RC. Design, synthesis and in-vivo hypoglycemic evaluation of novel non - TZD'S in a type - 2 diabetic model. Med Chem. 2013; 9:104-11.

15. Agrawal R. The first approved agent in the Glitazar's Class:Saroglitazar. Curr Drug Targets. 2014; 15:151-5.

16. Kim CO, Sil Oh E, Kim C, Park MS. Pharmacokinetic Interaction Between Amlodipine and Lobeglitazone, a Novel Peroxisome Proliferator-activated Receptor-gamma Agonist, in Healthy Subjects. Clin Ther. 2015; 37:1999-2006 e1.

17. Pinter T, Jana S, Courtemanche RJ, Hof F. Recognition properties of carboxylic acid bioisosteres: anion binding by tetrazoles, aryl sulfonamides, and acyl sulfonamides on a calix [4]arene scaffold. J Org Chem. 2011; 76:3733-41.

18. Pemberton N, Graden H, Evertsson E, Bratt E, Lepisto M, Johannesson P, Svensson PH. Synthesis and functionalization of cyclic sulfonimidamides: a novel chiral heterocyclic carboxylic Acid bioisostere. ACS Med Chem Lett. 2012; 3:574-8.

19. Pegklidou K, Koukoulitsa C, Nicolaou I, Demopoulos VJ. Design and synthesis of novel series of pyrrole based chemotypes and their evaluation as selective aldose reductase inhibitors. A case of bioisosterism between a carboxylic acid moiety and that of a tetrazole. Bioorg Med Chem. 2010; 18:2107-14. 
20. Bruncko M, Oost TK, Belli BA, Ding H, Joseph MK, Kunzer A, Martineau D, McClellan WJ, Mitten M, Ng SC, Nimmer PM, Oltersdorf T, Park CM, et al. Studies leading to potent, dual inhibitors of Bcl-2 and Bcl-xL. J Med Chem. 2007; 50:641-62.

21. Himo F, Demko ZP, Noodleman L, Sharpless KB. Mechanisms of tetrazole formation by addition of azide to nitriles. J Am Chem Soc. 2002; 124:12210-6.

22. Cronet P, Petersen JFW, Folmer R, Blomberg N, Sjoblom K, Karlsson U, Lindstedt EL, Bamberg K. Structure of the PPAR alpha and -gamma ligand binding domain in complex with AZ 242; Ligand selectivity and agonist activation in the PPAR family. Structure. 2001; 9:699-706.

23. Nolte RT, Wisely GB, Westin S, Cobb JE, Lambert MH, Kurokawa R, Rosenfeld MG, Willson TM, Glass CK, Milburn MV. Ligand binding and co-activator assembly of the peroxisome proliferator-activated receptor-gamma. Nature. 1998; 395:137-43.

24. Connors RV, Wang Z, Harrison M, Zhang A, Wanska M, Hiscock S, Fox B, Dore M, Labelle M, Sudom A, Johnstone S, Liu J, Walker NP, et al. Identification of a PPARdelta agonist with partial agonistic activity on PPARgamma. Bioorg Med Chem Lett. 2009; 19:3550-4.

25. Gawande ND, Subashini S, Murugan M, Subbarayalu M. Molecular screening of insecticides with sigma glutathione S-transferases (GST) in cotton aphid Aphis gossypii using docking. Bioinformation. 2014; 10:679-83.

26. Yadava U, Gupta H, Roychoudhury M. Stabilization of microtubules by taxane diterpenoids: insight from docking and MD simulations. J Biol Phys. 2015; 41:117-33.

27. Kaczor AA, Targowska-Duda KM, Patel JZ, Laitinen T, Parkkari T, Adams Y, Nevalainen TJ, Poso A. Comparative molecular field analysis and molecular dynamics studies of $\alpha / \beta$ hydrolase domain containing 6 (ABHD6) inhibitors. Journal of Molecular Modeling. 2015; 21.

28. Khan I, Senthilkumar CS, Upadhyay N, Singh H, Sachdeva M, Jatawa SK, Tiwari A. In silico docking of methyl isocyanate (MIC) and its hydrolytic product (1, 3-dimethylurea) shows significant interaction with DNA Methyltransferase 1 suggests cancer risk in BhopalGas-Tragedy survivors. Asian Pacific Journal of Cancer Prevention. 2015; 16:7663-70.

29. Shaik JB, Palaka BK, Penumala M, Kotapati KV, Devineni SR, Eadlapalli S, Darla MM, Ampasala DR, Vadde R, Amooru GD. Synthesis, pharmacological assessment, molecular modeling and in silico studies of fused tricyclic coumarin derivatives as a new family of multifunctional anti-Alzheimer agents. Eur J Med Chem. 2016; 107:219-32.

30. Joshi RK, Nanda S, Rout E, Kar B, Naik PK, Nayak S. Molecular modeling and docking characterization of CzR1, a CC-NBS-LRR R-gene from Curcuma zedoaria Loeb. that confers resistance to Pythium aphanidermatum. Bioinformation. 2013; 9:560-4.
31. Jakubik J, El-Fakahany EE, Dolezal V. Towards predictive docking at aminergic G-protein coupled receptors. J Mol Model. 2015; 21:284.

32. Chaudhari P, Bari S. In silico exploration of c-KIT inhibitors by pharmaco-informatics methodology: pharmacophore modeling, 3D QSAR, docking studies, and virtual screening. Mol Divers. 2016; 20:41-53.

33. Blessy JJ, Sharmila DJ. Molecular simulation of $\mathrm{N}$-acetylneuraminic acid analogs and molecular dynamics studies of cholera toxin-Neu5Gc complex. J Biomol Struct Dyn. 2015; 33:1126-39.

34. Hayes JM, Skamnaki VT, Archontis G, Lamprakis C, Sarrou J, Bischler N, Skaltsounis AL, Zographos SE, Oikonomakos NG. Kinetics, in silico docking, molecular dynamics, and MM-GBSA binding studies on prototype indirubins, KT5720, and staurosporine as phosphorylase kinase ATP-binding site inhibitors: the role of water molecules examined. Proteins. 2011; 79:703-19.

35. Sastry GM, Adzhigirey M, Day T, Annabhimoju R, Sherman W. Protein and ligand preparation: parameters, protocols, and influence on virtual screening enrichments. J Comput Aided Mol Des. 2013; 27:221-34.

36. Husain A, Madhesia D, Rashid M, Ahmad A, Khan SA. Synthesis and in vivo diuretic activity of some new benzothiazole sulfonamides containing quinoxaline ring system. J Enzyme Inhib Med Chem. 2016:1-8.

37. Kirubakaran P, Kothapalli R, Singh Kh D, Nagamani S, Arjunan S, Muthusamy K. In silico studies on marine actinomycetes as potential inhibitors for Glioblastoma multiforme. Bioinformation. 2011; 6:100-6.

38. Yadava U, Shukla BK, Roychoudhury M, Kumar D. Pyrazolo[3,4-d]pyrimidines as novel inhibitors of O-acetylL-serine sulfhydrylase of Entamoeba histolytica: an in silico study. J Mol Model. 2015; 21:96.

39. Kalva S, Vinod D, Saleena LM. Combined structure- and ligand-based pharmacophore modeling and molecular dynamics simulation studies to identify selective inhibitors of MMP-8. J Mol Model. 2014; 20:2191.

40. Kaczor AA, Targowska-Duda KM, Patel JZ, Laitinen T, Parkkari T, Adams Y, Nevalainen TJ, Poso A. Comparative molecular field analysis and molecular dynamics studies of alpha/beta hydrolase domain containing 6 (ABHD6) inhibitors. J Mol Model. 2015; 21:250.

41. Singh KD, Muthusamy K. Molecular modeling, quantum polarized ligand docking and structure-based 3D-QSAR analysis of the imidazole series as dual AT(1) and ET(A) receptor antagonists. Acta Pharmacol Sin. 2013; 34:1592-606.

42. Katari SK, Natarajan P, Swargam S, Kanipakam H, Pasala C, Umamaheswari A. Inhibitor design against JNK1 through e-pharmacophore modeling docking and molecular dynamics simulations. J Recept Signal Transduct Res. 2016:1-14.

43. Kallubai M, Amineni U, Mallavarapu M, Kadiyala V. In Silico Approach to Support that p-Nitrophenol 
Monooxygenase from Arthrobacter sp. Strain JS443 Catalyzes the Initial Two Sequential Monooxygenations. Interdiscip Sci. 2015; 7:157-67.

44. Pradhan D, Priyadarshini V, Munikumar M, Swargam S, Umamaheswari A, Bitla A. Para-(benzoyl)-phenylalanine as a potential inhibitor against LpxC of Leptospira spp.: homology modeling, docking, and molecular dynamics study. J Biomol Struct Dyn. 2014; 32:171-85. 